Dissertação apresentada à Universidade Federal de Viçosa, como parte das exigências do Programa de Pós-Graduação em Ciência Florestal, para obtenção do título de Magister Scientiae.

Orientador: Sebastião Venâncio Martins 
Ficha catalográfica elaborada pela Biblioteca Central da Universidade Federal de Viçosa - Campus Viçosa

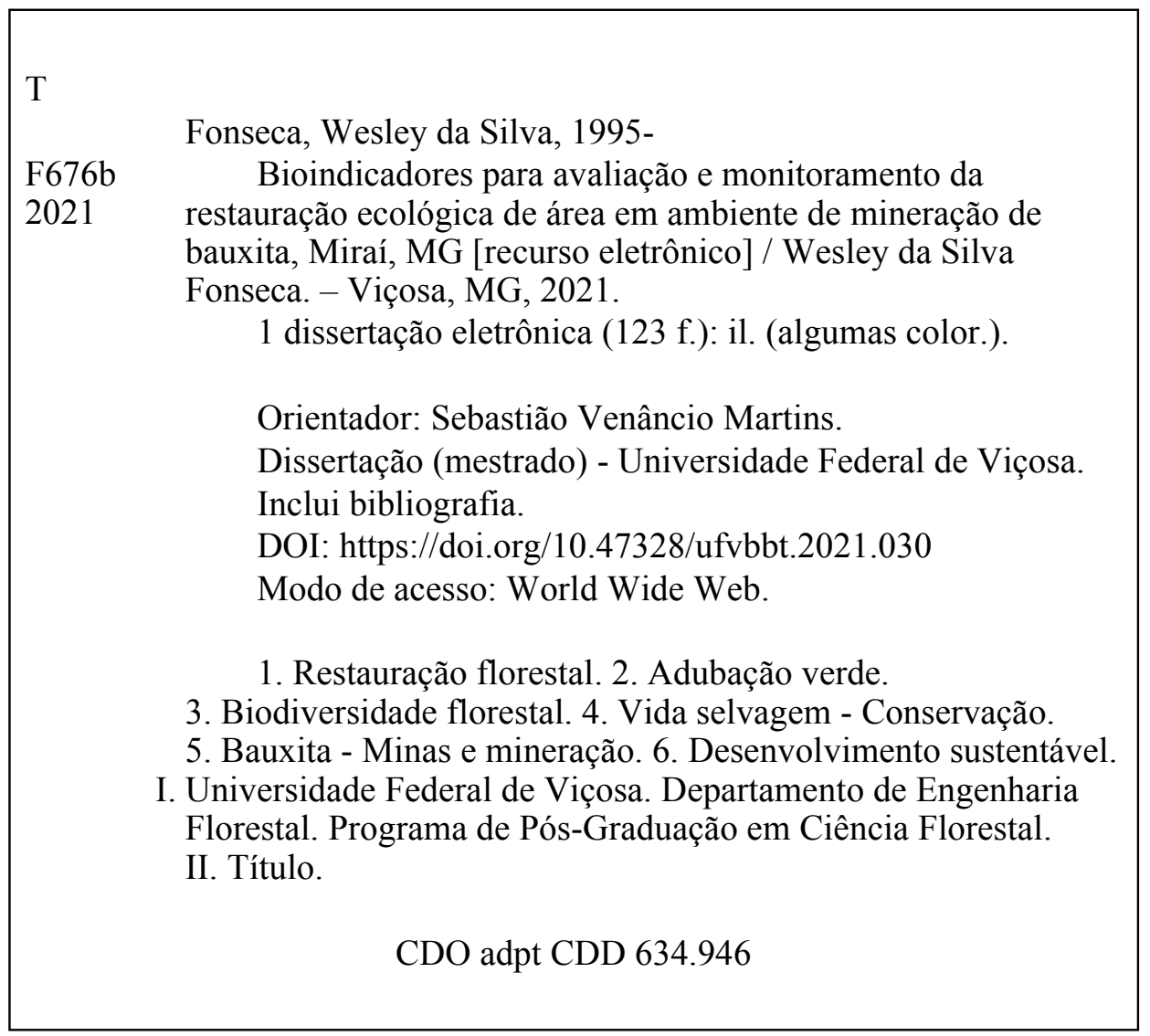


WESLEY DA SILVA FONSECA

\section{BIOINDICADORES PARA AVALIACÃO E MONITORAMENTO DA RESTAURAÇÃO ECOLÓGICA DE ÁREA EM AMBIENTE DE MINERAÇÃO DE BAUXITA, MIRAÍ, MG}

Dissertação apresentada à Universidade Federal de Viçosa, como parte das exigências do Programa de Pós-Graduação em Ciência Florestal, para obtenção do título de Magister Scientiae.

APROVADA: 09 de julho de 2021

Assentimento:
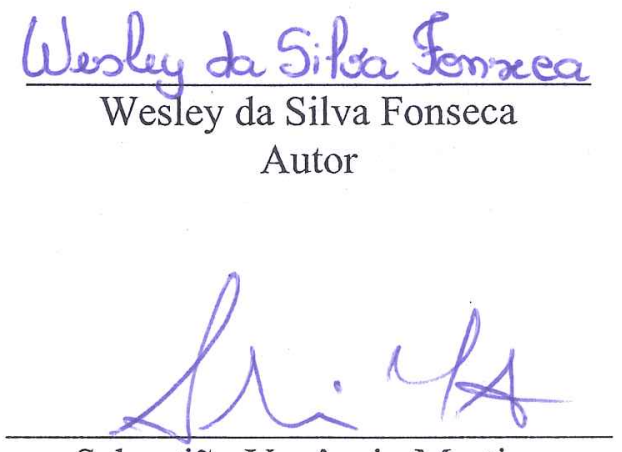

Sebastião Venâncio Martins

Orientador 
Dedico este trabalho à minha família. 


\section{AGRADECIMENTOS}

A Deus pelo dom da vida e por guiar meus passos em um caminho de luz.

Aos meus pais, Sirlei e Juarez, por todo incentivo ao longo de todos esses anos e pelo apoio incondicional em minha trajetória acadêmica. Vocês são meus maiores exemplos de persistência, resiliência e união. Minha eterna gratidão.

À minha família por todo suporte, apoio e confiança depositada.

Ao meu orientador e amigo professor Dr. Sebastião Venâncio Martins pelos ensinamentos, conselhos, oportunidades, incentivos, confiança, disponibilidade e cordialidade ao longo de todos esses anos.

Aos membros da banca, Pedro Manuel Villa e José Marinaldo Gleriani, pelas contribuições na melhoria dessa dissertação.

À Universidade Federal de Viçosa, pela infraestrutura disponibilizada para a realização das atividades e pela excelência no ensino, pesquisa e extensão. "Ediscere, Scire, Agere, Vincere".

Aos professores, que priorizam transmitir valores e uma formação sólida a todos os alunos, obrigado pelo seu trabalho e compromisso.

Ao Departamento de Engenharia Florestal e ao Programa de Pós-graduação Stricto Sensu em Ciência Florestal (PPGCF), pelo apoio institucional à pesquisa científica.

Ao Laboratório de Restauração Florestal - LARF, por ser um dos pilares de minha pesquisa científica, por meio de parcerias, convênios e projetos.

Aos amigos do laboratório (LARF), em especial, Luiz Cosimo, Pedro Villa, Diego Balestrin, William Alves, Mirian Valente, Patrícia Laviola, Mateus Oliveira, Aline Pilocelli e Angela Gioconda. É um grande prazer trabalhar com uma equipe comprometida, dedicada, alegre e solícita.

À Coordenação de Aperfeiçoamento de Pessoal de Nível Superior (CAPES), pela bolsa de mestrado concedida. O presente trabalho foi realizado com apoio da Coordenação de Aperfeiçoamento de Pessoal de Nível Superior - Brasil (CAPES) - Código de Financiamento 001. 
À Companhia Brasileira de Alumínio (CBA) pelo apoio logístico e financeiro para a realização desta pesquisa. Em especial, à engenheira florestal Juliana Paiva, pelo profissionalismo, apoio ao projeto e pela confiança depositada. O compromisso da CBA e o seu apoio à pesquisa científica em prol de uma mineração de bauxita sustentável, é motivo de muito orgulho.

A empresa JSL, pelo apoio na logística, transporte e coleta de dados.

Aos meus amigos, pela convivência e pelos momentos inesquecíveis que compartilhamos. Uma verdadeira família em Viçosa! Em especial, à Tamilis Emerick que esteve comigo ao longo de toda esta trajetória, por toda atenção, cumplicidade, companheirismo e pelos fortes laços de irmandade. À Jéssica pela convivência e por tornar os dias mais serenos. À Suellen, por ser uma pessoa solícita, prontamente disposta a ajudar. À Carol V. e a Carol M., por estarem sempre presentes e vibrando a cada conquista, mesmo à distância.

A todas as demais pessoas que contribuíram para a realização deste trabalho e que, de alguma forma, estiveram presentes em minha vida durante os anos de Mestrado. 
"E às vezes, perdido

Eu me encontro em tuas asas, Beija-Flor Por mais que existam barreiras Eu vim pra vencer no teu ninho É bom lembrar, eu não estou sozinho" (G.R.E.S. Beija-Flor de Nilópolis) 


\section{BIOGRAFIA}

Wesley da Silva Fonseca, filho de Juarez Antônio da Fonseca e Sirlei Marcelina da Silva Fonseca, nasceu em 27 de novembro de 1995, no município de Muriaé, Minas Gerais.

Cursou o ensino fundamental na Escola Estadual Professor Orlando de Lima Faria, em Muriaé, MG, e o ensino médio no Instituto Federal de Educação, Ciência e Tecnologia do Sudeste de Minas - Campus Muriaé, obtendo o título de Técnico em Agroecologia em dezembro de 2013.

Em 2014, iniciou o curso de Engenharia Florestal pela Universidade Federal de Viçosa, MG. No ano de 2015, iniciou o estágio no Viveiro de Pesquisa da UFV na área de Meteorologia Aplicada a Sistemas Florestais.

Em 2016, iniciou o estágio no Laboratório de Restauração Florestal - LARF, desenvolvendo trabalhos nas áreas de Ecologia e Restauração Florestal, tendo sido bolsista de iniciação científica.

Em 2018, foi contratado pela Sociedade de Investigações Florestais como Assistente Técnico Florestal, com ênfase na Restauração Florestal, concluindo a graduação no mesmo ano.

Em 2019, iniciou o curso de Mestrado no Programa de Pós-graduação Stricto Sensu em Ciência Florestal, com ênfase em Meio Ambiente e Conservação da Natureza, pela Universidade Federal de Viçosa, Viçosa-MG, obtendo em julho de 2021 o título de Mestre em Ciência Florestal. 


\section{RESUMO}

FONSECA, Wesley da Silva, M.Sc., Universidade Federal de Viçosa, julho de 2021. Bioindicadores para avaliação e monitoramento da restauração ecológica de área em ambiente de mineração de bauxita, Miraí, MG. Orientador: Sebastião Venâncio Martins.

Este estudo teve como objetivos avaliar a restauração florestal, comparar técnicas de nucleação e apresentar novas perspectivas para o monitoramento da fauna de uma área no ambiente de mineração de bauxita, em Miraí-MG. Para isso, foram avaliados a adubação verde na recuperação do solo, a florística, a fitossociologia e a fauna, após 4 anos da implantação do projeto de restauração. O estudo foi realizado em uma área de 2 ha, na qual funcionava o setor administrativo da Companhia Brasileira de Alumínio - CBA, em que todas as construções foram removidas deixando o subsolo exposto, compactado e de baixa fertilidade. Esta área de estudo foi incluída no programa de compensação ambiental da empresa. Assim, foi realizado o preparo do solo com ripper, adubação química e a implantação de técnicas de restauração ecológica. A cobertura do solo e a produção de fitomassa dos adubos verdes foram avaliadas ao final de 18 meses. Os atributos do solo foram avaliados em três épocas (0, 18 e 24 meses após a semeadura). Para avaliação da composição florística e estrutura fitossociológica da vegetação, foi realizado o inventário florestal tipo censo total, com identificação de todos os indivíduos com CAP $\geq 10 \mathrm{~cm}$. Foram calculados os parâmetros densidade relativa, dominância relativa e o valor de cobertura e os índices de diversidade da comunidade vegetal (Shannon e Equabilidade de Pielou). No tocante à comparação de técnicas de nucleação, foram alocadas 40 parcelas de 1 x $1 \mathrm{~m}$, nas quais foram testados quatro tratamentos (Transposição de banco de sementes e serapilheira; Semeadura direta de espécies arbóreas nativas; Poleiros artificiais e Regeneração natural). Quanto ao monitoramento da fauna, foram instaladas três armadilhas fotográficas para monitorar a vida selvagem (janeiro/2020 - janeiro/2021). As câmeras ficaram ativas e programadas para capturar imagens 24 horas por dia, a qualquer movimento. Além disso, foi realizado o método de busca ativa para identificação de todos animais pertencentes as classes: Amphibia, Reptilia, Aves e Mammalia. Como resultados, constatou-se que o rápido recobrimento do solo promovido pelos adubos verdes garantiu proteção contra eventuais processos erosivos e evitou a invasão de gramíneas exóticas agressivas, propiciando melhores condições para as mudas plantadas. A deposição de fitomassa colaborou para aumento dos teores de matéria orgânica e aumento da fertilidade do solo em todos os tratamentos. De acordo com o estudo 
fitossociológico, a área é floristicamente heterogênea, com baixa dominância ecológica e apresentou similaridade florística com outros estudos realizados na região. O conhecimento dos atributos funcionais das espécies é essencial para o planejamento e execução de projetos de restauração ecológica e permite definir as metodologias e técnicas mais adequadas para cada cenário. A similaridade florística entre áreas no ambiente de mineração de bauxita foi influenciada principalmente pela localização geográfica, técnica de restauração e idade de restauração das áreas. Quanto às técnicas de nucleação, a semeadura direta e a transposição de solo e serapilheira se destacaram como alternativas para a restauração ecológica. Cabe destacar a necessidade de adaptar essas técnicas aos múltiplos filtros ambientais regionais e às características ecológicas das paisagens de modo a aproveitar a resiliência do ambiente. As armadilhas fotográficas forneceram uma abordagem inovadora no contexto da restauração ecológica para avaliar a relação fauna-flora e aspectos da ecologia comportamental das espécies. A presença da fauna de diferentes classes, níveis tróficos e padrões de sociabilidade indica que à medida que o processo sucessional avance, espera-se que aumente a complexidade das interações ecológicas intraespecíficas e interespecíficas. Assim, pode-se concluir que as técnicas de restauração ecológica, recuperação do solo e ações de conservação realizadas pela empresa, bem como a preservação de fragmentos florestais, têm se mostrado eficientes e desempenham um papel importante na conservação da biodiversidade regional.

Palavras-chave: Adubação verde. Mineração sustentável. Monitoramento de fauna. Nucleação. Restauração florestal. Técnicas alternativas. 


\begin{abstract}
FONSECA, Wesley da Silva, M.Sc., Universidade Federal de Viçosa, July, 2021. Bioindicators for the evaluation and monitoring of a site under ecological restoration in the bauxite mining environment, in Miraí, MG. Advisor: Sebastião Venâncio Martins.
\end{abstract}

This study aimed to evaluate green manure in soil recovery, evaluate floristics and phytosociology after 4 years of seedlings planting, compare nucleation techniques and present new perspectives for fauna monitoring, in an area in the bauxite mining environment, in Miraí-MG, Brazil. The study was carried out in a 2 ha area, in which the administrative sector of Companhia Brasileira de Alumínio - CBA operated. All the buildings were removed leaving the subsoil exposed, compacted and of low fertility. This study area was included in the company's environmental compensation program. Thus, soil preparation with ripper, chemical fertilization and the implementation of ecological restoration techniques was carried out. Soil cover and phytomass production of green manures were evaluated at the end of 18 months. Soil attributes were evaluated at three times (0,18 and 24 months after sowing). For phytosociological evaluation of the area under restoration, a total census type forest inventory was carried out, identifying all individuals with breast height circumference $(\mathrm{CBH}) \geq 10 \mathrm{~cm}$. The parameters relative density, relative dominance and cover value and plant community diversity indices (Shannon-Wiener and Pielou Equability) were calculated. Regarding the comparison of nucleation techniques, 40 plots of 1 x $1 \mathrm{~m}$ were allocated, in which four treatments were tested (Litter and soil seed bank transposition; Direct seeding of native tree species; Artificial perches and Natural regeneration). For fauna monitoring, three camera traps were installed to monitor wildlife (from January, 2020 to January, 2021). The cameras were active and programmed to capture images 24 hours a day, at any movement. In addition, the active search method was performed to identify all animals belonging to the classes: Amphibia, Reptilia, Birds and Mammalia. As a result, the rapid covering of the soil promoted by green manures ensured protection against eventual erosion processes and prevented the invasion of aggressive exotic grasses, providing better conditions for the seedlings planted. The phytomass deposition contributed to increase the organic matter content and increase soil fertility in all treatments. According to the phytosociological study, the area is floristically heterogeneous, with low ecological dominance and showed floristic similarity with other studies carried out in the region. Knowledge of the functional attributes of species is essential 
for the planning and execution of ecological restoration projects and allows the definition of the most appropriate methodologies and techniques for each scenario. The floristic similarity between areas in the bauxite mining environment was mainly influenced by geographic location, restoration technique and restoration age of the areas. For nucleation techniques, direct seeding and transposition of soil and litter stood out as alternative techniques for ecological restoration. It is worth highlighting the need to adapt these techniques to the multiple regional environmental filters and to the ecological characteristics of the landscapes in order to take advantage of the resilience of the environment. Camera traps provided an innovative approach to assess the fauna-floral relationship and aspects of the species' behavioral ecology. The presence of fauna from different classes, trophic levels and sociability patterns indicates that as the successional process advances, it is possible that the complexity of intraspecific and interspecific ecological interactions increases. Thus, it can be concluded that the ecological restoration techniques, soil recovery and conservation actions carried out by the company, as well as the preservation of forest fragments, have been shown to be efficient and play an important role in the conservation of regional biodiversity.

Keywords: Green manure. Sustainable mining. Fauna monitoring. Nucleation. Forest restoration. Alternative techniques. 


\section{LISTA DE ILUSTRAÇÕES}

\section{CAPÍTULO 1 - ADUBAÇÃO VERDE: UMA ALTERNATIVA PARA RECUPERAÇÃO DO SOLO DE ÁREA EM AMBIENTE DE MINERAÇÃO DE

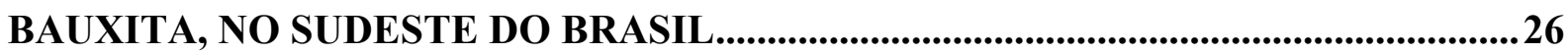

Figura 1-1. Localização da área de estudo, em Miraí-MG, Brasil. ........................................ 31

Figura 1-2. Situação inicial do solo, crescimento e manejo dos adubos verdes...................... 32

Figura 1-3. Médias de cobertura do solo (\%) das espécies de adubos verdes. Médias seguidas de letras diferentes são estatisticamente diferentes $\mathrm{p} \leq 0.05$ (Tukey). Caj = Cajanus cajan; Cro $=$ Crotalaria juncea e Sty $=$ Stylosanthes guianensis 34

Figura 1-4. Média de peso seco das espécies de adubo verde. Médias seguidas de letras diferentes são estatisticamente diferentes $\mathrm{p} \leq 0.05$ (Tukey). Caj = Cajanus cajan; Cro = Crotalaria juncea e Sty $=$ Stylosanthes guianensis .

CAPÍTULO 2 - ESTUdO FITOSSOCIOLÓGICO DE ÁREA EM RESTAURAÇÃo ECOLÓGICA NO AMBIENTE DE MINERAÇÃO DE BAUXITA, NO SUDESTE DO BRASIL

Figura 2-1. Localização da área de estudo, em Miraí-MG, Brasil ..... 54

Figura 2-2. Distribuição de espécies e indivíduos em: Categoria Sucessional e Síndrome de Dispersão

Figura 2-3. Resistência à penetração de um Latossolo Vermelho-Amarelo distrófico típico, em diferentes épocas: 2017 (solo exposto) e 2021 (após a implantação de técnicas de restauração ecológica).

Figura 2-4. Similaridade florística entre diferentes estudos realizados em ambiente de mineração de bauxita, na região.

CAPÍTULO 3 - TÉCNICAS ALTERNATIVAS PARA A RESTAURAÇÃO ECOLÓGICA DE ÁREA NO AMBIENTE DE MINERAÇÃO DE BAUXITA NO SUDESTE DO BRASIL

Figura 3-1. Localização da área de estudo, em Miraí-MG, Brasil 79

Figura 3-2. Barplot de A) riqueza de espécies e B) abundância de indivíduos. Números seguidos de letras diferentes são estatisticamente diferentes $\mathrm{p} \leq 0.05$ (Tukey). T1= Transposição de banco de sementes, $\mathrm{T} 2=$ Semeadura direta, $\mathrm{T} 3=$ Poleiros artificiais, $\mathrm{T} 4=$ Controle. 
Figura 3-3. Barplot da cobertura do solo nos tratamentos de nucleação, nos anos 2018 e 2020. $\mathrm{T} 1=$ Transposição de banco de sementes, $\mathrm{T} 2=$ Semeadura direta, $\mathrm{T} 3=$ Poleiros artificiais, $\mathrm{T} 4=$ Controle.

CAPÍTULO 4 - MONITORAMENTO DE FAUNA COMO INDICADOR DE RESTAURAÇÃO ECOLÓGICA DE UMA ÁREA EM AMBIENTE DE MINERAÇÃO DE BAUXITA NA ZONA DA MATA MINEIRA........................................................96

Figura 4-1. Localização da área de estudo, Miraí - MG, Brasil 101

Figura 4-2. Registro das armadilhas fotográficas de espécies "quase ameaçadas" de extinção segundo IUCN: A) Chrysocyon brachyurus Illiger. (Lobo-guará) e B) Strix hylophila Temminck (Coruja-listrada). 105

Figura 4-3. Registro das armadilhas fotográficas das espécies frugívoras: A) Penelope obscura Temminck (Jacuaçú) e B) Coendou prehensilis (Ouriço). 105

Figura 4-4. Alimentação A) Celeus flavus se alimentando de insetos do tronco e B) Didelphis aurita se alimentando de grãos e frutos.

Figura 4-5. Utilização de poleiros artificiais por Sicalis flaveola (A) e Knipolegus lophotes (B). 107

Figura 4-6. Forrageamento de Turdus rufiventris (A) e interações interespecíficas em Molothrus bonariensis (B) 107 


\section{LISTA DE TABELAS}

\section{CAPÍTULO 1 - ADUBAÇÃO VERDE: UMA ALTERNATIVA PARA}

RECUPERAÇÃO DO SOLO DE ÁREA EM AMBIENTE DE MINERAÇÃO DE

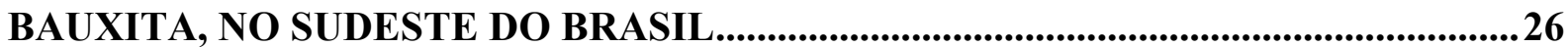

Tabela 1-1. Análises químicas de solo dos diferentes tratamentos na camada $0-20 \mathrm{~cm}$, em diferentes épocas $(0,18$ e 24 meses após a semeadura).

Tabela 1-2. Classificação das propriedades químicas do solo, após 18 meses da semeadura de adubos verdes, de acordo com as recomendações para o uso de corretivos e fertilizantes em Minas Gerais. $\mathrm{Mba}=$ Muito baixo; $\mathrm{Ba}=$ Baixo; $\mathrm{M}=$ Médio; $\mathrm{Bo}=\mathrm{Bom} ; \mathrm{Mbo}=$ Muito bom. .... 37 Tabela 1-3. Classificação das propriedades químicas do solo, após 24 meses da semeadura de adubos verdes, de acordo com as recomendações para o uso de corretivos e fertilizantes em Minas Gerais. $\mathrm{Mba}=$ Muito baixo; $\mathrm{Ba}=$ Baixo; $\mathrm{M}=$ Médio; $\mathrm{Bo}=\mathrm{Bom}$; $\mathrm{Mbo}=$ Muito bom ......38

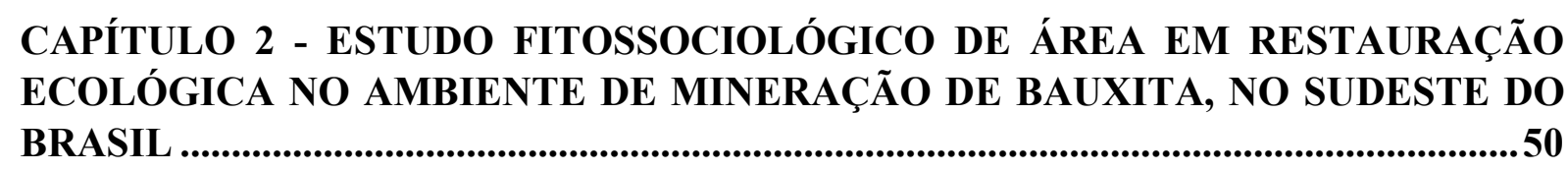

Tabela 2-1. Lista florística das espécies plantadas na área de estudo, Miraí-MG, Brasil .......55 Tabela 2-2. Descrição e caracterização das áreas de estudo usadas para comparar a similaridade florística. 56

Tabela 2-3. Parâmetros fitossociológicos das espécies encontradas na área de estudos, após 4 anos de restauração ecológica, Miraí - MG. 58

Tabela 2-4. Parâmetros fitossociológicos das famílias botânicas encontradas na área de estudo.

CAPÍtUlO 3 - TÉCNICAS ALTERNATIVAS PARA A RESTAURAÇÃO ECOLÓGICA DE ÁREA NO AMBIENTE DE MINERAÇÃO DE BAUXITA NO

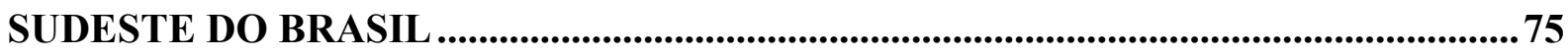

Tabela 3-1. Lista de espécies arbóreas utilizadas no tratamento T2 - semeadura direta......... 80 Tabela 3-2. Florística e distribuição das espécies arbustivas e arbóreas encontradas em cada tratamento 82 
CAPÍTULO 4 - MONITORAMENTO DE FAUNA COMO INDICADOR DE RESTAURAÇÃO ECOLÓGICA DE UMA ÁREA EM AMBIENTE DE MINERAÇÃO DE BAUXITA NA ZONA DA MATA MINEIRA......................................................96

Tabela 4-1. Lista de espécies da fauna, presentes na área em restauração ecológica, no ambiente de mineração de bauxita, em Miraí-MG, Brasil 103 


\section{SUMÁRIO}

INTRODUÇÃO GERAL

CAPÍTULO 1 - ADUBAÇÃO VERDE: UMA ALTERNATIVA PARA RECUPERAÇÃO DO SOLO DE ÁREA EM AMBIENTE DE MINERAÇÃO DE BAUXITA, NO SUDESTE DO BRASIL.......................................................................26

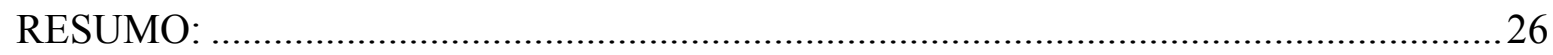

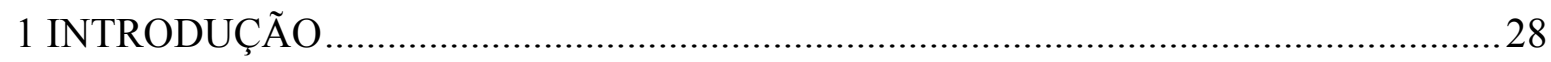

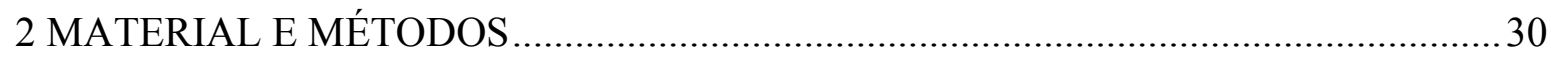

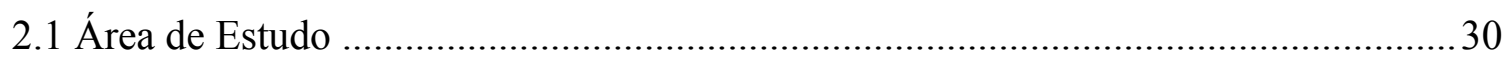

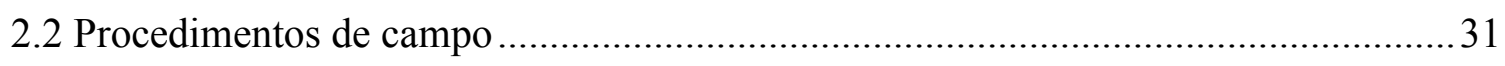

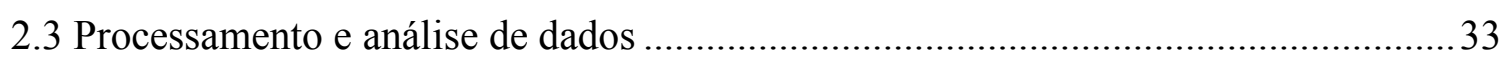

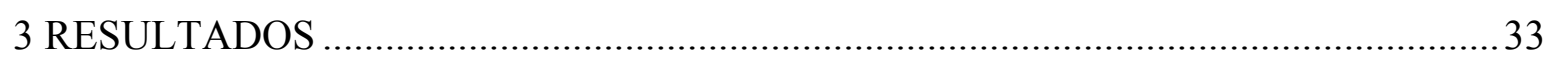

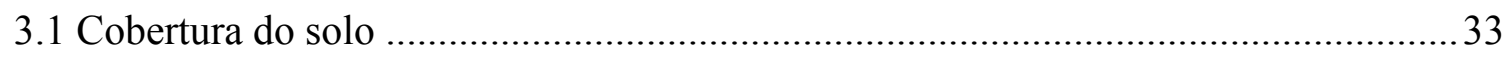

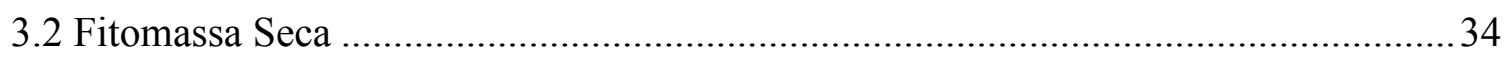

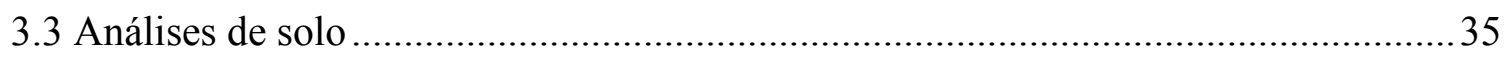

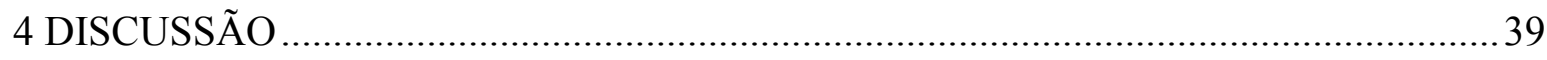

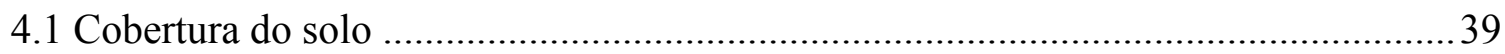

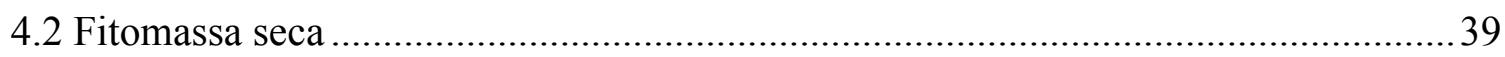

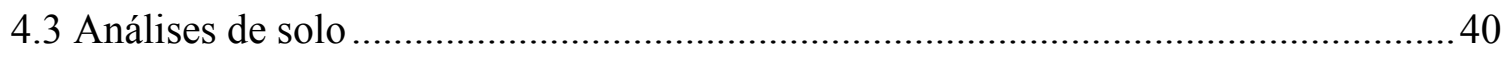

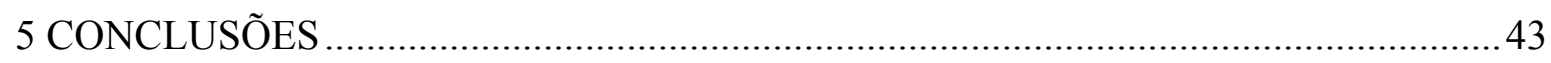

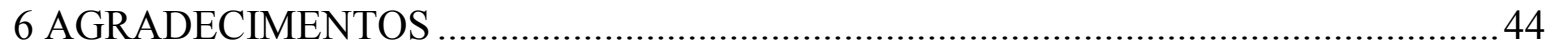

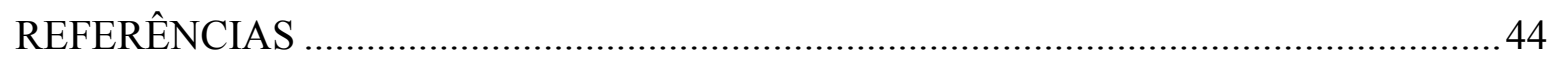

CAPÍTULO 2 - ESTUdO FITOSSOCIOLÓGICO DE ÁREA EM RESTAURAÇÃO ECOLÓGICA NO AMBIENTE DE MINERAÇÃO DE BAUXITA, NO SUDESTE DO

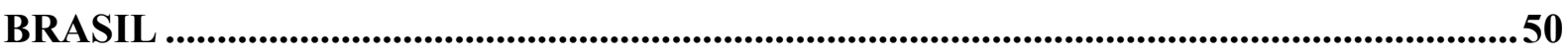

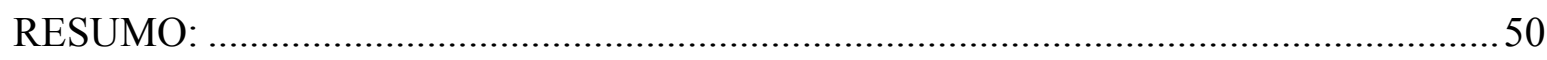

1 INTRODUÇÃ

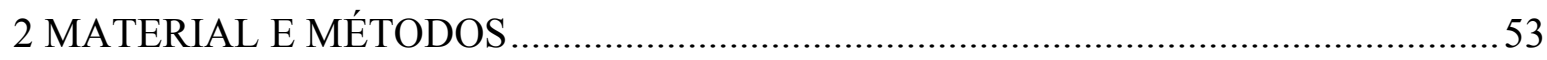

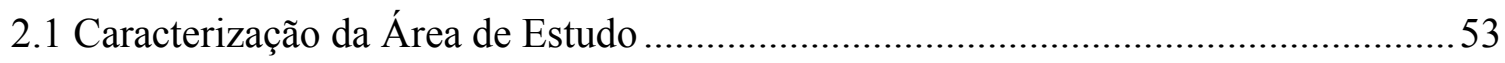

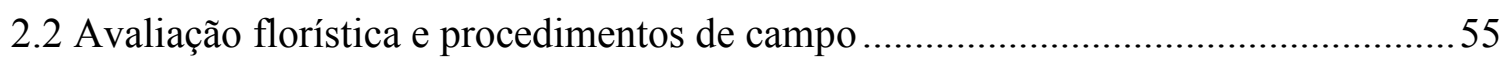

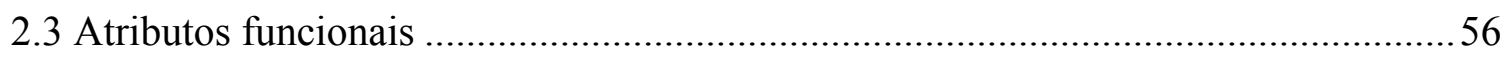

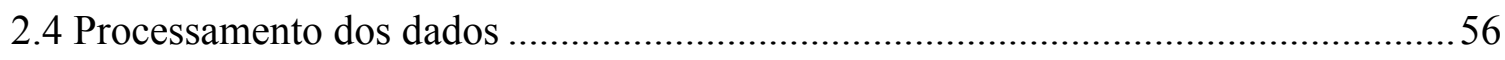

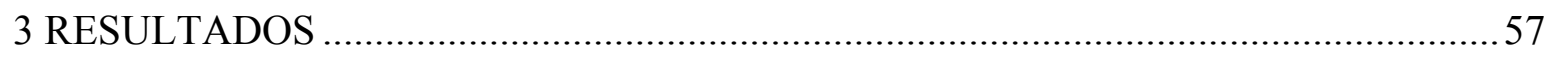

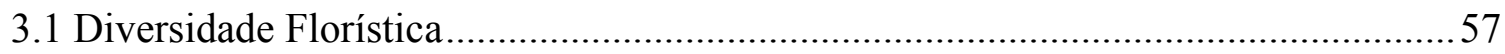


3.2 Atributos funcionais 59

3.3 Atributos físicos. 61

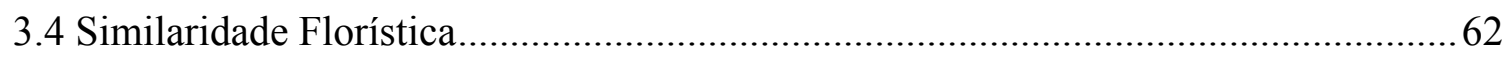

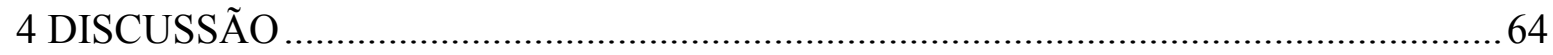

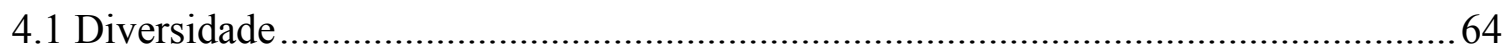

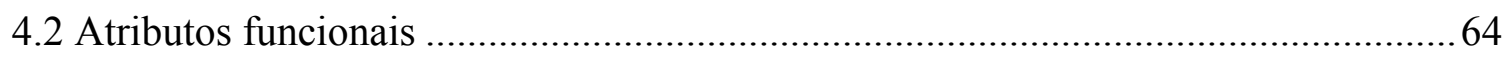

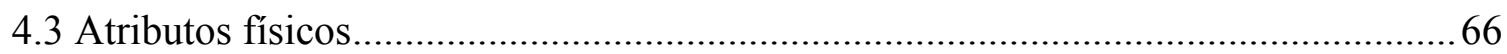

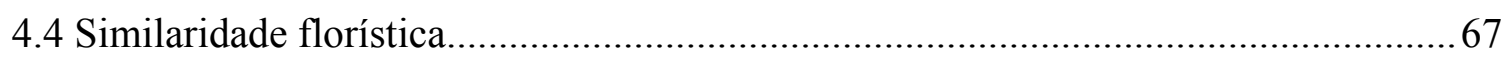

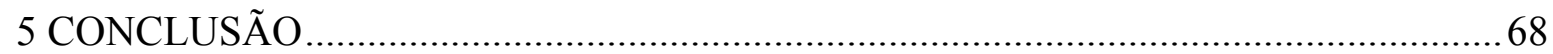

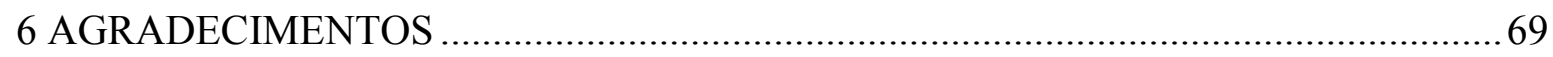

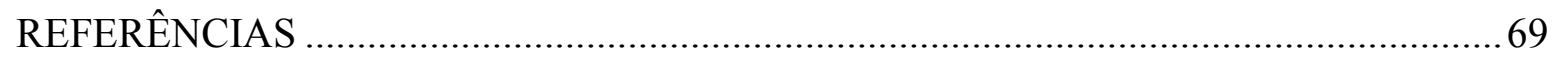

CAPÍTULO 3 - TÉCNICAS ALTERNATIVAS PARA A RESTAURAÇÃO ECOLÓGICA DE ÁREA NO AMBIENTE DE MINERAÇÃO DE BAUXITA NO

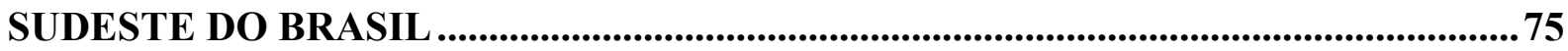

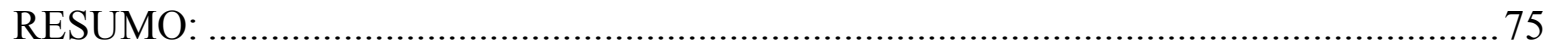

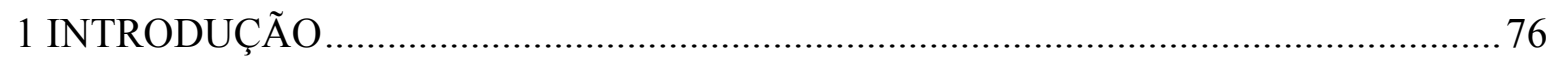

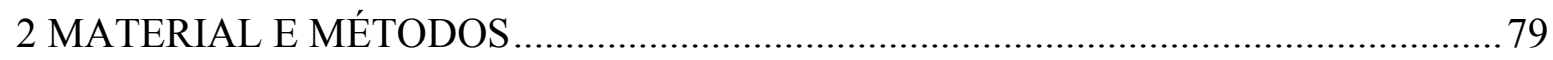

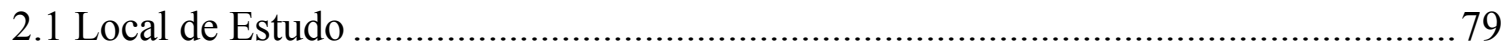

2.2 Avaliação florística e Procedimentos de campo ........................................................ 80

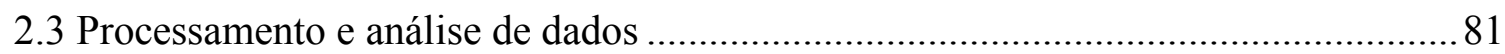

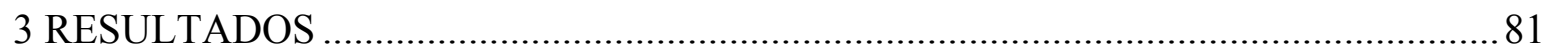

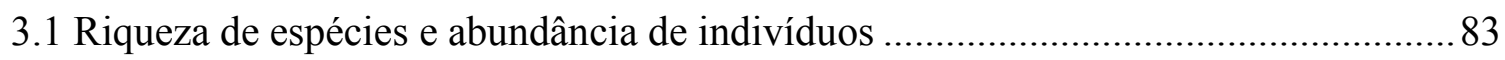

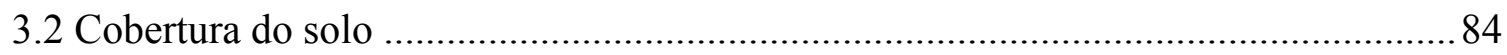

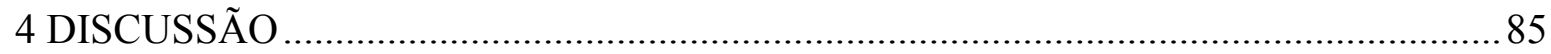

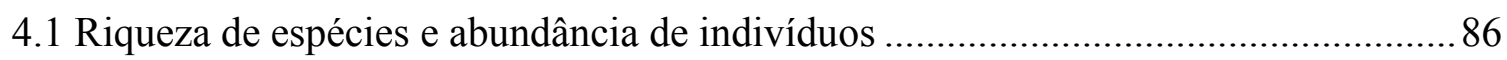

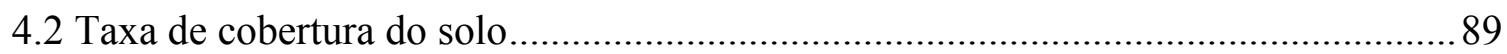

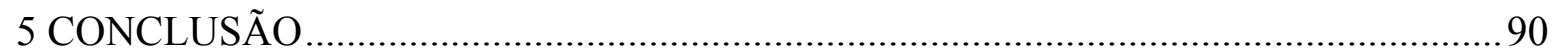

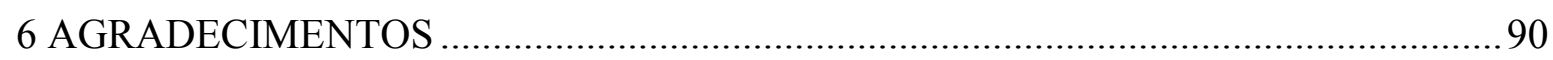

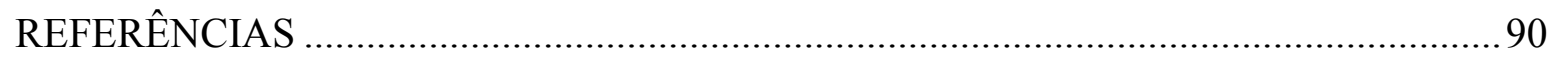

CAPÍTULO 4 - MONITORAMENTO DE FAUNA COMO INDICADOR DE RESTAURAÇÃO ECOLÓGICA DE UMA ÁREA EM AMBIENTE DE MINERAÇÃO DE BAUXITA NA ZONA DA MATA MINEIRA................................................................96

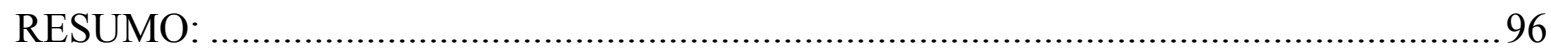

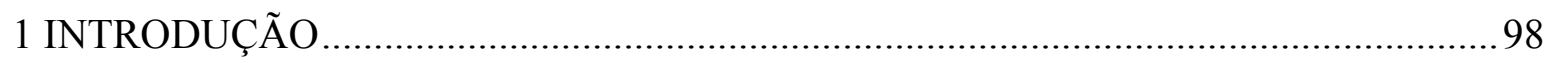

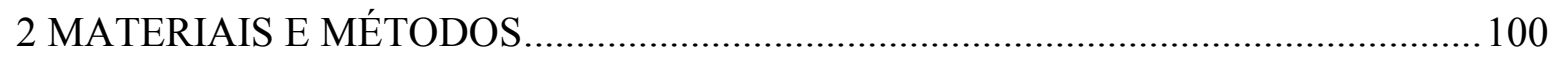




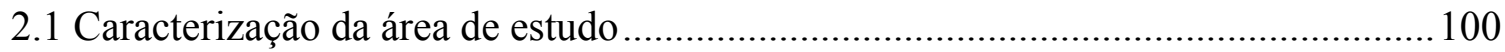

2.2 Procedimentos de campo e processamento dos dados.............................................. 102

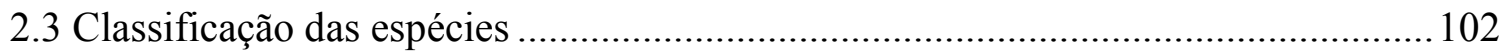

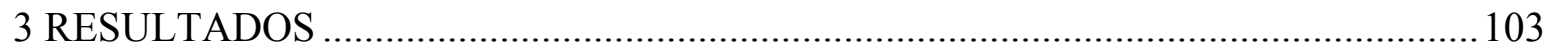

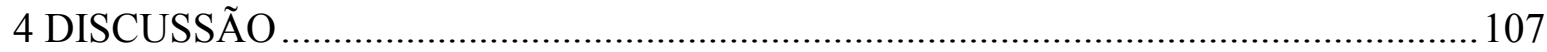

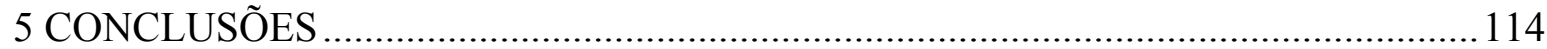

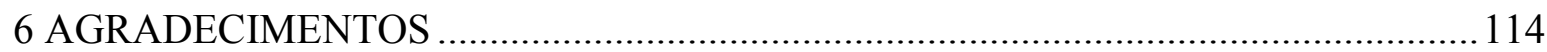

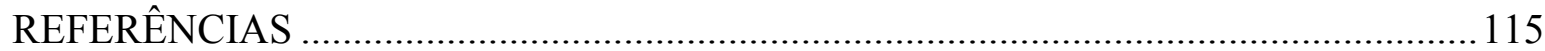

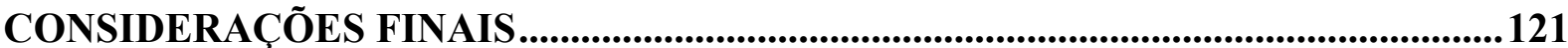




\section{INTRODUÇÃO GERAL}

A restauração ecológica de ecossistemas é um mecanismo importante para combater o aumento global da degradação de ecossistema e a crise contemporânea de perda de biodiversidade e de mudanças climáticas (Bastin et al 2019; Diaz et al 2019; Rodríguez-Uña et al 2020). Neste contexto, a ONU declarou o período entre 2021-2030 como a "Década de Restauração de Ecossistemas" visando combater as mudanças climáticas, melhorar a segurança alimentar, a conservação da biodiversidade e fornecimento de água (UNGA 2019).

Sendo assim, as metas e desafios assumidos em acordos internacionais para a restauração de ambientes, como a Agenda 2030 e o Acordo de Paris (UN 2021), reforçam a necessidade de restaurar o equilíbrio do ambiente e retornar a sua trajetória histórica de modo a contemplar o restabelecimento das interrelações fauna-flora, parâmetros socioeconômicos e serviços ecossistêmicos (Chazdon 2008; Benayas et al 2009; Martin \& Lyons 2018; Cross et al 2019b; Martins et al 2020a; Martins et al 2020b);

No cenário brasileiro, a Mata Atlântica é um dos biomas mais ricos em biodiversidade e mais ameaçados, sendo considerado hotspot global (Rezende et al 2018). Assim sendo, é considerada área prioritária para conservação devido aos elevados índices de endemismo, por abrigar espécies ameaçadas de extinção da fauna e flora e pela alta fragmentação do habitat (Püttker et al 2020; Strassburg et al 2020). Cabe salientar que este bioma é o lar de mais de 125 milhões de brasileiros e contribui em 70 \% do Produto Interno Bruto Nacional (PIB), assim sendo, este domínio fitogeográfico possui relevância também no âmbito econômico (Scarano \& Ceotto 2015; Rezende et al 2018).

Nessa perspectiva, a mineração de bauxita é uma das atividades industriais que contribui para o desenvolvimento socioeconômico do Brasil, devido a geração de importantes receitas e empregos diretos e indiretos para as comunidades locais, além de influência no Índice de Desenvolvimento Humano Municipal (IDH-M) (ANM 2019; MME 2020). Contudo, para exploração deste mineral são necessárias alterações nas camadas do solo, tendo em vista que este minério é encontrado geralmente em camadas superficiais e áreas relativamente pequenas, os impactos podem ser controlados e corrigidos de forma relativamente rápida (Kamble \& Bhosale 2019; Balestrin et al 2020). 
Neste sentido, para que a mineração ocorra de forma sustentável e em conformidade com a legislação ambiental, as empresas realizam a restauração nas áreas mineradas e em áreas de compensação ambiental (Martins et al 2020a; Balestrin et al 2020). Geralmente, as áreas exploradas pela mineração de bauxita no Sudeste do Brasil são áreas antropizadas (principalmente pastagens e plantios de café) que, ocasionalmente, possuem indivíduos arbóreos nativos (Cosimo 2020). De acordo com a Lei da Mata Atlântica (nº 11.428/2006) e com o Decreto n ${ }^{\circ}$ 47749/2019 do estado de Minas Gerais, a supressão de árvores isoladas está condicionada a plantios de compensação.

Diante desta demanda, o Laboratório de Restauração Florestal - LARF / UFV e a Companhia Brasileira de Alumínio (CBA) firmaram uma parceria, em 2011, com objetivo de desenvolver pesquisas e orientações técnicas sobre restauração florestal em áreas mineradas e em áreas de compensação ambiental, em prol de uma mineração de bauxita sustentável (Martins et al 2020a). Estas pesquisas são fundamentais, tendo em vista que cada área no ambiente de mineração sofre influência variada de diferentes fatores: edáficos, topográficos, clima e microclima, paisagem, biodiversidade, amplitude do impacto, resiliência, dentre outros agentes (IAI et al 2016; Stuble et al 2017; Balestrin et al 2019; Martins et al 2020b; Barbosa et al 2021; Gwenzi 2021)

Nesse contexto, o planejamento da restauração ecológica nestas áreas não é uma tarefa simples, pois cada área perturbada ou degradada possui desafios específicos (Rodríguez-Uña et al 2020) e condições ecológicas únicas (Stuble et al 2017). Sendo assim, não existe uma "receita universal" de restauração que possa ser aplicada em grande escala, por conseguinte, os projetos de restauração ecológica devem ser planejados de forma holística, de modo a contemplar os diferentes filtros ambientais regionais e às diversas oportunidades ecológicas das paisagens (Martins 2018).

Diante disso, a avaliação e monitoramento de áreas por meio de bioindicadores são etapas fundamentais para alcançar o sucesso da restauração ecológica (Viani et al 2018). Nesse sentido, os bioindicadores são essenciais para a melhor compreensão dos processos ecológicos e das inter-relações entre fauna e flora (Londe et al 2020), permitem definir o estado atual do projeto, subsidiar a tomada de decisões, corrigir possíveis falhas e verificar a necessidade de sofrer interferências (Viani et al 2017; Balestrin et al 2019; Londe et al 2020). Além disso, é possível determinar o estágio em que a área atinge a autossustentabilidade e também permitem avaliar a efetividade das técnicas de restauração implantadas (Londe et al 2020; Martins et al 2020a). 
O primeiro passo para restauração ecológica de uma área impactada no ambiente de mineração de bauxita é a recuperação do solo. Dessa forma, a adubação verde é uma alternativa promissora que pode contribuir para o sucesso dos projetos de restauração nestes ambientes (Martins et al 2015; Martins 2018). Os adubos verdes são capazes de promover rápida cobertura do solo, atenuar os processos erosivos, aumentar a estabilidade dos agregados e melhorar a infiltração de água no solo (Bonini \& Alves 2011; Souza et al 2021). Em consequência, auxiliam no controle de espécies invasoras e promovem aumento dos teores de matéria orgânica (Reis et al 2019; Melander et al 2020). Além disso, são capazes de melhorar a fertilidade do solo, devido a fixação biológica de nitrogênio (Vásquez-Castro et al 2020).

A restauração ativa por meio de plantio de mudas é indicada principalmente para áreas com baixa resiliência e que não estejam inseridas em uma matriz florestal (Martins 2018; Reid et al 2018; Atkinson \& Bonser 2020). Desse modo, é importante verificar o desenvolvimento das mudas plantadas e a contribuição de cada espécie para o processo sucessional. Nesse sentido, os estudos florísticos e fitossiológicos são essenciais para gerar informações qualitativas e quantitativas, identificar áreas prioritárias para a restauração (Cosimo 2020) e definir metodologias de restauração mais adequadas para cada cenário no ambiente de mineração (Balestrin et al 2020; Martins et al 2020a). Além disso, o conhecimento dos atributos funcionais permite identificar espécies-chave para a restauração da funcionalidade do ecossistema (Barbosa et al 2021).

Uma nova tendência em projetos de restauração ecológica são modelos baseados na conservação da biofuncionalidade (Reis et al 2014). Nessa perspectiva, a nucleação é uma técnica inspirada na teoria ecológica da facilitação que visa aumentar a probabilidade de rotas alternativas de sucessão e desencadear processos de sucessão natural (Yarranton e Morrison 1974). Desse modo, além do restabelecimento da cobertura vegetal, as técnicas de nucleação são capazes de restabelecer processos ecológicos, possibilitar uma maior integração com a paisagem natural e assim restaurar a complexidade do ecossistema (Reis et al 2014; Martins 2018).

Assim sendo, a utilização de técnicas de nucleação como transposição do solo e serapilheira, semeadura direta e poleiros artificias é inovadora na restauração ecológica de áreas no ambiente de mineração de bauxita no Sudeste do Brasil (Martins 2018). Dessa forma, os estudos comparativos são fundamentais para avaliar a efetividade deste conjunto de 
técnicas neste cenário, além de indicar se a nucleação pode ser uma alternativa ao plantio de mudas convencional, tendo em vista principalmente a redução dos custos.

A fauna de diferentes níveis tróficos é fundamental para restaurar o equilíbrio do ecossistema, visto que a funcionalidade do ecossistema está intimamente relacionada à diversidade de fauna (Gagic et al 2015; Cross et al 2019). Contudo, a importância da fauna é negligenciada em muitos projetos de restauração ecológica (Cross et al 2019). Nessa perspectiva, o monitoramento da fauna contribui para uma melhor compreensão das relações fauna-flora e de aspectos comportamentais e de uso do habitat (Burton et al 2015; Hale et al 2020; Delisle et al 2021).

Tendo em vista os desafios para avaliar o comportamento animal, principalmente relacionados ao pesquisador (Caravaggi et al 2017; Luciano et al 2020), as armadilhas fotográficas se destacam como importantes tecnologias para o monitoramento da fauna. As câmeras são acionadas por sensores infravermelhos que permitem observar a distribuição e o comportamento das espécies de forma minimamente invasiva e econômica, além de contribuir para elucidar as relações fauna-flora no ambiente em restauração ecológica (Rovero \& Zimmermann, 2016; Bessone et al 2020).

Portanto, este estudo teve como objetivo avaliar a adubação verde na recuperação do solo, avaliar a florística e a fitossociologia após 4 anos do plantio de mudas, comparar técnicas de nucleação e apresentar novas perspectivas para o monitoramento da fauna na restauração, em uma área no ambiente de mineração de bauxita, na Zona da Mata, em Minas Gerais, Sudeste do Brasil.

Com vistas a induzir uma melhor compreensão, este estudo está organizado em quatro capítulos: 1) Adubação verde: Uma alternativa para recuperação do solo de área em ambiente de mineração de bauxita, no Sudeste do Brasil; 2) Estudo fitossociológico de área em restauração ecológica no ambiente de mineração de bauxita, no Sudeste do Brasil; 3) Técnicas alternativas para a restauração ecológica de área no ambiente de mineração de bauxita no Sudeste do Brasil; 4) Monitoramento de fauna como indicador de restauração ecológica de uma área em ambiente de mineração de bauxita na Zona da Mata Mineira. 


\section{REFERÊNCIAS}

ANM. (2019). Brazilian Mineral Yearbook - Main Metallic Commodities 2018. 1 st ed. Brasília: National Mining Agency.

Atkinson J \& Bonser SP. (2020). "Active" and "passive" ecological restoration strategies in meta-analysis. Restoration Ecology, 28(5), 1032-1035.

Balestrin D, Martins SV, Schoorl JM, Lopes AT, de Andrade CF. (2019). Phytosociological study to define restoration measures in a mined area in Minas Gerais, Brazil. Ecological Engineering, 135, 8-16.

Balestrin D, Martins SV, Fonseca CA. (2020). Ecological restoration and forest coverage advancement in a region influenced by bauxite mining, Minas Gerais, Brazil. In: de Vlieger K. (Ed.). Recent advances in ecological restoration. New York: Nova Science Publishers, 143-154.

Barbosa RS, Pereira GFM, Ribeiro SS, Hage ALF, Costa GF, Salomão RP, Schwartz G. (2021). Key species selection for forest restoration after bauxite mining in the Eastern Amazon. Ecological Engineering, 162, 106190.

Bastin JF, Finegold Y, Garcia C, Mollicone D, Rezende M, Routh D, ... \& Crowther T. W. (2019). The global tree restoration potential. Science, 365(6448), 76-79.

Benayas JMR, Newton AC, Diaz A, Bullock JM. (2009). Enhancement of biodiversity and ecosystem services by ecological restoration: a meta-analysis. Science, 325(5944), 11211124.

Bessone M, Kühl HS, Hohmann G, Herbinger I, N'Goran KP, Asanzi P, ... \& Iyomi MD. (2020). Drawn out of the shadows: Surveying secretive forest species with camera trap distance sampling. Journal of Applied Ecology. 57(5), 963-974.

Burton AC, Neilson E, Moreira D, Ladle A, Steenweg R, Fisher JT, ... \& Boutin S. (2015). Wildlife camera trapping: a review and recommendations for linking surveys to ecological processes. Journal of Applied Ecology, 52(3), 675-685.

Caravaggi A, Banks PB, Burton AC, Finlay CM, Haswell PM, Hayward MW, ... \& Wood MD. (2017). A review of camera trapping for conservation behaviour research. Remote Sensing in Ecology and Conservation, 3(3), 109-122.

Chazdon RL. (2008). Beyond deforestation: restoring forests and ecosystem services on degraded lands. Science, 320(5882), 1458-1460.

Cosimo LHE. (2020). Indicação de áreas prioritárias para restauração florestal compensatória à mineração de bauxita na Zona da Mata de Minas Gerais. 2020. Dissertação (Mestrado em Ciência Florestal). Universidade Federal de Viçosa, Viçosa, 2020.

Cross SL, Bateman PW, \& Cross AT. (2019b). Restoration goals: Why are fauna still overlooked in the process of recovering functioning ecosystems and what can be done about it?. Ecological Management \& Restoration. 21(1):4-8

Delisle ZJ, Flaherty EA, Nobbe MR, Wzientek CM, \& Swihart RK. (2021). Next-Generation Camera Trapping: Systematic Review of Historic Trends Suggests Keys to Expanded 
Research Applications in Ecology and Conservation. Frontiers in Ecology and Evolution, 9, 97.

Díaz S, Settele J, Brondízio ES, Ngo HT, Agard J, Arneth A, ... \& Zayas, C. N. (2019). Pervasive human-driven decline of life on Earth points to the need for transformative change. Science, 366(6471).

Gagic V, Bartomeus I, Jonsson T. et al. (2015) Functional identity and diversity of animals predict ecosystem functioning better than species-based indices. Proceedings of the Royal Society B: Biological Sciences 282, 20142620

Gwenzi W. (2021). Rethinking restoration indicators and end-points for post-mining landscapes in light of novel ecosystems. Geoderma, 387, 114944.

Hale R, Blumstein DT, Mac Nally R, \& Swearer SE. (2020). Harnessing knowledge of animal behavior to improve habitat restoration outcomes. Ecosphere, 11(4), e03104.

Kamble PH \& Bhosale SM. (2019). Assessment of Impact of Bauxite Mining on Environment. i-Manager's Journal on Future Engineering and Technology. 14(4):14-21

IAI, BAC, Wagner C. (2016). Sustainable Bauxite Mining - A Global Perspective. In: Donaldson D, Raahauge BE. (eds) Essential Readings in Light Metals. Springer, Cham. https://doi.org/10.1007/978-3-319-48176-0_7

Londe V, Farah FT, Rodrigues RR, Martins FR. (2020). Reference and comparison values for ecological indicators in assessing restoration areas in the Atlantic Forest. Ecological Indicators, 110, 105928.

Luciano BFL, Ceron K, Bôlla DA, Zocche JJ, \& Carvalho F. (2020). New records of predation attempt on Rhinella spp. in the Atlantic Forest: The importance of camera trap in recording species natural history. Herpetology Notes, 13, 253-256.

Martin DM \& Lyons JE. (2018). Monitoring the social benefits of ecological restoration. Restoration Ecology, 26(6), 1045-1050.

Martins SV, Miranda Neto A, Ribeiro TM. (2015). Uma abordagem sobre diversidade e técnicas de restauração ecológica. In: Sebastião Venâncio Martins. (Org.). Restauração ecológica de ecossistemas degradados. Restauração ecológica de ecossistemas degradados. 1ed.Viçosa, MG: Editora UFV, 2015, v. 1, p. 19-41.

Martins SV, Cosimo LHE, Balestrin D, Fonseca WS, Andrade CF, Barros RS. (2020a). Restoration of Tree and Shrub Diversity Post Bauxite Mining, in the Southeastern Region of Minas Gerais, Brazil. In: Kristian de Vlieger. (Org.). Recent Advances in Ecological Restoration. 1ed.Estados Unidos: Nova, 2020, v.1, p. 33-62.

Martins WBR, Lima MDR, Junior UDOB, Amorim LSVB, de Assis Oliveira F, Schwartz G. (2020b). Ecological methods and indicators for recovering and monitoring ecosystems after mining: A global literature review. Ecological Engineering, 145, 105707.

MME. (2020). Mineral Sector Bulletin. 2 nd ed. Ministério de Minas e Energia. Brasília: National Mining Agency

Püttker T, Crouzeilles R, Almeida-Gomes M, Schmoeller M, Maurenza D, Alves-Pinto H, ... \& Metzger JP. (2020). Indirect effects of habitat loss via habitat fragmentation: A cross-taxa analysis of forest-dependent species. Biological Conservation, 241, 108368. 
Reid JL, Fagan ME, Zahawi RA. (2018). Positive site selection bias in meta-analyses comparing natural regeneration to active forest restoration. Science advances, 4(5), eaas9143.

Reis A, Bechara FC, Tres DR, Trentin BE. (2014). Nucleation: Biocentric conception for the ecological restoration. Ciência Florestal, 24(2):509-519.

Rezende CL, Scarano FR, Assad ED, Joly CA, Metzger JP, Strassburg BBN, .. \& \& Mittermeier RA. (2018). From hotspot to hopespot: An opportunity for the Brazilian Atlantic Forest. Perspectives in ecology and conservation, 16(4), 208-214.

Rodríguez-Uña A, Cruz-Alonso V, Rohrer Z, \& Martínez-Baroja L. (2020). Fresh perspectives for classic forest restoration challenges. Restoration Ecology. 28(1): 12-15

Rovero F \& Zimmermann F. (2016). Camera trapping for wildlife research. Exeter, England: Pelagic Publishing Ltd.

Scarano FR, Ceotto P. (2015). Brazilian Atlantic forest: impact, vulnerability, and adaptation to climate change. Biodiversity and Conservation, 24(9), 2319-2331.

Souza DC, Engel VL, de Mattos EC. (2021). Direct seeding to restore tropical seasonal forests: effects of green manure and hydrogel amendment on tree species performances and weed infestation. Restoration Ecology, 29(1), e13277.

Strassburg BB, Iribarrem A, Beyer HL, Cordeiro CL, Crouzeilles R, Jakovac CC, ... \& Brooks TM. (2020). Global priority areas for ecosystem restoration. Nature, 1-6.

United Nations. (2021). Decade on Ecosystem Restoration (2021-2030). Disponível em $<$ https://www.decadeonrestoration.org/> [acessado em 02 de janeiro de 2021]

UNGA (Assembléia Geral das Nações Unidas) (2019) Década das Nações Unidas sobre Restauração de Ecossistemas (2021-2030). Documento da ONU A / RES / 73/284 (6 de agosto de 2020).

Vásquez-Castro DC, Rodrigues RR, Meli P, Brancalion PHS, Silva RR, \& Couto HTZ. (2020). Preliminary results of using green manure species as a cost-effective option for forest restoration. Scientia Forestalis, 48(127), e3374

Viani RA, Holl KD, Padovezi A, Strassburg BB, Farah FT, Garcia LC., ... \& Brancalion, PH. (2017). Protocol for monitoring tropical forest restoration: perspectives from the Atlantic Forest Restoration Pact in Brazil. Tropical Conservation Science, 10, 1940082917697265.

Viani, R. A., Barreto, T. E., Farah, F. T., Rodrigues, R. R., \& Brancalion, P. H. (2018). Monitoring young tropical forest restoration sites: how much to measure?. Tropical Conservation Science, 11, 1940082918780916.

Yarranton GA \& Morrison RG. (1974) Spatial dynamics of a primary succession: nucleation. Journal of Ecology, 62, 417-428. 


\section{CAPÍtULO 1 - ADUBAÇÃO VERDE: UMA ALTERNATIVA PARA RECUPERAÇÃO DO SOLO DE ÁREA EM AMBIENTE DE MINERAÇÃo DE BAUXITA, NO SUDESTE DO BRASIL}

RESUMO: A adubação verde visa melhorar as condições químicas, físicas, biológicas e estruturais do solo, bem como promover sua rápida cobertura, e a incorporação de matéria orgânica. O objetivo desse estudo foi avaliar a cobertura do solo e a fitomassa seca produzida por três espécies de adubos verdes e a sua influência nos atributos químicos do solo para a restauração ecológica de uma área no ambiente de mineração de bauxita. $\mathrm{O}$ estudo foi realizado em uma área de 2 ha, na qual funcionava o setor administrativo da Companhia Brasileira de Alumínio - CBA, localizada no município de Miraí, Minas Gerais, na qual todas as construções foram removidas deixando o subsolo exposto, compactado e de baixa fertilidade. Esta área de estudo foi incluída no programa de compensação ambiental da empresa. Foi realizado o preparo do solo com ripper, adubação química e a semeadura de três espécies de adubos verdes em janeiro/2017: Cajanus cajan (L.) Huth (guandu), Crotalaria juncea L. (crotalária-juncea) e Stylosanthes guianensis (Aubl.) Sw. (estilosantes). A cobertura do solo e a produção de fitomassa foram avaliadas ao final de 18 meses. Os atributos do solo foram avaliados em três épocas $(0,18$ e 24 meses após a semeadura). As médias dos valores de cobertura do solo e de peso seco, obtidas nos três tratamentos foram comparadas através do teste de Tukey para amostras independentes $(\mathrm{p}<0,05)$. As espécies $C$. cajan $(89 \%)$ e $C$. juncea (75\%) apresentaram os melhores desempenhos na cobertura do solo, significativamente maiores que o promovido por $S$. guianensis $(59,5 \%)$. No que tange a produção de fitomassa, C. cajan $\left(853,90 \mathrm{~g} \cdot \mathrm{m}^{-2}\right)$ e $S$. guianensis $\left(716,18 \mathrm{~g} \cdot \mathrm{m}^{-2}\right)$ foram as espécies que mais produziram material vegetal. A espécie $C$. juncea $\left(402,26\right.$ g.m² $\left.{ }^{-2}\right)$ apresentou menor produção de fitomassa, sendo considerada estatisticamente semelhante a $S$. guianensis. A calagem foi eficiente para elevar o $\mathrm{pH}$ do solo e aumentar a concentração dos nutrientes cálcio e magnésio. O rápido recobrimento do solo promovido pelos adubos verdes garantiu proteção contra eventuais processos erosivos e evitou a invasão de gramíneas exóticas agressivas, propiciando melhores condições para as mudas plantadas. A deposição de fitomassa colaborou para aumento dos teores de matéria orgânica e aumento da fertilidade do solo em todos os tratamentos. Os teores de N-total do solo aumentaram consideravelmente após 24 meses da semeadura dos adubos verdes (Cro: 914\%; Sty: 536\% e Caj: 532\%), quando comparados aos valores iniciais de solo exposto. Portanto, as técnicas de restauração aplicadas: preparo do solo, adubação química e semeadura de adubos verdes foram eficientes 
para promover o rápido recobrimento do solo e melhoria das suas propriedades químicas. Pode-se concluir que a adubação verde é uma alternativa viável que contribui para o sucesso dos projetos de restauração florestal de áreas no ambiente da mineração de bauxita.

Palavras-chaves: Técnicas alternativas; Preparo de solo; Qualidade de solo; Áreas mineradas; Recuperação de Áreas Degradadas.

ABSTRACT: Green manure aims to improve the chemical, physical, biological and structural conditions of the soil, as well as to promote its rapid coverage, and the incorporation of organic matter. The objective of this study was to evaluate the soil cover and dry mass produced by three species of green manures and their influence on the chemical attributes of the soil for the ecological restoration of an area in the bauxite mining environment. The study was carried out in a 2 ha area, where the administrative sector of Companhia Brasileira de Alumínio - CBA was located, in Miraí, Minas Gerais, in which all the buildings were removed leaving the subsoil exposed, compacted and with low fertility. This study area was included in the company's environmental compensation program. The soil preparation was carried out with ripper, chemical fertilization and the sowing of three species of green fertilizers in January, 2017: Cajanus cajan (L.) Huth (pigeon pea), Crotalaria juncea L. (sunn hemp) and Stylosanthes guianensis (Aubl.) Sw. (stylo). Soil cover and phytomass production were evaluated at the end of 18 months. Soil attributes were evaluated at three times ( 0,18 and 24 months after sowing). The mean values of soil cover and dry weight obtained in the three treatments were compared using the Tukey test for independent samples $(\mathrm{p}<0.05)$. The species C. cajan $(89 \%)$ and C. juncea $(75 \%)$ showed the best performances in land cover, significantly higher than that promoted by S. guianensis (59.5\%). Regarding phytomass production, C. cajan (853.90 $\left.\mathrm{gm}^{-2}\right)$ and S. guianensis (716.18 $\mathrm{gm}^{-2}$ ) were the species that produced the most plant material. The species C. juncea $(402.26 \mathrm{~b}$ $\mathrm{gm}^{-2}$ ) presented lower phytomass production, being considered statistically similar to $S$. guianensis. Liming was effective in raising soil $\mathrm{pH}$ and increasing the concentration of calcium and magnesium nutrients. The quick covering of the soil promoted by the green fertilizers guaranteed protection against eventual erosive processes and avoided the invasion of aggressive exotic grasses, providing better conditions for the seedlings planted. The phytomass deposition contributed to increase the organic matter content and increase soil fertility in all treatments. The total-N contents of the soil increased considerably after 24 months of sowing of the green manures (Cro: 914\%; Sty: 536\% and Caj: 532\%), when 
compared to the initial values of exposed soil. Therefore, the restoration techniques applied: soil preparation, chemical fertilization and sowing of green manures were efficient to promote the fast covering of the soil and improvement of the chemical soil properties. It can be concluded that green manure is a viable alternative that contributes to the success of forest restoration projects in areas in the bauxite mining environment.

Keywords: Alternative techniques; Soil preparation; Soil quality; Mined areas; Recovery of Degraded Areas.

\section{INTRODUÇÃO}

A bauxita é um importante minério, do qual se obtêm o alumínio, o terceiro elemento em maior abundância na crosta terrestre (ABAL 2017). Este mineral é encontrado em alta quantidade e qualidade $\left(>40 \% \mathrm{Al}_{2} \mathrm{O}_{3}\right.$ ) em reservas brasileiras (ANM 2020). Por esta razão, o Brasil possui uma posição de destaque na produção e exploração das reservas minerais existentes em seu território (MME 2020). Nesse sentido, a exploração de bauxita possui relevante participação no Produto Interno Bruto Nacional (PIB), além de promover o desenvolvimento socioeconômico regional através da geração de empregos diretos e indiretos (ANM 2019; MME 2020).

Contudo, a mineração de bauxita provoca impactos pontuais devido a remoção da camada superficial do solo (camada fértil) (Kamble \& Bhosale 2019). Todavia, pelo fato deste minério ser encontrado geralmente em camadas próximas à superfície do solo e afloramentos na superfície, os impactos podem ser controlados e corrigidos de forma que a recuperação das áreas mineradas e das áreas sob influência da mineração de bauxita seja relativamente rápida (ABAL 2017; Balestrin et al 2019a; Melo \& Sánchez 2020; Balestrin et al 2020; Martins et al 2020). Desse modo, para garantir a sustentabilidade, as empresas mineradoras precisam realizar ações de restauração tanto nas áreas mineradas quanto nas áreas de compensação, visando à recuperação do ambiente (Martins et al 2020).

Nessa perspectiva, áreas sem cobertura vegetal são vulneráveis à erosão hídrica devido aos efeitos da erosividade das chuvas e à erodibilidade dos solos (Ferreira et al 2021). Em consequência, os principais impactos desse processo são a degradação da estrutura e redução dos teores de matéria orgânica e de nutrientes do solo (Anache et al 2017; Hou et al 2021), impactos estes que podem ser intensificados devido às mudanças climáticas (Almagro et al 2017). 
Tendo em vista que a degradação do solo provoca a interrupção do funcionamento do ecossistema e declínio da biodiversidade em todo o mundo, principalmente em regiões tropicais (Butchart et al 2010; Kaiser-Bunbury et al 2017), torna-se necessário adaptar os projetos de restauração ecológica às peculiaridades regionais (Stuble et al 2017; Martins 2018). Desse modo, é importante que as técnicas além de restaurar as funções ecológicas e reduzir os impactos, também acelerem o recobrimento vegetal, de forma economicamente viável e no menor tempo possível (Gann et al 2019).

Neste contexto, a adubação verde é uma alternativa potencial para a restauração ecológica de ecossistemas, tendo em vista os inúmeros benefícios físicos, químicos e biológicos nas propriedades do solo (Martins et al 2015) e sua contribuição na mitigação das mudanças climáticas (Delgado et al 2021). Dessa maneira, os adubos verdes se destacam por promover rápida cobertura do solo e auxiliar no controle de espécies invasoras (Reis et al 2019; Melander et al 2020), bem como atenuar os processos erosivos e aumentar a estabilidade dos agregados, garantindo desse modo melhorias na infiltração de água no solo (Bonini \& Alves 2011).

Além disso, os adubos verdes são capazes de realizar relações de simbiose com bactérias fixadoras de nitrogênio e, por conseguinte, são capazes de incrementar esse nutriente no solo, permitindo assim uma redução nos gastos com as fertilizações nitrogenadas. Outrossim, devido ao aporte de quantidades expressivas de fitomassa, os adubos verdes promovem um aumento no teor de matéria orgânica do solo (Gao et al 2018). E então, consequentemente, ocorre redução da acidez, aumento da capacidade de troca catiônica (CTC) e melhorias no microclima do solo e na ciclagem de nutrientes (Iserhagen et al 2014).

Diante disso, a adubação verde é uma estratégia a ser considerada nos projetos de restauração ecológica devido aos múltiplos serviços ecossistêmicos (Martins et al 2015; Vásquez-Castro et al 2020). Desse modo, a adubação verde é uma técnica condicionante de solo, capaz de mitigar os efeitos da erosão hídrica e aumentar a fertilidade do solo (Ma et al 2021). Além disso, os adubos verdes são capazes de estabelecer interações com a fauna, o que facilita o processo sucessional e contribui para o aumento da diversidade (Marshall \& Lynch 2020).

Portanto, a restauração ecológica de uma área impactada no ambiente de mineração se inicia na recuperação do solo, dessa forma, os adubos verdes são ferramentas promissoras que podem contribuir para o sucesso dos projetos de restauração. Assim, este estudo teve como 
objetivo avaliar a cobertura do solo e a fitomassa seca produzida por três espécies de adubos verdes e sua influência nos atributos químicos para recuperação do solo de área no ambiente de mineração de bauxita.

\section{MATERIAL E MÉTODOS}

\subsection{Area de Estudo}

Este estudo foi realizado no município de Miraí ( $21^{\circ} 4^{\prime} 5^{\prime \prime S}$ e $\left.42^{\circ} 33^{\prime} 28^{\prime \prime} \mathrm{W}\right)$, na região denominada Zona da Mata, no Sudeste do estado de Minas Gerais - Brasil. O clima da região é do tipo Cwa segundo a classificação de Koppen, caracterizado como temperado úmido com inverno seco e verão quente. A precipitação média anual é de $1.564 \mathrm{~mm}$ e a temperatura média anual é de $23,5^{\circ} \mathrm{C}$ (AGEVAP 2013).

O relevo é caracterizado como forte ondulado e montanhoso e de acordo com o Sistema Brasileiro de Classificação de Solos (Santos et al 2018), o solo predominante na região é o Latossolo Vermelho-Amarelo distrófico típico. A vegetação característica da região é classificada como Floresta Estacional Semidecidual Montana, inserida no Domínio Floresta Atlântica (IBGE 2012).

Este estudo foi conduzido em uma área de 2 ha, em altitude de $715 \mathrm{~m}$, que até o final do ano de 2016 era destinada ao setor administrativo da Companhia Brasileira de Alumínio CBA (Figura 1-1). Com a mudança de localização do setor administrativo da empresa, todas as construções foram removidas e consequentemente, o subsolo ficou exposto, compactado e de baixa fertilidade. Assim, esta área foi incluída no programa de compensação ambiental da empresa pela mineração de bauxita. 
Figura 1-1. Localização da área de estudo, em Miraí-MG, Brasil.

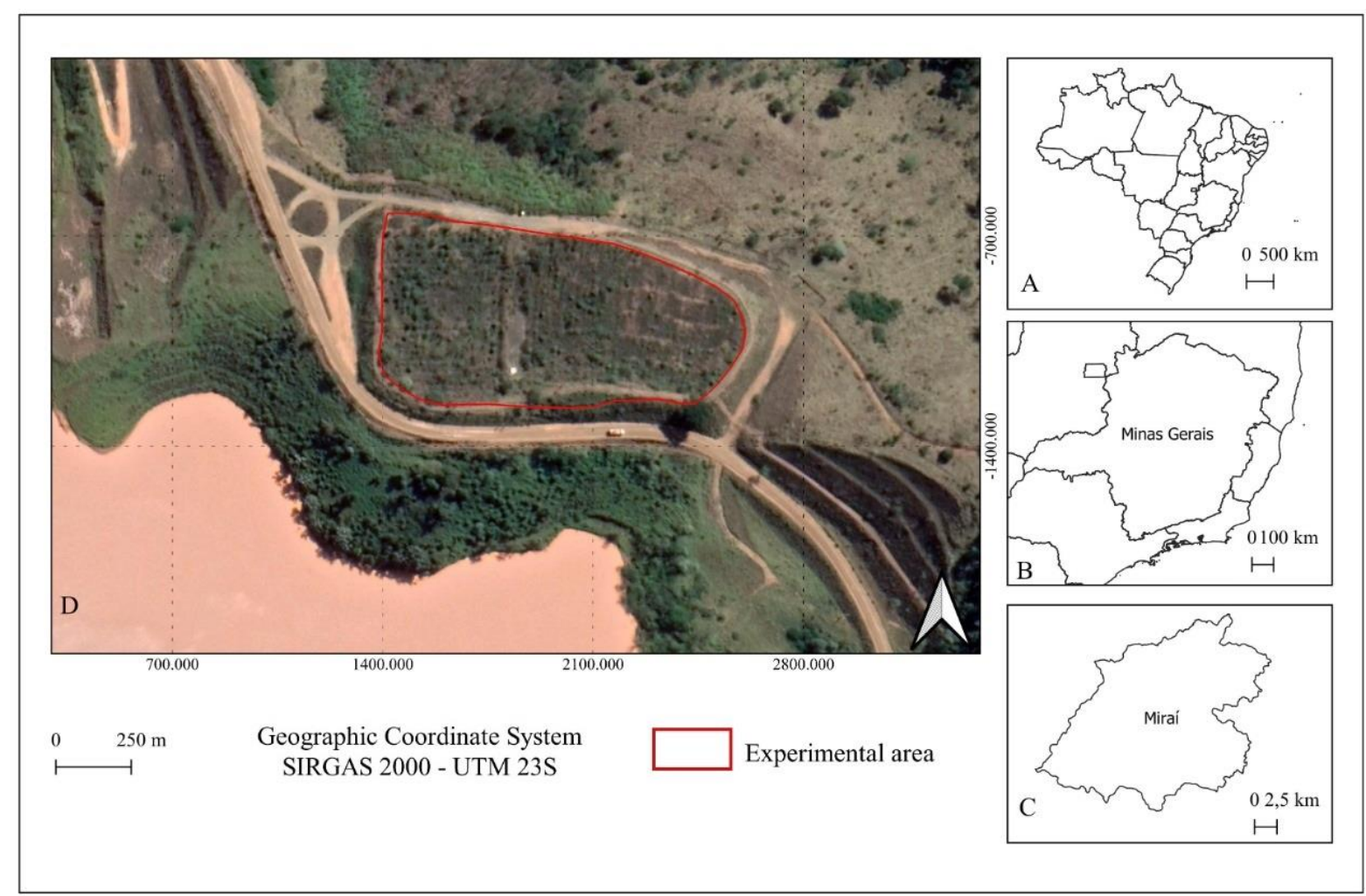

Dessa maneira, foi realizado o preparo do solo através de um subsolador ripper na profundidade de $60 \mathrm{~cm}$, com a finalidade de romper a camada compactada e homogeneizar a superfície do solo. Em sequência foi realizada, em área total, a correção da acidez com 4 toneladas $\mathrm{ha}^{-1}$ de calcário e fertilização com 2 toneladas $\mathrm{ha}^{-1}$ de fosfato natural reativo e 1 tonelada $h^{-1}$ de NPK 10-30-10. Posteriormente, foi realizada a semeadura de três adubos verdes em sulcos, na proporção de $150 \mathrm{~kg} \mathrm{ha}^{-1}$ de sementes, de modo a promover a rápida cobertura do solo. Em complemento, foram plantadas mudas de 18 espécies arbóreas nativas com diferentes características sucessionais, em espaçamento 4,0 x 4,0 metros.

\subsection{Procedimentos de campo}

Os três adubos verdes semeados em janeiro/2017 foram: Cajanus cajan (L.) Millsp. (Feijão-guandu); Crotalaria juncea L. (Crotalária-juncea) e Stylosanthes guianensis (Aubl.) Sw. (Estilosantes). A situação inicial do solo logo após a remoção das estruturas construídas e da terraplanagem, o avanço da cobertura e o manejo dos adubos verdes semeados podem ser observados na figura 1-2. 
Figura 1-2. Situação inicial do solo, crescimento e manejo dos adubos verdes
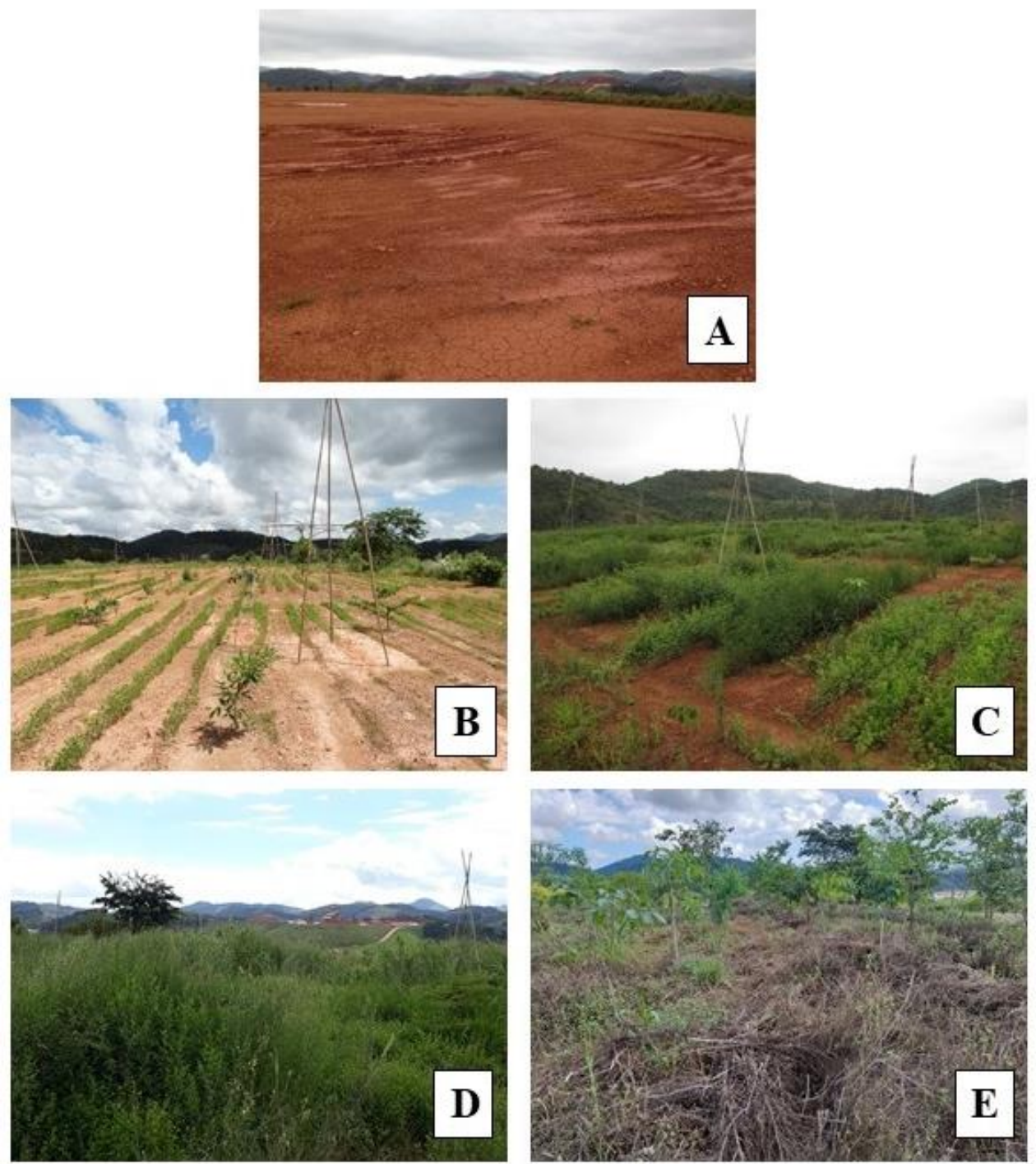

(A: solo exposto, situação inicial; B: Adubos verdes, após 6 meses da semeadura; C: Adubos verdes, após 12 meses da semeadura; D: Adubos verdes, após 18 meses da semeadura; E: Manejo dos adubos verdes, para favorecer o desenvolvimento das mudas plantadas).

Foram alocadas 10 parcelas de 1 x $1 \mathrm{~m}$ para avaliação do potencial de cobertura de cada espécie de adubo verde após 18 meses da semeadura. Sendo assim, foram testados três tratamentos compostos por dez repetições cada, distribuídas por meio de delineamento inteiramente casualizado. O tratamento T1 - C. cajan (Caj); o T2 - C. juncea (Cro) e T3 - S. guianensis (Sty).

A taxa de cobertura do solo foi obtida através da avaliação visual das parcelas por meio da escala percentual, na qual a nota 0 correspondeu à ausência de cobertura vegetal do solo e a nota 100 corresponde a cobertura completa do solo. Além disso, a produção de fitomassa foi avaliada através da coleta de todo material vegetal acima do solo por meio do uso um gabarito de $0,25 \mathrm{~m}^{2}$, em cada parcela. $\mathrm{O}$ material coletado foi armazenado em sacos 
plásticos devidamente identificados e transportado para o Laboratório de Restauração Florestal - LARF/UFV, onde foi seco em estufa a $72^{\circ} \mathrm{C}$ por 48 horas e o peso seco foi mensurado.

As análises químicas do solo na área de estudo foram realizadas mediante a obtenção de trinta pontos de amostragem de solo, coletados aleatoriamente em cada tratamento, através de um trado holandês na camada de $0-20 \mathrm{~cm}$. As amostras simples obtidas foram misturadas e geraram uma amostra composta para cada tratamento. Para avaliar e comparar as características químicas do solo sob os três adubos verdes, as coletas de solo foram realizadas em diferentes épocas $(0,18$ e 24 meses após a semeadura).

As amostras compostas foram enviadas para o Laboratório de Solos da Universidade Federal de Viçosa para as devidas análises. Posteriormente, os resultados foram interpretados de acordo com o Guia de Recomendação para corretivos e fertilizantes de Minas Gerais (Alvarez et al 1999) e comparados com os resultados de análises de solo, realizadas anteriormente à implementação das técnicas de restauração.

\subsection{Processamento e análise de dados}

Para comparar as médias dos valores de cobertura do solo e de peso seco, obtidas nos três tratamentos, utilizou-se à análise de variância ANOVA one-way seguido por um teste posterior de Tukey para amostras independentes $(\mathrm{p}<0,05)$ (Crawley 2012). Para a realização das análises e avaliação estatística, foi utilizado o software R versão 3.5.3 (R Core Team, 2019).

\section{RESULTADOS}

\subsection{Cobertura do solo}

A análise de variância mostrou diferenças entre os tratamentos, tanto para a cobertura do solo quanto para o peso seco $(p<0,05)$. O maior percentual de cobertura do solo foi observado na espécie Cajanus cajan, com média de 89\%, seguida de Crotalaria juncea com $75 \%$. Stylosanthes guianensis apresentou o menor percentual de cobertura, com média de $59,5 \%$, sendo estatisticamente inferior a $C$. cajan e semelhante a $C$. juncea pelo teste de Tukey (Figura 1-3). 
Figura 1-3. Médias de cobertura do solo (\%) das espécies de adubos verdes. Médias seguidas de letras diferentes são estatisticamente diferentes $\mathrm{p} \leq 0.05$ (Tukey). Caj = Cajanus cajan; Cro $=$ Crotalaria juncea $\mathrm{e}$ Sty $=$ Stylosanthes guianensis.

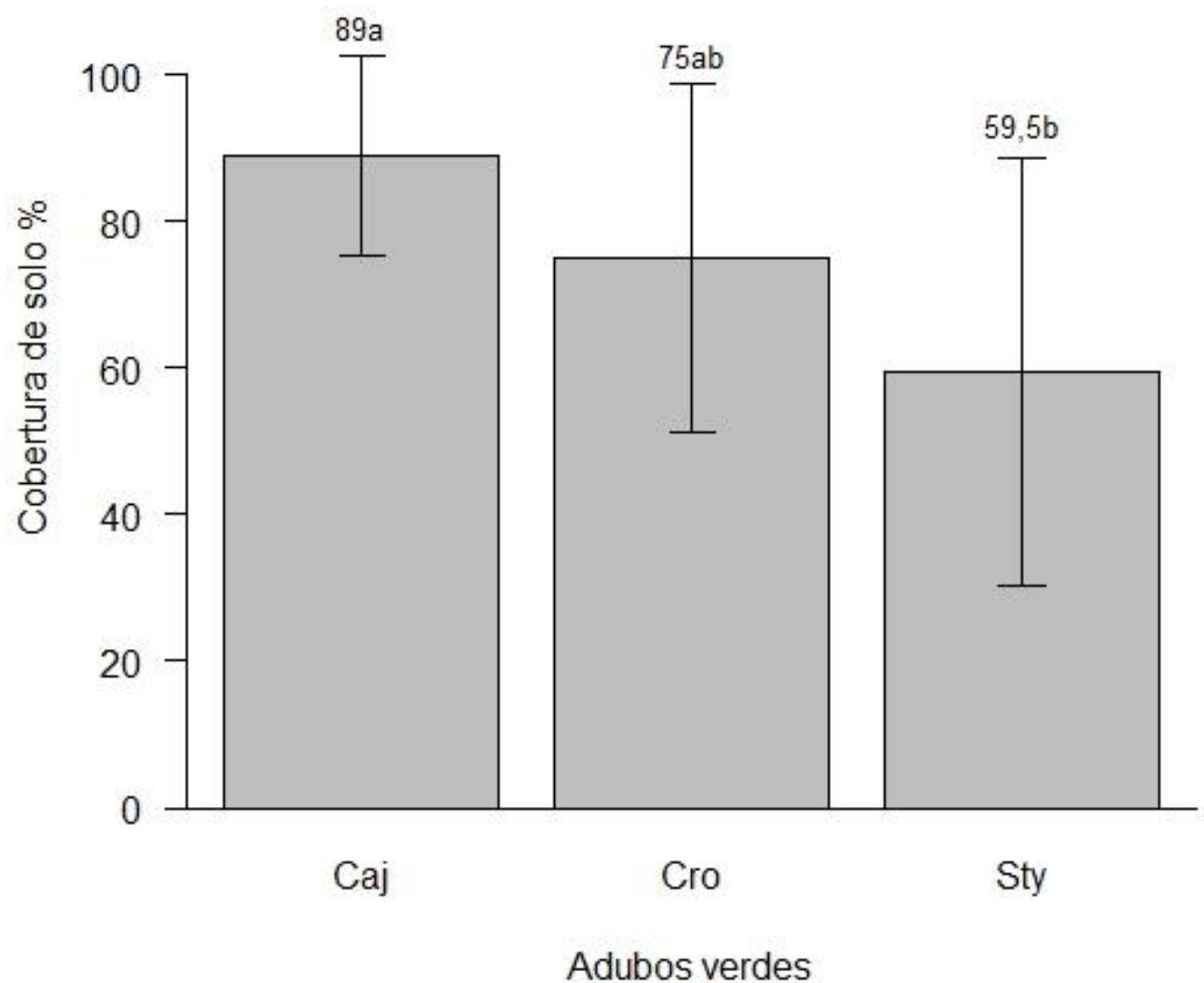

\subsection{Fitomassa Seca}

As espécies que mais produziram fitomassa seca foram $C$. cajan com média de 853,90 g. $\mathrm{m}^{-2}$ e $S$. guianensis com 716,18 g.m $\mathrm{m}^{-2}$. C. juncea apresentou menor peso seco, equivalente à 402,26 g.m m $^{-2}$, sendo considerada estatisticamente menor que C. cajan, porém semelhante à $S$. guianensis pelo teste de Tukey $\mathrm{p} \leq 0.05$ (Figura 1-4). 
Figura 1-4. Média de peso seco das espécies de adubo verde. Médias seguidas de letras diferentes são estatisticamente diferentes $\mathrm{p} \leq 0.05$ (Tukey). Caj = Cajanus cajan; Cro $=$ Crotalaria juncea e Sty $=$ Stylosanthes guianensis .

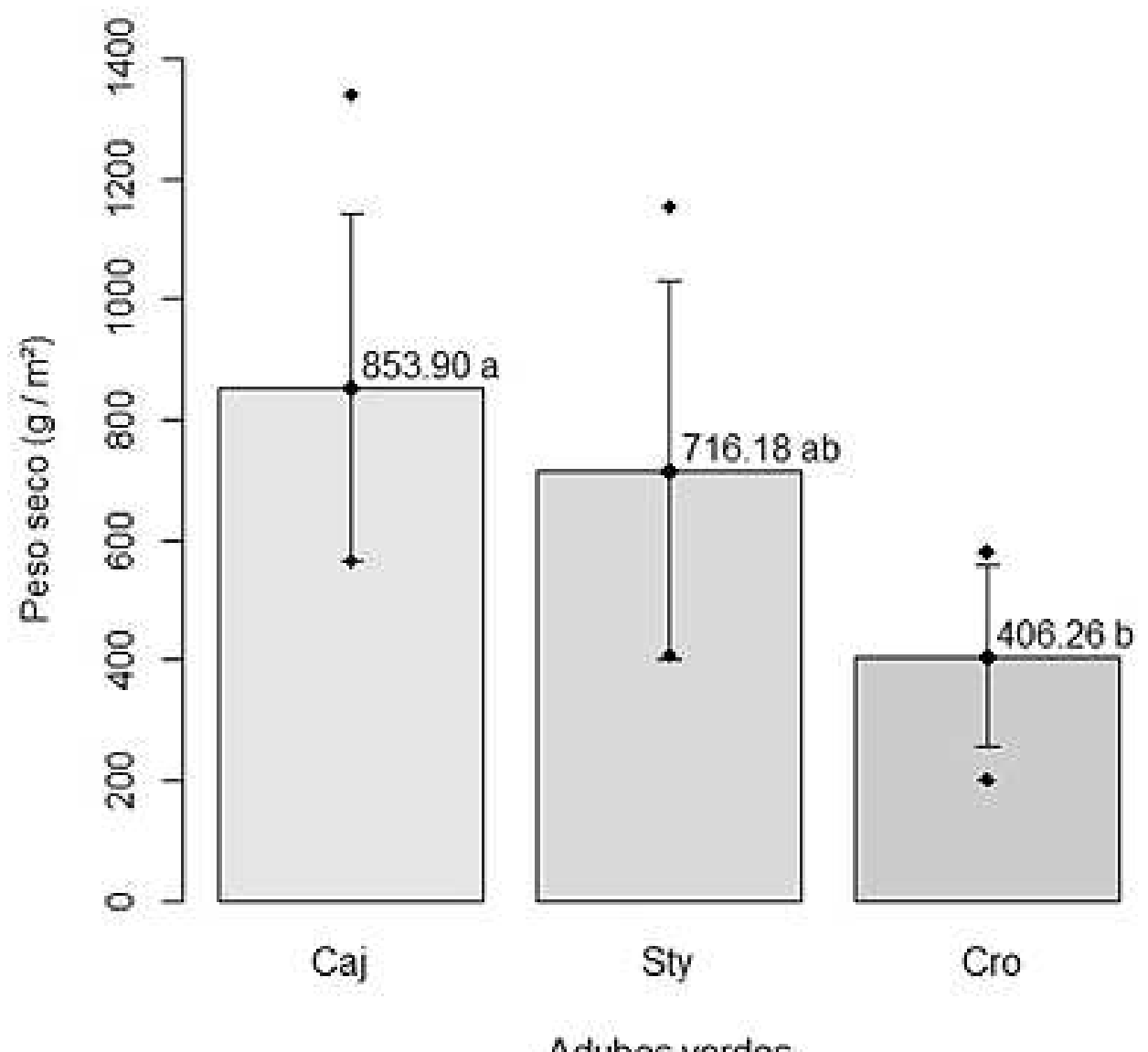

Adubos verdes

\subsection{Análises de solo}

De acordo com o Guia de Recomendação para corretivos e fertilizantes de Minas Gerais (Alvarez et al 1999), as amostras de solo coletadas antes das técnicas de preparo de solo e fertilização (mês 0 ), indicam nível de acidificação médio $\left(\mathrm{pH}-\mathrm{H}_{2} \mathrm{O}=5,39\right)$, conteúdo muito baixo de matéria orgânica $(\mathrm{MO}=0,25)$, soma de bases baixa $(\mathrm{SB}=0,82)$, baixa capacidade de troca catiônica $(\mathrm{t}=0,82)$ e uma baixa saturação de bases $(\mathrm{V}=35,3)$. Assim, com o objetivo de avaliar, relacionar e comparar as características químicas do solo sob os três adubos verdes em diferentes épocas $(0,18$ e 24 meses após a semeadura), a Tabela 1-1 foi elaborada. 
Tabela 1-1. Análises químicas de solo dos diferentes tratamentos na camada $0-20 \mathrm{~cm}$, em diferentes épocas $(0,18$ e 24 meses após a semeadura).

\begin{tabular}{|c|c|c|c|c|}
\hline Parâmetros & Meses & Cro & Sty & Caj \\
\hline \multirow{3}{*}{$\begin{array}{c}\mathbf{p H} \\
\left(\mathrm{H}_{2} 0\right)\end{array}$} & 0 & 5,39 & 5,39 & 5,39 \\
\hline & 18 & 6,97 & 7,06 & 6,84 \\
\hline & 24 & 7,54 & 7,49 & 7,40 \\
\hline \multirow{3}{*}{$\begin{array}{c}\text { MO } \\
(\mathrm{dag} / \mathrm{kg})\end{array}$} & 0 & 0,25 & 0,25 & 0,25 \\
\hline & 18 & 1,88 & 1,75 & 2,28 \\
\hline & 24 & 5,09 & 2,93 & 3,26 \\
\hline \multirow{3}{*}{$\begin{array}{l}\text { N-total } \\
\text { (dag/kg) }\end{array}$} & 0 & 0,022 & 0,022 & 0,022 \\
\hline & 18 & 0,076 & 0,061 & 0,076 \\
\hline & 24 & 0,223 & 0,140 & 0,139 \\
\hline \multirow{3}{*}{$\begin{array}{c}\mathbf{P} \\
\left(\mathrm{mg} / \mathrm{dm}^{3}\right)\end{array}$} & 0 & 4,40 & 4,40 & 4,40 \\
\hline & 18 & 463,1 & 463,1 & 283,8 \\
\hline & 24 & 614,7 & 509,7 & 547,6 \\
\hline \multirow{3}{*}{$\underset{\left(\mathrm{mg} / \mathrm{dm}^{3}\right)}{\mathbf{K}}$} & 0 & 21 & 21 & 21 \\
\hline & 18 & 89 & 52 & 58 \\
\hline & 24 & 283 & 98 & 161 \\
\hline \multirow{3}{*}{$\begin{array}{c}\mathbf{C a}^{2+} \\
\left(\mathrm{cmolc} / \mathrm{dm}^{3}\right)\end{array}$} & 0 & 0,59 & 0,59 & 0,59 \\
\hline & 18 & 4,22 & 3,52 & 3,13 \\
\hline & 24 & 4,87 & 4,2 & 4,46 \\
\hline \multirow{3}{*}{$\begin{array}{c}\mathbf{M g}^{2+} \\
\left(\mathrm{cmolc}^{2} \mathrm{dm}^{3}\right)\end{array}$} & 0 & 0,18 & 0,18 & 0,18 \\
\hline & 18 & 1,76 & 0,86 & 0,72 \\
\hline & 24 & 2,16 & 1,83 & 2,00 \\
\hline \multirow{3}{*}{$\begin{array}{c}\mathbf{H}+\mathbf{A l} \\
\left(\mathrm{cmolc} / \mathrm{dm}^{3}\right)\end{array}$} & 0 & 1,5 & 1,5 & 1,5 \\
\hline & 18 & 0,6 & 0,0 & 0,3 \\
\hline & 24 & 0,0 & 0,2 & 0,6 \\
\hline \multirow{3}{*}{$\begin{array}{c}\text { SB } \\
\left(\mathrm{cmolc} / \mathrm{dm}^{3}\right)\end{array}$} & 0 & 0,82 & 0,82 & 0,82 \\
\hline & 18 & 6,21 & 4,51 & 4,00 \\
\hline & 24 & 7,76 & 6,28 & 6,87 \\
\hline \multirow{3}{*}{$\underset{\left(\mathrm{cmolc} / \mathrm{dm}^{3}\right)}{\mathbf{t}}$} & 0 & 0,82 & 0,82 & 0,82 \\
\hline & 18 & 6,21 & 4,51 & 4,00 \\
\hline & 24 & 7,76 & 6,28 & 6,87 \\
\hline \multirow{3}{*}{$\underset{\left(\mathrm{cmolc} / \mathrm{dm}^{3}\right)}{\mathbf{T}}$} & 0 & 2,32 & 2,32 & 2,32 \\
\hline & 18 & 6,81 & 4,51 & 4,30 \\
\hline & 24 & 7,76 & 6,48 & 7,47 \\
\hline \multirow{3}{*}{$\begin{array}{c}\mathbf{V} \\
(\%)\end{array}$} & 0 & 35,3 & 35,3 & 35,3 \\
\hline & 18 & 91,2 & 100 & 93,0 \\
\hline & 24 & 100 & 96,9 & 92,0 \\
\hline \multirow{3}{*}{$\begin{array}{l}\text { P-rem } \\
(\mathrm{mg} / \mathrm{L})\end{array}$} & 0 & 12,9 & 12,9 & 12,9 \\
\hline & 18 & 17,6 & 18,2 & 18,6 \\
\hline & 24 & 26,4 & 24,4 & 20,8 \\
\hline
\end{tabular}

Caj (Cajanus cajan); Cro (Crotalaria juncea); Sty (Stylosanthes guianensis); MO (Matéria Orgânica); N-total (Nitrogênio total); P (Fósforo); K (Potássio); $\mathrm{Ca}^{2+}$ (Cálcio); $\mathrm{Mg}^{2+}$ (Magnésio); $\mathrm{H}+\mathrm{Al}$ (Acidez potencial); $\mathrm{SB}=$ Soma de Bases Trocáveis; $\mathrm{t}$ (Capacidade de Troca Catiônica Efetiva); T - (Capacidade de Troca Catiônica a pH 7,0); V (Índice de Saturacão por Bases); P-rem (Fósforo Remanescente) 
A calagem foi eficiente para elevar o $\mathrm{pH}$ do solo e aumentar a concentração dos nutrientes cálcio $\left(\mathrm{Ca}^{2+}\right)$ e magnésio $\left(\mathrm{Mg}^{2+}\right)$. A fosfatagem elevou a concentração de fósforo (P) no solo. A soma de bases e saturação por bases aumentaram após as ações realizadas, enquanto que a acidez trocável diminuiu. Observou-se aumento do N-total do solo em todos os tratamentos após 18 meses da semeadura dos adubos verdes, no solo sob crotalária e guandu houve um aumento de $245 \%$ e no solo sob estilosantes um aumento de $177 \%$, em relação aos valores iniciais obtidos antes da implantação do projeto de restauração, refletindo a contribuição dos três adubos verdes através da fixação biológica de nitrogênio.

Em consonância, percebe-se uma melhora nas demais propriedades químicas do solo, de acordo com critérios propostos por Alvarez et al (1999), apresentados na Tabela 1-2. No solo sob crotalária observou-se nível de acidificação médio $\left(\mathrm{pH}-\mathrm{H}_{2} \mathrm{O}=6,97\right)$, conteúdo baixo de matéria orgânica $(\mathrm{MO}=1,88)$, soma de bases muito boa $(\mathrm{SB}=6,21)$, boa capacidade de troca catiônica $(\mathrm{t}=6,21)$ e uma muito boa saturação de bases $(\mathrm{V}=91,2 \%)$. Apesar da matéria orgânica receber a classificação baixa, em relação à análise anterior houve um aumento de $652 \%$.

Tabela 1-2. Classificação das propriedades químicas do solo, após 18 meses da semeadura de adubos verdes, de acordo com as recomendações para o uso de corretivos e fertilizantes em Minas Gerais. $\mathrm{Mba}=$ Muito baixo; $\mathrm{Ba}=\mathrm{Baixo} ; \mathrm{M}=$ Médio; $\mathrm{Bo}=\mathrm{Bom} ; \mathrm{Mbo}=$ Muito bom.

\begin{tabular}{|cccccccccccccc|}
\hline $\begin{array}{c}\text { Adubos } \\
\text { verdes }\end{array}$ & $\mathbf{p H}$ & $\mathbf{M O}$ & $\mathbf{P}$ & $\mathbf{K}$ & $\mathbf{C a}^{2+}$ & $\mathbf{M g}^{2+}$ & $\mathbf{H}+\mathbf{A l}$ & $\mathbf{S B}$ & $\mathbf{t}$ & $\mathbf{T}$ & $\mathbf{V}$ & $\mathbf{P}-\mathbf{r e m}$ \\
\hline Cro & $\begin{array}{c}\text { Acidez } \\
\text { fraca }\end{array}$ & Ba & Mbo & Bo & Mbo & Mbo & Mba & Mbo & Bo & M & Mbo & Mbo \\
\hline Sty & Neutra & Ba & Mbo & M & Bo & M & Mba & Bo & M & M & Mbo & Mbo \\
\hline Caj & $\begin{array}{c}\text { Acidez } \\
\text { fraca }\end{array}$ & M & Mbo & M & Bo & M & Mba & Bo & M & Ba & Mbo & Mbo \\
\hline
\end{tabular}

Caj (Cajanus cajan); Cro (Crotalaria juncea); Sty (Stylosanthes guianensis)

No solo sob estilosantes, observou-se $\mathrm{pH}$ neutro $\left(\mathrm{pH}-\mathrm{H}_{2} \mathrm{O}=7,06\right)$, conteúdo baixo de matéria orgânica $(\mathrm{MO}=1,75)$, boa soma de bases $(\mathrm{SB}=4,51)$, média capacidade de troca catiônica $(\mathrm{t}=4,51)$ e uma muito boa saturação de bases $(\mathrm{V}=100 \%)$. No solo sob guandu observou nível de acidificação fraco $\left(\mathrm{pH}-\mathrm{H}_{2} \mathrm{O}=6,84\right)$, conteúdo médio de matéria orgânica $(\mathrm{MO}=2,28)$, média capacidade de troca catiônica $(\mathrm{t}=4,00)$ e muito boa saturação de bases $(\mathrm{V}=93,0 \%)$. 
Após 24 meses da semeadura dos adubos verdes, houve aumento nos teores dos nutrientes $\mathrm{N}, \mathrm{P}, \mathrm{K}, \mathrm{Ca}^{2+}$ e $\mathrm{Mg}^{2+}$ e fósforo remanescentes (P-rem), em todos os tratamentos. Os incrementos nos valores desses nutrientes resultaram em aumento da capacidade de troca catiônica e aumento da soma de bases trocáveis, como efeito, constata-se um aumento na fertilidade do solo.

Observou-se nível de alcalinidade fraca em todos os tratamentos e a classificação muito boa nas propriedades: fósforo, cálcio, magnésio, soma de bases, saturação de bases e fósforo remanescente. Quanto a capacidade de troca catiônica, todos adubos verdes apresentaram boa classificação. O solo sob crotalária apresentou conteúdo bom de matéria orgânica, enquanto os solos sob estilosantes e o guandu apresentaram conteúdo médio de MO (Tabela 1-3).

Tabela 1-3. Classificação das propriedades químicas do solo, após 24 meses da semeadura de adubos verdes, de acordo com as recomendações para o uso de corretivos e fertilizantes em Minas Gerais. $\mathrm{Mba}=$ Muito baixo; $\mathrm{Ba}=\mathrm{Baixo} ; \mathrm{M}=$ Médio; $\mathrm{Bo}=\mathrm{Bom} ; \mathrm{Mbo}=$ Muito bom

\begin{tabular}{|cccccccccccccc|}
\hline $\begin{array}{c}\text { Adubos } \\
\text { verdes }\end{array}$ & $\mathbf{p H}$ & $\mathbf{M O}$ & $\mathbf{P}$ & $\mathbf{K}$ & $\mathbf{C a}^{2+}$ & $\mathbf{M g}^{2+}$ & $\mathbf{H}+\mathbf{A l}$ & $\mathbf{S B}$ & $\mathbf{t}$ & $\mathbf{T}$ & $\mathbf{V}$ & P-rem \\
\hline Cro & $\begin{array}{c}\text { Alcalinidade } \\
\text { fraca }\end{array}$ & Bo & Mbo & Mbo & Mbo & Mbo & Mba & Mbo & Bo & M & Mbo & Mbo \\
\hline Sty & $\begin{array}{c}\text { Alcalinidade } \\
\text { fraca }\end{array}$ & M & Mbo & Bo & Mbo & Mbo & Mba & Mbo & Bo & M & Mbo & Mbo \\
\hline Caj & $\begin{array}{c}\text { Alcalinidade } \\
\text { fraca }\end{array}$ & M & Mbo & Mbo & Mbo & Mbo & Mba & Mbo & Bo & M & Mbo & Mbo \\
\hline
\end{tabular}

Caj (Cajanus cajan); Cro (Crotalaria juncea); Sty (Stylosanthes guianensis)

De modo a favorecer o crescimento das espécies arbóreas plantadas, foi realizado o manejo dos adubos verdes através da roçagem sem incorporação, após 18 meses da semeadura. Em consequência, após 24 meses da semeadura observa-se aumento nos teores de N-total e de matéria orgânica. Quanto aos teores de matéria orgânica, observou-se aumento significativo no solo sob crotalária (1936 \%), em relação ao valor inicial obtido no solo exposto, seguido do solo sob guandu (1204\%) e no solo sob estilosantes (1072\%).

O mesmo comportamento pode ser observado nos teores de N-total do solo, houve aumento em todos os tratamentos, com destaque para o solo sob crotalária, com um aumento de $914 \%$ em relação à situação inicial de solo exposto, seguido de estilosantes com aumento de $536 \%$ e Guandu com $532 \%$ de aumento. 


\section{DISCUSSÃO}

\subsection{Cobertura do solo}

$\mathrm{O}$ rápido recobrimento promovido pelos adubos verdes, garantiu maior proteção do solo contra a radiação solar e contra o impacto das gotas de chuva, minimizando assim os processos erosivos, além de diminuir a infestação de plantas indesejáveis, conforme estudos em diferentes regiões tropicais com a espécie C. cajan (Silva et al 2015; Nascimento et al 2019; Souza et al 2021). Cajanus cajan apresentou os melhores resultados na cobertura do solo e no peso seco, dessa forma é uma espécie chave para potencializar os benefícios dos adubos verdes, além de ser uma opção viável a ser considerada em projetos de restauração ecológica de áreas com solo exposto (Martins 2018).

A taxa de cobertura do solo promovida por C. cajan neste estudo $(89,0 \%)$ foi superior ao indicado por Pacheco et al (2017) para a mesma espécie (74,9\%) após 156 dias da semeadura. Além disso, valores similares de cobertura foram observados pelos autores em espécies do gênero Stylosanthes (55,3\%) e valores inferiores no gênero Crotalaria (41,6\% $55,6 \%$ ). Esse contraste reforça a necessidade desse estudo, uma vez que os resultados são intimamente relacionados às condições edáficas, regime pluviométrico, manejo, condições experimentais e época de avaliação.

Os efeitos dos adubos verdes C. cajan, Crotalaria juncea e Stylosanthes guianensis na cobertura, proteção do solo e melhoria das propriedades físicas são descritos em diversos estudos (Long et al 2017; Martins 2018; Melander et al 2020; Soares et al 2021; Silva et al 2021; Neto et al 2021). Dentre os principais resultados, destacam-se aumento da fertilidade e melhorias no índice de estabilidade de agregados e resistência à penetração de raízes. Em complemento, os estudos reforçam os benefícios do consórcio entre leguminosas e gramíneas, visando a potencialização dos efeitos na recuperação do solo.

\subsection{Fitomassa seca}

Quanto a fitomassa seca, a maior produção por C. cajan $\left(853,90\right.$ g.m $\left.\mathrm{m}^{-2}\right)$ verificada neste estudo, corrobora com Cavalcante et al (2012), quando comparada a outras seis plantas de cobertura, incluindo duas espécies do gênero Crotalaria (C. juncea e C. spectabilis Roth). A produção de C. cajan descrita pelos autores $\left(870 \mathrm{~g} \mathrm{~m}^{-2}\right)$, foi similar a este estudo, embora a produção das crotalárias tenha sido inferior $\left(250-300 \mathrm{~g} \mathrm{~m}^{-2}\right)$ e a coleta do material tenha sido realizada aos 129 dias. Além disso, resultados superiores também foram encontrados em 
demais regiões brasileiras, como observado por Carneiro et al (2008); Xavier et al (2017) e Nascimento et al (2019).

Em contrapartida, na mesma tipologia florestal da área de estudo e em Latossolo Vermelho-Amarelo encontraram-se valores inferiores de fitomassa seca de C. cajan $\left(301 \mathrm{~g} \mathrm{~m}^{-}\right.$ ${ }^{2}$ ) (Mendonça et al 2017). Quanto à S. guianensis, valores inferiores $\left(339,18 \mathrm{~g} \mathrm{~m}^{-2}\right)$ foram encontrados em pesquisa conduzida em área degradada (Godoi et al 2008). Em suma, a produção de fitomassa varia de acordo com a espécie, genótipo, época de semeadura, condições edafoclimáticas e as práticas de manejo adotadas. Tendo em vista essas variações, torna-se necessário avaliar os adubos verdes, em diferentes condições e ambientes (Alcântara et al., 2000).

\subsection{Análises de solo}

Os solos das regiões tropicais geralmente são intemperizados, ácidos e apresentam baixa fertilidade natural (Neto et al 2021). Sendo assim, a calagem é uma prática essencial para: neutralizar a acidez do solo, fornecer cálcio e magnésio, reduzir a toxicidade de alguns elementos, aumentar a capacidade de troca catiônica e, consequentemente, aumentar a disponibilidade de nutrientes para as plantas (Carmeis Filho et al 2017; Bossolani et al 2020).

As contribuições da adubação verde no aumento do $\mathrm{pH}$ do solo também foram descritas por Neto et al (2021) em estudo conduzido em Latossolo Vermelho-Amarelo. Ademais, os autores observaram maior produção de biomassa em função da correção da acidez e aumento da atividade biológica do solo. Dessa forma, a calagem estimula processos de tamponamento do solo e, consequentemente altera a dinâmica de cátions trocáveis e dissolução de elementos. Assim, à medida que o $\mathrm{pH}$ aumenta, a disponibilidade de íons metálicos como $\mathrm{Al}^{3+}$ diminui, favorecendo o crescimento da microbiota edáfica e o desenvolvimento das plantas (Carmeis Filho et al 2017; Holland et al 2018; Bossolani et al 2020).

Nesse sentido, as técnicas de preparo de solo, calagem e adubação fosfatada foram essenciais para a recuperação do solo. Em complemento, Nascimento et al (2019) afirmaram que a escarificação mecânica do solo promoveu aumento no rendimento de fitomassa seca de quatro plantas de cobertura, dentre elas Cajanus cajan e Crotalaria juncea. Desse modo, a decomposição da fitomassa dos adubos verdes neste estudo contribuiu para a elevação do pH (Tabela 1-1), principalmente devido ao aporte de matéria orgânica. 
Nessa perspectiva, melhorar a qualidade e a quantidade de matéria orgânica do solo (MOS), em solos tropicais, é essencial para aumentar a sustentabilidade do ecossistema (Carmeis Filho et al 2017). Sendo assim, no presente estudo as três espécies de adubos verdes contribuíram para o aumento dos teores de MOS. Nesse sentido, a matéria orgânica é um componente fundamental para o equilíbrio edáfico, sendo considerada um dos principais indicadores de qualidade de solo, devido seu papel estrutural e funcional (Soares et al 2020).

Ademais, a MOS aumenta a estabilidade dos agregados e o volume dos poros, consequentemente, aumenta a aeração do solo e melhora a capacidade de retenção e armazenamento de água, assim permite um melhor crescimento radicular (Bonini \& Alves 2011). Nessa perspectiva, em experimentos conduzidos em diversas regiões e com diferentes espécies de adubos verdes, observa-se aumento dos teores de MOS e da capacidade de troca catiônica (Sharma et al 2017; Oliveira et al 2017; Gao et al 2018; Liu et al 2020).

A decomposição da matéria orgânica é um processo ecológico complexo e muito importante, pois influencia diretamente na dinâmica nutricional e na microbiota do solo (Soares et al 2020). Diante dessa relevância, a relação entre MOS e nitrogênio é alvo de estudos em áreas pós-mineração de bauxita (Banning et al 2008) e em outras regiões tropicais (Hicks et al 2019; Sellan et al 2020).

O nitrogênio é o nutriente de maior dinâmica nos solos tropicais, sendo encontrado nas formas mineral, orgânica, iônica e gasosa (Amazonas et al 2011). Essas constantes transformações ocorrem de forma rápida no solo, influenciadas por inúmeros fatores como: umidade do solo, temperatura, $\mathrm{pH}$, microrganismos, fertilidade, relação $\mathrm{C} / \mathrm{N}$ dos resíduos, plantas fixadoras de N, preparo e manejo do solo, entre outros (Figueiredo et al 2019; Rastetter et al 2020; Rocha et al 2021). Diante dessa complexidade, não existe uma metodologia que contemple todos esses fatores e forneça um índice padrão de disponibilidade de nitrogênio (Villar 2007).

Na adubação verde, as espécies leguminosas são as principais fixadoras de nitrogênio por meio da relação simbiótica com bactérias do solo (Rhizobium e Bradyrhizobium) (Muller et al 2021). Em função disso, os teores de N-total do solo aumentaram consideravelmente após 24 meses da semeadura dos adubos verdes (Cro: 914\%; Sty: 536\% e Caj: 532\%), quando comparados aos valores iniciais de solo exposto. Estudos recentes ressaltam o potencial de Crotalaria juncea na incorporação de nitrogênio e na melhoria da fertilidade do solo (Barbosa 
et al 2020; Yao et al 2021; Ma et al 2021), no aumento da biomassa (Subaedah et al 2016) e na recuperação do solo em minas de bauxita (Narayanan et al 2021).

Estes resultados demonstram a eficiência da adubação verde no aumento dos teores de nitrogênio no solo e na melhoria dos parâmetros edáficos. Devido ao rápido crescimento e alta produção de fitomassa, os adubos verdes contribuem significativamente para o aumento dos teores de matéria orgânica do solo. Além disso, adubos verdes fornecem diversos serviços ecossistêmicos como controle de gramíneas exóticas invasoras e controle da erosão (Ma et al 2021).

A fixação biológica de $\mathrm{N}$ realizada pelos adubos verdes também pode fornecer $\mathrm{N}$ para espécies não-leguminosas. Desse modo, é possível que as espécies arbóreas plantadas na área tenham absorvido parte do $\mathrm{N}$ e incorporado em sua biomassa, tendo em vista que o $\mathrm{N}$ é um dos nutrientes que mais limita o crescimento das espécies arbóreas em regiões tropicais (Amazonas et al 2011; Bossolani et al 2020). A utilização de N pelas espécies arbóreas plantadas também foi verificada por Silva et al (2016) em estudos conduzidos na região e em área pós-mineração de bauxita. Os autores relataram que o plantio de mudas em consórcio com Cajanus cajan resultou em maior incremento em área basal, menor mortalidade, rápido recobrimento do solo, melhorias na fertilidade e maior disponibilidade de nitrogênio devido a fixação biológica.

Saldanha et al (2017) destacaram que a adubação verde com C. cajan proporciona benefícios físicos na conservação do solo, no entanto não é capaz de suprir a demanda de nitrogênio da cultura principal. Desse modo, tendo em vista que a fixação biológica de nitrogênio é um processo complexo (Borges et al 2016) e que os solos da região são naturalmente de baixa fertilidade, recomenda-se que os projetos de restauração ecológica realizem a adubação nitrogenada complementar, manejo dos adubos verdes e o monitoramento da fertilidade do solo, periodicamente (Soares et al 2020).

Os teores de N-total (dag/kg) após 2 anos da semeadura dos adubos verdes (Cro = 0,223; Sty =0,140; Caj =0,139) corroboram com o verificado por Balestrin 2018, em área após 6 anos de restauração por meio da condução da regeneração natural $(0,130 \mathrm{dag} / \mathrm{kg})$ e com Balestrin et al 2019, em área após 14 anos de restauração por plantio de mudas $(0,139$ dag/kg), ambos estudos conduzidos em áreas pós-mineração de bauxita pela CBA nessa mesma região. Diante disso, os adubos verdes foram eficientes na recuperação dos teores de nitrogênio, em menor tempo de restauração. Além disso, os resultados superiores observados 
em Crotalaria juncea (Cro) ressaltam o potencial desta espécie na recuperação do solo, em projetos de restauração ecológica na região.

Nesse sentido, o manejo dos adubos verdes, após 24 meses da semeadura, mostrou-se eficiente na incorporação de matéria orgânica no solo, tendo em vista que esta técnica favoreceu a decomposição da fitomassa dos adubos, e consequentemente o aumento da fertilidade do solo. Além disso, o acréscimo de N-total observado na análise de solo aos 24 meses, em relação à análise anterior, é resultante da incorporação de fitomassa e da fixação biológica de nitrogênio promovida pelos adubos verdes, visto que, o nitrogênio é considerado o nutriente que melhor retorna ao sistema solo-planta por meio de resíduos vegetais (Hungria et al., 2015).

Assim, a adubação verde é alternativa promissora para a recuperação e conservação do solo de áreas impactadas, tendo em vista as melhorias físicas, químicas e biológicas nos atributos do solo. Além disso, estudos recentes indicam que as plantas de cobertura podem contribuir para a mitigação das mudanças climáticas, em virtude da cobertura do solo, redução da erosão e fixação de carbono orgânico por meio da incorporação de matéria orgânica (Yao et al 2019; Delgado et al 2021).

Cabe salientar que os efeitos proporcionados pela adubação verde variam de acordo com a espécie utilizada, microrganismos edáficos, condições edafoclimáticas, manejo e com a adaptação ecológica dos adubos verdes às condições locais (Alcântara et al., 2000). Portanto, as peculiaridades de cada ambiente e as características intrínsecas de cada espécie são determinantes para o planejamento da adubação verde como uma alternativa para a recuperação de solos em projetos de restauração ecológica.

\section{CONCLUSÕES}

Os adubos verdes utilizados foram eficientes na recuperação do solo e são ferramentas potenciais para os projetos de restauração ecológica de áreas mineradas na região, devido aos múltiplos serviços ecossistêmicos. As espécies Cajanus cajan e Crotalaria juncea se destacaram no recobrimento do solo, enquanto C. cajan e Stylosanthes guianensis foram mais eficientes na produção de fitomassa seca. Todas as espécies influenciaram positivamente nos teores de matéria orgânica e colaboraram para o aumento dos teores de N-total do solo, 
devido à fixação biológica de nitrogênio. Crotalaria juncea foi a espécie mais promissora na recuperação dos níveis de N-total do solo.

O rápido recobrimento do solo e a deposição de quantidades expressivas de fitomassa indica que a adubação verde é uma técnica capaz de mitigar os efeitos da erosão hídrica e aumentar a fertilidade do solo. Além disso, as técnicas de restauração aplicadas: preparo do solo com ripper, calagem, adubação química e a semeadura dos adubos verdes promoveram o rápido crescimento das mudas plantadas, a cobertura do solo e a regeneração natural na área. As ações de recuperação e conservação do solo realizadas pela empresa foram fundamentais para os resultados encontrados.

\section{AGRADECIMENTOS}

Os autores agradecem à Coordenação de Aperfeiçoamento de Pessoal de Nível Superior (CAPES) pela bolsa de mestrado para Wesley Fonseca, ao CNPq pela bolsa de produtividade em pesquisa do orientador prof. Sebastião V. Martins e a Companhia Brasileira de Alumínio (CBA) pela infraestrutura e apoio financeiro ao projeto.

\section{REFERÊNCIAS}

ABAL. (2017). Relatório Bauxita no Brasil - Mineração Responsável e Competitividade. 1 st ed. São Paulo: Associação Brasileira de Alumínio, 66p.

AGEVAP. (2013). Plano municipal de saneamento básico, São Sebastião da Vargem Alegre, MG. Associação pró-gestão das águas da bacia hidrográfica do Rio Paraíba do Sul. PrintPaper Editora Gráfica, 2013

Alcântara FA, Furtini Neto AE; Paula MB; Mesquita HA, Muniz JA. (2000). Adubação verde na recuperação da fertilidade. Pesquisa Agropecuária Brasileira, Brasília, $35(2), 277-88$.

Almagro A, Oliveira PTS, Nearing MA, \& Hagemann S. (2017). Projected climate change impacts in rainfall erosivity over Brazil. Scientific reports, 7(1), 1-12.

Amazonas NT, Martinelli LA, de Cássia Piccolo M, Rodrigues RR. (2011). Nitrogen dynamics during ecosystem development in tropical forest restoration. Forest Ecology and Management, 262(8), 1551-1557.

Anache JA, Wendland EC, Oliveira PT, Flanagan DC, \& Nearing MA. (2017). Runoff and soil erosion plot-scale studies under natural rainfall: A meta-analysis of the Brazilian experience. Catena, 152, 29-39. 
ANM. (2019). Brazilian Mineral Yearbook - Main Metallic Commodities. 1 st ed. Brasília: National Mining Agency.

ANM. (2020). Anuário Mineral Brasileiro Principais Substâncias Metálicas 2020 Prévia: Agência Nacional de Mineração. Disponível em: <https://www.gov.br/anm/pt$\mathrm{br} /$ centrais-de-conteudo/publicacoes/serie-estatisticas-e-economia-mineral/anuariomineral/anuario-mineral-brasileiro>. Acesso em 23 de agosto de 2020.

Balestrin D, Martins SV, Schoorl JM, Lopes AT, de Andrade CF. (2019a). Phytosociological study to define restoration measures in a mined area in Minas Gerais, Brazil. Ecological Engineering, 135, 8-16.

Balestrin D, Martins SV, Fonseca CA, (2020). Ecological restoration and forest coverage advancement in a region influenced by bauxite mining, Minas Gerais, Brazil. In: de Vlieger K. (Ed.). Recent advances in ecological restoration. New York: Nova Science Publishers, 143-154.

Bonini CDSB, Alves MC. (2011). Recovery of soil physical properties by green manure, liming, gypsum and pasture and spontaneous native species. Revista Brasileira de Ciência do Solo, 35(4), 1397-1406.

Banning NC, Grant CD, Jones DL, Murphy DV. (2008). Recovery of soil organic matter, organic matter turnover and nitrogen cycling in a post-mining forest rehabilitation chronosequence. Soil Biology and Biochemistry, 40(8), 2021-2031.

Barbosa IR, Santana RS, Mauad M, Garcia RA. (2020). Dry matter production and nitrogen, phosphorus and potassium uptake in Crotalaria juncea and Crotalaria spectabilis. Pesquisa Agropecuária Tropical, 50.

Borges WL, Prin Y, Ducousso M, Le Roux C, De Faria SM. (2016). Rhizobial characterization in revegetated areas after bauxite mining. brazilian journal of microbiology, 47(2), 314-321.

Bossolani JW, Crusciol CAC, Merloti LF, Moretti LG, Costa NR, Tsai SM, Kuramae EE. (2020). Long-term lime and gypsum amendment increase nitrogen fixation and decrease nitrification and denitrification gene abundances in the rhizosphere and soil in a tropical notill intercropping system. Geoderma, 375, 114476.

Butchart SH, Walpole M, Collen B, Van Strien A, Scharlemann JP, Almond RE, Watson R. (2010). Global biodiversity: indicators of recent declines. Science, 328(5982), 1164-1168.

Carmeis Filho AC, Penn CJ, Crusciol CA, Calonego JC. (2017). Lime and phosphogypsum impacts on soil organic matter pools in a tropical Oxisol under long-term notill conditions. Agriculture, Ecosystems \& Environment, 241, 11-23

Carneiro MAC, Cordeiro MAS, Assis PCR, Moraes ES, Pereira HS, Paulino HB, Souza ED. (2008). Produção de fitomassa de diferentes espécies de cobertura e suas alterações na atividade microbiana de solo de cerrado. Bragantia, 67(2), 455-462.

Cavalcante VS, Santos VR, dos Santos Neto AL, dos Santos MA, dos Santos CG, Costa LC. (2012). Biomassa e extração de nutrientes por plantas de cobertura. Revista Brasileira de Engenharia Agrícola e Ambiental,16(5): 521-529.

Crawley MJ. (2012). The R book, 2nd edn. Wiley, London, 912 
Delgado JA, Mosquera VHB, Alwang JR, Villacis-Aveiga A, Ayala YEC, Neer D, Monar C, López LOE. (2021). Chapter Five - Potential use of cover crops for soil and water conservation, nutrient management, and climate change adaptation across the tropics. In Donald L. Sparks (Ed). Advances in Agronomy, Academic Press165: 175-247.

Ferreira AM, da Silva AM, dos Passos CA, Valentino CH, Gonçalves FA, \& Menezes PHBJ (2021). Estimated water soil erosion by the Water Erosion Prediction Project model in the Gigante Stream Basin, Minas Gerais, Brazil. Engenharia Sanitaria e Ambiental, 26, 471483.

Figueiredo V, Enrich-Prast A, Rütting T. (2019). Evolution of nitrogen cycling in regrowing Amazonian rainforest. Scientific reports, 9(1), 1-8.

Gann GD, McDonald T, Walder B, Aronson J, Nelson CR, Jonson J, ... \& Hua F. (2019). International principles and standards for the practice of ecological restoration. Restoration Ecology, 27, S1-S46.

Gao SJ, Gao JS, Cao WD, Zou CQ, Huang J, Bai JS, Dou FG. (2018). Effects of longterm green manure application on the content and structure of dissolved organic matter in red paddy soil. Journal of integrative agriculture, 17(8), 1852-1860.

Godoi EL, Borges JD, Leandro WM. (2008). Índices de cobertura vegetal e fitomassa de Stylosanthes guianensis Cv. Mineirão em área degradada, fertilizada com adubo mineral e biossólido. Pesquisa Agropecuária Tropical, 38(1), 21-26.

Hicks LC, Meir P, Nottingham AT, Reay DS, Stott AW, Salinas N, Whitaker J. (2019). Carbon and nitrogen inputs differentially affect priming of soil organic matter in tropical lowland and montane soils. Soil Biology and Biochemistry, 129, 212-222.

Holland JE, Bennett AE, Newton AC, White PJ, McKenzie BM, George TS, ... \& Hayes RC. (2018). Liming impacts on soils, crops and biodiversity in the UK: A review. Science of the Total Environment, 610, 316-332.

Hou T, Filley TR, Tong Y, Abban B, Singh S, Papanicolaou AT, ... \& Chaubey I. (2021). Tillage-induced surface soil roughness controls the chemistry and physics of eroded particles at early erosion stage. Soil and Tillage Research, 207, 104807.

Hungria M, Nogueira MA, Araujo RS (2015) Soybean seed co-inoculation with Bradyrhizobium spp. and Azospirillum brasilense: a new biotechnological tool to improve yield and sustainability. American Journal of Plant Sciences 6, 811-817.

IBGE. (2012). Manual Técnico da Vegetação Brasileira. 2nd ed. Manuais Técnicos em Geociências. Rio de Janeiro: Instituto Brasileiro de Geografia e Estatística.

Iserhagen I, Brancalion PHS, Rodrigues RR (2014). Adubação verde na restauração florestal. In: Lima filho OF. de; Ambrosano EJ; Rossi F; Carlos JAD. (Ed.). (Org.). Adubação verde e plantas de cobertura no Brasil: fundamentos e prática. 1ed.Brasília: Embrapa, v. 2, p. 269-287.

Kaiser-Bunbury CN, Mougal J, Whittington AE, Valentin T, Gabriel R, Olesen JM, Blüthgen N. (2017). Ecosystem restoration strengthens pollination network resilience and function. Nature, 542(7640), 223-227.

Kamble PH \& Bhosale SM. (2019). Assessment of Impact of Bauxite Mining on Environment. i-Manager's Journal on Future Engineering and Technology. 14(4):14-21 
Köppen W. (1948). Climatologia: con un estudio de los climas de la tierra. México: Fondo de Cultura Econômica.

Liu S, Wang J, Pu S, Blagodatskaya E, Kuzyakov Y, Razavi BS. (2020). Impact of manure on soil biochemical properties: A global synthesis. Science of The Total Environment, 745, 141003.

Long H, Zhang D, He G. (2017). The effects of planted and plowed Stylosanthes guianensis on degrading soil fertility in hilly countries of dry-hot valley. Acta Ecologica Sinica, 37(5), 279-283.

Ma D, Yin L, Ju W, Li X, Liu X, Deng X, \& Wang S. (2021). Meta-analysis of green manure effects on soil properties and crop yield in northern China. Field Crops Research, 266, 108146.

Marshall CB, Lynch DH. (2020). Soil microbial and macrofauna dynamics under different green manure termination methods. Applied Soil Ecology, 148, 103505.

Martins SV, Miranda Neto A, Ribeiro TM. (2015). Uma abordagem sobre diversidade e técnicas de restauração ecológica. In: Sebastião Venâncio Martins. (Org.). Restauração ecológica de ecossistemas degradados. Restauração ecológica de ecossistemas degradados. 1ed.Viçosa, MG: Editora UFV, 2015, v. 1, p. 19-41.

Martins SV. (2018). Alternative Forest Restoration Techniques. In: Viana H, editor. New Perspectives in Forest Science. 1st ed. London: IntechOpen; p. 131-148.

Martins SV, Cosimo LHE, Balestrin D, Fonseca WS, Andrade CF, Barros RS. (2020). Restoration of Tree and Shrub Diversity Post Bauxite Mining, in the Southeastern Region of Minas Gerais, Brazil. In: Kristian de Vlieger. (Org.). Recent Advances in Ecological Restoration. 1ed.Estados Unidos: Nova, v.1, p. 33-62.

Melander B, Rasmussen IA, Olesen JE, (2020). Legacy effects of leguminous green manure crops on the weed seed bank in organic crop rotations. Agric. Ecosyst. Environ. 302, 107078. https://doi.org/10.1016/j.agee.2020.107078.

Melo CES \& Sánchez LE. (2020). Evaluation of environmental rehabilitation practices in bauxite mining at the plateau of Poços de Caldas. REM-International Engineering Journal, 73(2), 247-252.

Mendonça EDS, Lima PCD, Guimarães GP, Moura WDM, Andrade FV. (2017). Biological nitrogen fixation by legumes and $\mathrm{N}$ uptake by coffee plants. Revista Brasileira de Ciência do Solo, 41.

MME. (2020). Mineral Sector Bulletin. 2 nd ed. Ministério de Minas e Energia. Brasília: National Mining Agency

Muller KE, Guinness J, Hecking M, Drinkwater LE. (2021). Estimating agronomically relevant symbiotic $\mathrm{N}$ fixation in green manure breeding programs. Crop Science. 1-17.

Narayanan M, Thangabalu R, Natarajan D, Kumarasamy S, Kandasamy S, Elfasakhany A, \& Pugazhendhi A. (2021). Reclamation competence of Crotalaria juncea with the amalgamation and influence of indigenous bacteria on a waste dump of bauxite mine. Chemosphere, 279, 130632. 
Nascimento V, Arf O, Alves MC, de Souza EJ, da Silva PRT, Kaneko FH, Galindo, F. S. (2019). Soil mechanical scarification increases the dry matter yield of cover crops under no-tillage. Idesia, 37(4), 29-39.

Neto JF, Franzluebbers AJ, Crusciol CAC, Rigon JPG, Calonego JC, Rosolem CA, ... \& Ribeiro LC. (2021). Soil carbon and nitrogen fractions and physical attributes affected by soil acidity amendments under no-till on Oxisol in Brazil. Geoderma Regional, 24, e00347.

Oliveira KJ, de Lima JS, Ambrósio MMDQ, Neto FB, Chaves AP. (2017). Propriedades nutricionais e microbiológicas do solo influenciadas pela adubação verde. Revista de Ciências Agrárias, 40(1), 23-33.

Pacheco LP, Miguel ASDCS, Silva RGD, Souza EDD, Petter FA, Kappes C. (2017). Biomass yield in production systems of soybean sown in succession to annual crops and cover crops. Pesquisa Agropecuária Brasileira, 52(8), 582-591.

R-Core Team. (2019). R: A language and environment for statistical computing. R Foundation for Statistical Computing, Vienna, Austria. https:/www.R-project.org. [accessed 01 november 2019].

Rastetter EB, Kling GW, Shaver GR, Crump BC, Gough L, Griffin KL. (2020). Ecosystem Recovery from Disturbance is Constrained by N Cycle Openness, Vegetation-Soil $\mathrm{N}$ Distribution, Form of N Losses, and the Balance Between Vegetation and Soil-Microbial Processes. Ecosystems, 1-19.

Reis LK, Guerra A, Colado MLZ, Borges FLG, Oliveira MDR, Gondim EX, ... \& Garcia LC. (2019). Which spatial arrangement of green manure is able to reduce herbivory and invasion of exotic grasses in native species?. Ecological Applications, 29(8), e02000.

Rocha RS, Monteiro VF, de Abreu LCPC, Fernandes APD, dos Santos CRC. (2021). Effects of the planting of legume species and soil conditions on the recovery of a sand and pebble mining area. Land Degradation \& Development, 32(4), 1695-1705.

Saldanha ECM, Silva Júnior ML, Alves JDN, Mariano DC, Okumura RS. (2017). Consórcio milho e feijão-de-porco adubado com NPK no nordeste do Pará. Global Science and Technology, Rio Verde, 10(1), 20 - 28.

Santos HG, Jacomine PKT, Anjos LHC, Oliveira VA, Lumbreras JF, Coelho MR, Almeida JA, Araujo Filho JC, Oliveira JB, Cunha TJF. (2018). Sistema brasileiro de classificação de solos. Brasília (DF): Embrapa.

Silva AR, Collier LS, Flores RA, Santos VM, Barbosa JM. (2015) Soil fertility in agroforestry system with introduction of green manure. American-Eurasian Journal of Agriculture \& Environmental Sciences 15(1):29-35.

Silva KDA, Martins SV, Miranda Neto A, Demolinari RDA, Lopes AT. (2016). Restauração florestal de uma mina de bauxita: avaliação do desenvolvimento das espécies arbóreas plantadas. Floresta e Ambiente, 23(3), 309-319.

Silva MF, Fernandes MMH, Fernandes C, da Silva AMR, Ferraudo AS, Coelho AP. (2021). Contribution of tillage systems and crop succession to soil structuring. Soil and Tillage Research, 209, 104924. 
Sellan G, Thompson J, Majalap N, Robert R, Brearley FQ. (2020). Impact of soil nitrogen availability and $\mathrm{pH}$ on tropical heath forest organic matter decomposition and decomposer activity. Pedobiologia, 80, 150645.

Sharma P, Laor Y, Raviv M, Medina S, Saadi I, Krasnovsky A, ... \& Borisover M. (2017). Green manure as part of organic management cycle: Effects on changes in organic matter characteristics across the soil profile. Geoderma, 305, 197-207.

Soares JAH, de Souza ALT, de Abreu Pestana LF, Tanaka MO. (2020). Combined effects of soil fertility and vegetation structure on early decomposition of organic matter in a tropical riparian zone. Ecological Engineering, 152, 105899.

Soares MB, Tavanti RFR, Rigotti AR, de Lima JP, Freddi OS, Petter FA. (2021). Use of cover crops in the southern Amazon region: What is the impact on soil physical quality?. Geoderma, 384, 114796.

Souza DC, Engel VL, de Mattos EC. (2021). Direct seeding to restore tropical seasonal forests: effects of green manure and hydrogel amendment on tree species performances and weed infestation. Restoration Ecology, 29(1), e13277.

Stuble KL, Fick SE, Young TP. (2017). Every restoration is unique: testing year effects and site effects as drivers of initial restoration trajectories. Journal of Applied Ecology, 54(4), 1051-1057.

Subaedah S, Aladin A, Nirwana. (2016). Fertilization of nitrogen, phosphor and application of green manure of Crotalaria juncea in increasing yield of maize in marginal dry land. Agriculture and Agricultural Science Procedia, 9, 20-25.

Vásquez-Castro DC, Rodrigues RR, Meli P, Brancalion PHS, Silva RR, \& Couto HTZ. (2020). Preliminary results of using green manure species as a cost-effective option for forest restoration. Scientia Forestalis, 48(127), e3374

Villar MLP. (2007). Manual de interpretação de análise de plantas e solos e recomendação de adubação. Série Documentos, 35. Cuiabá: EMPAER-MT, 182 p.

Yao Z, Zhang D, Liu N, Yao P, Zhao N, Li Y, ... \& Gao Y. (2019). Dynamics and sequestration potential of soil organic carbon and total nitrogen stocks of leguminous green manure-based cropping systems on the Loess Plateau of China. Soil and Tillage Research, 191, 108-116.

Yao Z, Xu Q, Chen Y, Liu N, Li Y, Zhang S, ... \& Gao Y. (2021). Leguminous green manure enhances the soil organic nitrogen pool of cropland via disproportionate increase of nitrogen in particulate organic matter fractions. CATENA, 207, 105574.

Xavier FADS, Oliveira JIA, Silva MRD. (2017). Decomposition and nutrient release dynamics of shoot phytomass of cover crops in the Recôncavo Baiano. Revista Brasileira de Ciência do Solo, 41. 


\section{CAPÍTULO 2 - ESTUdO FITOSSOCIOLÓGICO DE ÁREA EM RESTAURAÇÃO ECOLÓGICA NO AMBIENTE DE MINERAÇÃO DE BAUXITA, NO SUDESTE DO BRASIL}

RESUMO: O objetivo deste estudo foi avaliar a composição florística e estrutura fitossociológica de uma área em processo de restauração ecológica no ambiente de mineração de bauxita, após quatro anos do início do projeto. O estudo foi realizado em uma área de 2 ha, na qual funcionava o setor administrativo da Companhia Brasileira de Alumínio - CBA, localizada no município de Miraí, MG, Sudeste do Brasil. Em janeiro/2017, todas as construções foram removidas deixando o subsolo exposto, compactado e de baixa fertilidade. Esta área de estudo foi incluída no programa de compensação ambiental da empresa. A primeira etapa da restauração foi a subsolagem com ripper, seguida de adubação química em área total e o plantio de espécies nativas. Após 4 anos, foi realizado o inventário de todos os indivíduos arbustivos e arbóreos com circunferência à altura do peito (CAP) $\geq 10 \mathrm{~cm} \mathrm{e}$ calculados os parâmetros fitossociológicos (densidade relativa, dominância relativa e o valor de cobertura) e índices de diversidade da comunidade vegetal (Shannon e Equabilidade de Pielou. A similaridade florística foi avaliada por meio da análise de agrupamento, baseada no Índice de Jaccard. Foram registrados 929 indivíduos, pertencentes a 33 espécies e 14 famílias botânicas. O índice de diversidade $\left(\mathrm{H}^{\prime}\right)=2,620$ evidencia uma média diversidade florística e $\left(\mathrm{J}^{\prime}\right)=0,749$ indica que a área é floristicamente heterogênea e com baixa dominância ecológica. Houve predomínio de espécies com síndrome de dispersão zoocórica e de indivíduos anemocóricos. A categoria pioneira foi predominante, tanto em nível de espécies quanto de indivíduos. As famílias com maiores riqueza de espécies foram Fabaceae (7) e Solanaceae (5). A área apresentou similaridade florística com outros estudos realizados na região. O conhecimento dos atributos funcionais das espécies é essencial para o planejamento e execução de projetos de restauração ecológica e permite definir as metodologias e técnicas mais adequadas para cada cenário no ambiente de mineração de bauxita. Nesse sentido, em estágios inicias, as famílias Fabaceae e Asteraceae (recobrimento do solo) e Cannabaceae, Solanaceae, Urticaceae (atração da fauna dispersora) apresentam grande potencial para colaborar no avanço sucessional, sendo consideradas "famílias-chave". A similaridade florística entre áreas no ambiente de mineração de bauxita foi influenciada principalmente pela localização geográfica, técnica aplicada e idade de restauração das áreas.

Palavras-chave: Biodiversidade, Bauxita, Mata Atlântica, Mineração sustentável, Restauração ativa, Similaridade florística 
ABSTRACT: The aim of this study was to evaluate the floristic composition and phytosociology structure of an area undergoing ecological restoration in the bauxite mining environment after four years of the beginning of the project. The study was carried out in a 2 ha area, in which the administrative sector of Companhia Brasileira de Alumínio - CBA, located in Miraí, MG, Southeast Brazil, operated. In January, 2017, all the buildings were removed leaving the subsoil exposed, compacted and with low fertility. This study area was included in the company's environmental compensation program. The first stage of restoration was subsoiling with a ripper, followed by chemical fertilization in the total area and planting of native species. After 4 years, an inventory of all shrub and arboreal individuals with breast height circumference $(\mathrm{CBH}) \geq 10 \mathrm{~cm}$ was carried out and the phytosociological parameters (relative density, relative dominance and coverage value) and community diversity index were calculated (Shannon and Pielou Equability). Floristic similarity was assessed using cluster analysis, based on the Jaccard Index. 929 individuals were registered, belonging to 33 species and 14 botanical families. The diversity index $\left(\mathrm{H}^{\prime}\right)=2.620$ shows an average floristic diversity and $\left(\mathrm{J}^{\prime}\right)=0.749$ indicates that the area is floristically heterogeneous and with low ecological dominance. There was a predominance of species with zoochoric dispersion syndrome and of anemochoric individuals. The pioneer category was predominant, both in terms of species and individuals. The families with the highest species richness were Fabaceae (7) and Solanaceae (5). The area showed a floristic similarity with other studies carried out in the region. The knowledge of the species functional attributes is essential for the planning and execution of ecological restoration projects and allows to define the most appropriate methodologies and techniques for each scenario in the bauxite mining environment. In this sense, in the early stages, the families Fabaceae and Asteraceae (soil cover) and Cannabaceae, Solanaceae, Urticaceae (attraction of the dispersing fauna) have great potential to collaborate in the succession advance, being considered "key families". The floristic similarity between areas in the bauxite mining environment was mainly influenced by the geographical location, applied technique and age of restoration of the areas.

Keywords: Biodiversity, Bauxite, Atlantic Forest, Sustainable mining, Active restoration, Floristic similarity. 


\section{INTRODUÇÃO}

O Brasil possui a quarta maior reserva mundial de bauxita com 2,6 bilhões de toneladas, atrás de Guiné, Austrália e Vietnã. Além disso, é o quarto maior produtor com 29 milhões de toneladas, representando aproximadamente $8 \%$ da produção mundial (USGS 2020). Nesse sentido, o país se destaca tanto na produção quanto na exploração de reservas minerais existentes em seu território (MME 2020). Por conseguinte, a mineração contribui de forma significativa para o desenvolvimento socioeconômico do país, devido a geração de empregos diretos e indiretos para a comunidade local (ANM 2019), à influência no Índice de Desenvolvimento Humano Municipal (IDH-M), além de relevante participação no Produto Interno Bruto Nacional (PIB) (MME 2020).

Neste contexto, a bauxita é um minério muito importante, do qual se obtêm o alumínio, terceiro elemento em maior abundância na crosta terrestre (ABAL 2017). Esse mineral é encontrado em alta quantidade e qualidade $\left(>41 \% \mathrm{Al}_{2} \mathrm{O}_{3}\right)$, principalmente nos estados Pará e Minas Gerais (ANM 2020). Contudo, a mineração de bauxita provoca impactos pontuais devido a remoção das camadas superficiais de solo, embora não ocupe grandes extensões territoriais como agricultura e pecuária (Kamble \& Bhosale 2019; Balestrin et al 2020; Melo \& Sánchez 2020; Martins et al 2020a).

Assim, cada área no ambiente de mineração de bauxita pode sofrer influência variada de diversos fatores, dentre eles: variáveis edáficas, topográficas, clima e microclima, paisagem, biodiversidade, resiliência, amplitude do impacto, dentre outros agentes que atuam direta ou indiretamente na área (IAI et al 2016; Stuble et al 2017; Balestrin et al 2019a). Desse modo, para garantir a sustentabilidade da atividade minerária são necessárias ações de recuperação nas áreas diretamente e indiretamente afetadas pela exploração mineral (Martins et al 2020a).

Nessa perspectiva, os projetos de restauração ecológica são mecanismos importantes para combater a perda de biodiversidade e o aumento global da degradação de ecossistemas (Aronson \& Alexander 2013; Bastin et al 2019; Rodríguez-Uña et al 2020). Especialmente, por restaurar o equilíbrio do ambiente e retornar a sua trajetória histórica através da recomposição florística, do restabelecimento das relações entre fauna e flora (Kaiser-Bunbury et al 2017), da conservação da diversidade existente, e também melhoria dos parâmetros socioeconômicos (Wortley et al 2013; Martin \& Lyons 2018) e dos serviços ecossistêmicos (Chazdon 2008; Benayas et al 2009; Martins et al 2020b). 
Contudo, o planejamento da restauração ecológica não é uma tarefa fácil, visto que cada área perturbada ou degradada sofre influência variada de diversos fatores, possui desafios específicos (Rodríguez-Uña et al 2020) e condições ecológicas únicas (Stuble et al 2017). Dessa forma, a restauração ecológica em ambiente de mineração deve ser planejada de forma holística, de modo a adequar os projetos aos múltiplos filtros ambientais regionais e às diferentes oportunidades ecológicas das paisagens (Martins 2018).

Tendo em vista que não existe um modelo padrão de restauração para ser aplicado em grande escala, são necessários estudos afim de contemplar as peculiaridades e necessidades de cada ambiente (Martins 2018). Nesse sentido, os estudos de composição florística e estrutura fitossociológica são essenciais para a melhor compreensão dos processos ecológicos e das inter-relações entre as comunidades vegetais da área em restauração (Balestrin et al 2019a). Além disso, são importantes para gerar informações qualitativas e quantitativas que permitem a comparação com ecossistemas de referência, identificar áreas prioritárias para a restauração e definir metodologias de restauração mais adequadas para cada cenário no ambiente de mineração (Balestrin et al 2020).

Portanto, os estudos fitossociológicos são fundamentais para subsidiar a tomada de decisões em ambientes de mineração de bauxita, definir o estado atual do projeto, corrigir possíveis falhas e verificar a necessidade de sofrer novas interferências (Viani et al 2017; Balestrin et al 2019; Londe et al 2020). Além disso, é possível determinar o estágio em que a área apresenta sinais de autossustentabilidade, dispensando intervenções e contemplando os serviços ecossistêmicos (Benayas et al 2009).

Este estudo teve como objetivo avaliar a composição florística e estrutura fitossociológica de uma área em processo de restauração ecológica no ambiente de mineração de bauxita, após quatro anos de implantação do projeto de restauração.

\section{MATERIAL E MÉTODOS}

\subsection{Caracterização da Área de Estudo}

A área de estudo está localizada no município de Miraí ( $21^{\circ} 4^{\prime} 5^{\prime \prime} \mathrm{S}$ e $42^{\circ} 33^{\prime} 28^{\prime \prime} \mathrm{W}$ ), na região denominada Zona da Mata no Sudeste do estado de Minas Gerais - Brasil, em altitude de 715 m. A classificação climática da região do tipo Cwa, clima temperado úmido com inverno seco e verão quente (Köppen 1948). 
De acordo com o Sistema Brasileiro de Classificação de Solos, o solo predominante é o Latossolo Vermelho-Amarelo distrófico típico (Santos et al 2018). A vegetação característica da região é classificada como Floresta Estacional Semidecidual Montana, inserida no Domínio Floresta Atlântica (IBGE 2012).

Este estudo foi conduzido em uma área de 2 ha que era destinada ao setor administrativo da Companhia Brasileira de Alumínio - CBA (Figura 2-1). No final do ano 2016 houve mudança do setor administrativo da empresa e todas as construções foram removidas deixando o subsolo exposto, compactado e de baixa fertilidade, sendo esta área incluída no programa de compensação ambiental da empresa pela mineração de bauxita.

Figura 2-1. Localização da área de estudo, em Miraí-MG, Brasil

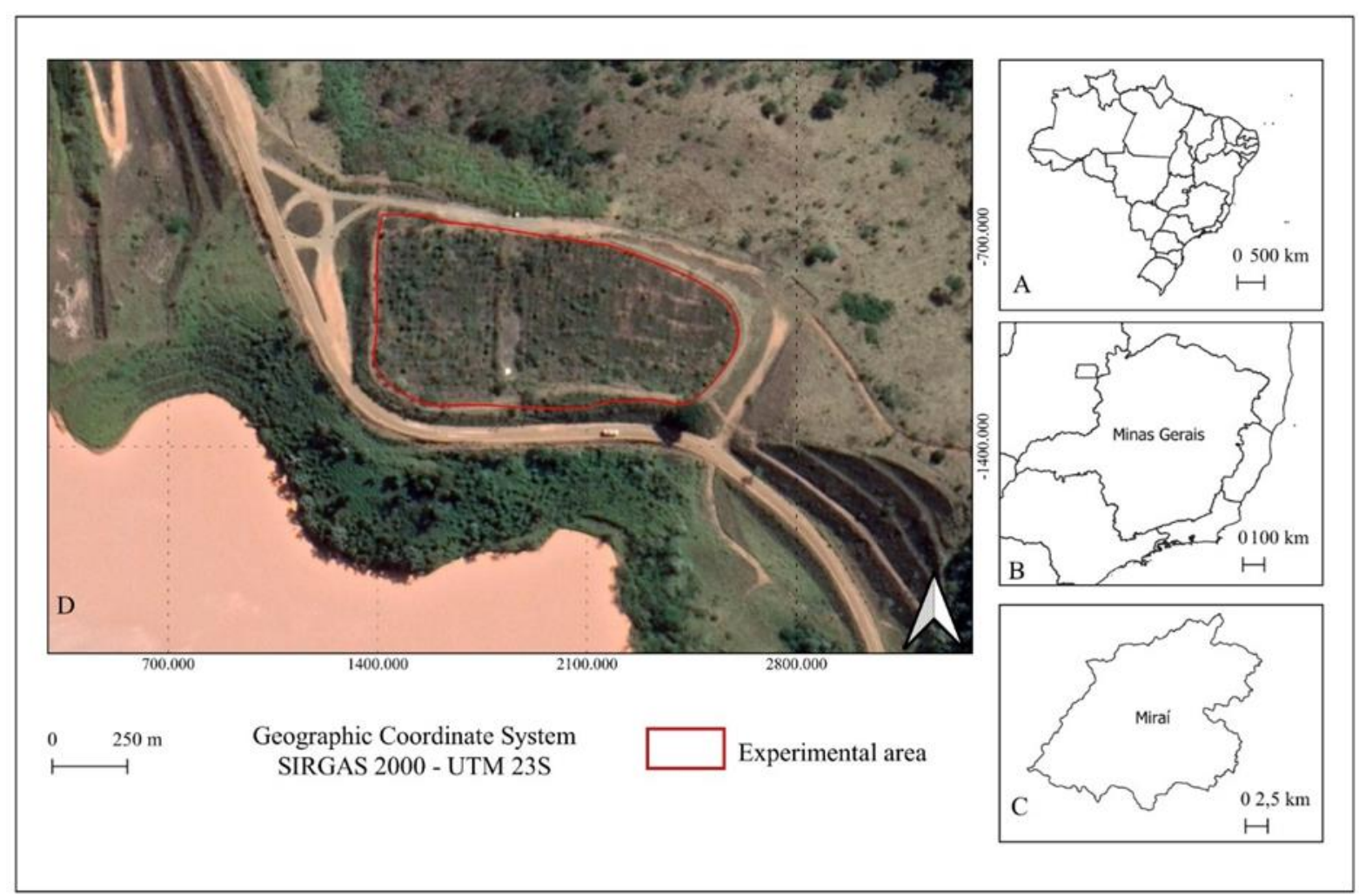

Em janeiro de 2017, foi realizado o preparo do solo em área total através de um subsolador ripper com o objetivo de romper a camada compactada e homogeneizar a superfície do solo. Em sequência foi realizado correção da acidez do solo, adubação química e combate às formigas em toda área. Após estes procedimentos, foram plantadas mudas de 18 espécies nativas com diferentes características sucessionais (Tabela 2-1), em espaçamento 4,0 x 4,0 metros e, posteriormente, foi realizada adubação de cobertura ao redor de cada muda e o cercamento da área. Embora o espaçamento normalmente utilizado pela empresa nas áreas de compensação seja o $3 \times 3 \mathrm{~m}$, neste caso optou-se de forma experimental por espaçamento 
maior para possibilitar a implantação de técnicas alternativas nas entrelinhas, como transposição de serapilheira, instalação de poleiros artificiais, e semeadura direta de espécies nativas da Mata Atlântica e de adubos verdes.

Tabela 2-1. Lista florística das espécies plantadas na área de estudo, Miraí-MG, Brasil

\begin{tabular}{|c|c|c|c|}
\hline Família & Espécies & CS & SD \\
\hline \multirow[t]{4}{*}{ Bignoniaceae } & Handroanthus heptaphyllus (Vell.) Mattos & $\mathrm{St}$ & Ane \\
\hline & Handroanthus impetiginosus (Mart. Ex DC.) Mattos & St & Ane \\
\hline & Tabebuia roseoalba (Ridl.) Sandwith & $\mathrm{Si}$ & Ane \\
\hline & Jacaranda micrantha Cham & $\mathrm{Si}$ & Ane \\
\hline Cannabaceae & Trema micrantha (L.) Blume & $\mathrm{P}$ & Zoo \\
\hline \multirow[t]{2}{*}{ Euphorbiaceae } & Alchornea glandulosa Poepp. & $\mathrm{P}$ & Zoo \\
\hline & Sapium glandulosum (L.) Morong & $\mathrm{P}$ & Zoo \\
\hline \multirow[t]{4}{*}{ Fabaceae } & Bauhinia forficata Link & $\mathrm{P}$ & Aut \\
\hline & Caesalpinia pluviosa DC. & $\mathrm{Si}$ & Aut \\
\hline & Clitoria fairchildiana R.A.Howard & $\mathrm{Si}$ & Aut \\
\hline & Senegalia polyphylla (DC.) Britton \& Killip & $\mathrm{P}$ & Aut \\
\hline Malvaceae & Pseudobombax grandiflorum (Cav.) A.Robyns & $\mathrm{P}$ & Ane \\
\hline Melastomataceae & Tibouchina granulosa (Desr.) Cogn. & $\mathrm{P}$ & Ane \\
\hline Myrtaceae & Psidium guajava L. & $\mathrm{P}$ & Zoo \\
\hline Solanaceae & Solanum pseudoquina A. St.-Hil. & $\mathrm{Si}$ & Zoo \\
\hline \multirow[t]{2}{*}{ Urticaceae } & Cecropia glaziovii Snethl. & $\mathrm{P}$ & Zoo \\
\hline & Cecropia hololeuca Miq. & $\mathrm{P}$ & Zoo \\
\hline Verbenaceae & Citharexylum myrianthum Cham. & $\mathrm{Si}$ & Zoo \\
\hline
\end{tabular}

CS: Categoria sucessional (P: Pioneira, Si: Secundária inicial, St: Secundária tardia, SD: Síndrome de dispersão (Zoo: Zoocórica, Ane: Anemocórica, Aut: Autocórica)

\subsection{Avaliação florística e procedimentos de campo}

Foi realizado o inventário de todos os indivíduos arbustivos e arbóreos plantados e regenerantes com circunferência à altura do peito $(\mathrm{CAP}) \geq 10 \mathrm{~cm}$ e, em seguida, calculados os parâmetros fitossociológicos (densidade relativa, dominância relativa e o valor de cobertura) e índice de diversidade da comunidade vegetal (Shannon e Equabilidade de Pielou) através do software Fitopac 2.1 (Shepherd 2010). Para a análise dos indicadores físicos, foram realizadas 
avaliações de resistência à penetração do solo na profundidade de 0-40 cm, utilizando um penetrômetro digital portátil PenetroLOG ${ }^{\circledR}$ - Falker, em diferentes épocas: 2017 (sub-solo exposto, antes das ações de restauração) e em 2021 (4 anos após o preparo do solo e plantio de mudas).

\subsection{Atributos funcionais}

Além disso, todos os indivíduos foram classificados em famílias e nomenclatura científica de acordo com o Angiosperm Phylogeny Group (APG IV 2016) e, as espécies encontradas foram classificadas em categorias sucessionais de acordo com Budowski (1965) e adaptadas por Gandolfi et al., (1995) para florestas secundárias brasileiras em: pioneiras (P), secundária inicial $(\mathrm{Si})$ e secundária tardia $(\mathrm{St})$. Quanto a síndrome de dispersão de propágulos, as espécies foram classificadas em: zoocóricas (Zoo), anemocóricas (Ane), autocóricas (Aut) (Pijl 1982) e quanto a forma de vida em arbóreas (A) e arbustivas (B).

\subsection{Processamento dos dados}

Com a finalidade de identificar possíveis padrões e comparar os resultados encontrados, a similaridade florística entre a vegetação deste estudo e a de outros estudos conduzidos na região e em áreas em ambiente de mineração de bauxita foram comparados (Tabela 2-2). O Índice de similaridade de Jaccard (SJ) (Mueller-Dombois e Ellenberg, 1974) foi selecionado para mensurar a similaridade florística entre as comunidades, sendo analisados mediante técnica de agrupamento (cluster analysis) (Kassambara 2017). Para isso foi construída uma matriz binária de presença e ausência de espécies. O dendrograma foi produzido usando o método UPGMA (Unweighted Pair Group Method with Arithmetic Mean). Estas análises foram realizadas usando a estatística em $\mathrm{R}$ versão 3.5 .3 e o pacote Vegan (R Core Team, 2019).

Tabela 2-2. Descrição e caracterização das áreas de estudo usadas para comparar a similaridade florística.

\begin{tabular}{lcccc}
\hline Descrição dos estudos & $\begin{array}{c}\text { Tipo de } \\
\text { vegetação / } \\
\text { restauração } \\
\text { avaliada }\end{array}$ & Localização & $\begin{array}{c}\text { Tipo de } \\
\text { vegetação }\end{array}$ & Referência \\
\hline $\begin{array}{l}\text { S1_RN (10 anos após } \\
\text { mineração de bauxita) }\end{array}$ & $\begin{array}{c}\text { Regeneração } \\
\text { natural }\end{array}$ & $\begin{array}{c}\text { Descoberto - } \\
\text { MG }\end{array}$ & $\begin{array}{c}\text { Floresta } \\
\text { Estacional } \\
\text { Semidecidual }\end{array}$ & $\begin{array}{c}\text { Miranda- } \\
\text { Neto et al } \\
2014\end{array}$
\end{tabular}

Continua... 
S2_PL (18 meses após mineração de bauxita)

S3_PL (14 anos após mineração de bauxita)

S4_RN (18 meses após mineração de bauxita)

S5_RN (6 anos após mineração de bauxita)

S6_PL (4 anos após mineração de bauxita)

S7_RN Ecossistema de referência (Floresta secundária preservada)

S8_RN (5 anos após mineração de bauxita)

S9_TN (4 anos de restauração em ambiente de mineração de bauxita)

S10_PL Este estudo (4 anos de restauração em ambiente de mineração de bauxita)
Plantio de mudas

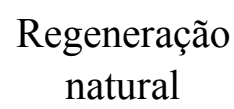

Regeneração natural

Plantio de mudas

Regeneração
natural

Regeneração natural

Técnicas de Nucleação

Plantio de mudas e regenerantes $\begin{array}{ccc}\text { Descoberto - } & \text { Floresta } & \text { Silva et al } \\ \text { MG } & \text { Estacional } & 2016\end{array}$

Floresta

Descoberto MG

Estacional

Semidecidual

Balestrin et

al 2019
Descoberto - $\quad \begin{gathered}\text { Floresta } \\ \text { Estacional Silva et al }\end{gathered}$
MG $\quad$ Semidecidual $\quad 2018 \mathrm{a}$

São Sebastião Floresta

da Vargem Estacional

Alegre-MG Semidecidual

Balestrin et

al 2018

São Sebastião Floresta

da Vargem Estacional

Alegre-MG Semidecidual

Lopes et al

2018

$\begin{array}{ccc}\text { São Sebastião } & \text { Floresta } & \text { Silva et al } \\ \text { da Vargem } & \text { Estacional } & 2021 \\ \text { Alegre - MG } & \text { Semidecidual } & \end{array}$

$\begin{array}{ccc}\text { São Sebastião } & \text { Floresta } & \text { Silva et al } \\ \text { da Vargem } & \text { Estacional } & 2021 \\ \text { Alegre-MG } & \text { Semidecidual } & \end{array}$

$\begin{array}{ccc}\text { Miraí - MG } & \text { Floresta } & \text { Fonseca } \\ & \text { Estacional } & 2021 \\ & \text { Semidecidual } & \end{array}$

$\begin{array}{ccc}\text { Miraí - MG } & \text { Floresta } & \text { Estudo } \\ & \text { Estacional } & \text { atual }\end{array}$

\section{RESULTADOS}

\subsection{Diversidade Florística}

$\mathrm{Na}$ área em processo de restauração foram registrados 929 indivíduos, pertencentes a 33 espécies e 14 famílias botânicas (Tabela 2-3). O Índice de Shannon-Wiener $\left(\mathrm{H}^{\prime}\right)=2,620$ evidencia uma média diversidade florística e o Índice de Equabilidade de Pielou (J') = 0,749 demonstra que a área é floristicamente heterogênea e com baixa dominância ecológica. 
Tabela 2-3. Parâmetros fitossociológicos das espécies encontradas na área de estudos, após 4 anos de restauração ecológica, Miraí - MG.

\begin{tabular}{|c|c|c|c|c|c|c|c|}
\hline Famílias botânicas / Espécies & NInd & DeRel & DoRel & $\begin{array}{l}\text { VC } \\
(\%)\end{array}$ & FV & CS & SD \\
\hline \multicolumn{8}{|l|}{ Anacardiaceae } \\
\hline Schinus terebinthifolia Raddi & 2 & 0,22 & 0,1 & 0,16 & A & $\mathrm{P}$ & Zoo \\
\hline \multicolumn{8}{|l|}{ Arecaceae } \\
\hline Syagrus romanzoffiana (Cham.) Glassman & 6 & 0,65 & 2,64 & 1,65 & A & $\mathrm{Si}$ & Zoo \\
\hline \multicolumn{8}{|l|}{ Asteraceae } \\
\hline Baccharis dracunculifolia DC. & 9 & 0,97 & 0,43 & 0,70 & $\mathrm{~B}$ & $\mathrm{P}$ & Ane \\
\hline Vernonanthura phosphorica (Vell.) H.Rob. & 241 & 25,94 & 15,04 & 20,49 & A & $\mathrm{P}$ & Ane \\
\hline \multicolumn{8}{|l|}{ Bignoniaceae } \\
\hline Handroanthus heptaphyllus (Vell.) Mattos & 5 & 0,54 & 0,12 & 0,33 & A & St & Ane \\
\hline Handroanthus impetiginosus (Mart. Ex DC.) Mattos & 36 & 3,88 & 1,6 & 2,74 & A & St & Ane \\
\hline Jacaranda micrantha Cham. & 41 & 4,41 & 2,75 & 3,58 & A & $\mathrm{Si}$ & Ane \\
\hline Tabebuia roseoalba (Ridl.) Sandwith & 28 & 3,01 & 1,57 & 2,29 & A & $\mathrm{Si}$ & Ane \\
\hline \multicolumn{8}{|l|}{ Cannabaceae } \\
\hline Trema micrantha (L.) Blume & 56 & 6,03 & 9,86 & 7,95 & A & $\mathrm{P}$ & Zoo \\
\hline \multicolumn{8}{|l|}{ Euphorbiaceae } \\
\hline Alchornea glandulosa Poepp. & 11 & 1,18 & 0,71 & 0,95 & A & $\mathrm{P}$ & Zoo \\
\hline Croton urucurana Baill. & 2 & 0,22 & 0,06 & 0,14 & A & $\mathrm{P}$ & Aut \\
\hline Sapium glandulosum (L.) Morong & 1 & 0,11 & 0,09 & 0,10 & A & $\mathrm{P}$ & Zoo \\
\hline \multicolumn{8}{|l|}{ Fabaceae } \\
\hline Bauhinia forficata Link & 75 & 8,07 & 10,09 & 9,08 & A & $\mathrm{P}$ & Aut \\
\hline Caesalpinia pluviosa DC. & 46 & 4,95 & 3,81 & 4,38 & A & $\mathrm{Si}$ & Aut \\
\hline Clitoria fairchildiana R.A.Howard & 120 & 12,92 & 26,82 & 19,87 & A & $\mathrm{Si}$ & Aut \\
\hline Piptadenia gonoacantha (Mart.) JFMacbr. & 5 & 0,54 & 0,16 & 0,35 & A & $\mathrm{Si}$ & Ane \\
\hline Senegalia polyphylla (DC.) Britton \& Killip & 4 & 0,43 & 0,13 & 0,28 & A & $\mathrm{P}$ & Aut \\
\hline Senna macranthera (Collad.) HSIrwin e Barneby & 1 & 0,11 & 0,02 & 0,07 & A & $\mathrm{P}$ & Zoo \\
\hline Senna multijuga (Rich.) HSIrwin e Barneby & 18 & 1,94 & 1,14 & 1,54 & A & $\mathrm{Si}$ & Aut \\
\hline \multicolumn{8}{|l|}{ Malvaceae } \\
\hline Pseudobombax grandiflorum (Cav.) A.Robyns & 2 & 0,22 & 0,06 & 0,14 & A & $\mathrm{P}$ & Ane \\
\hline \multicolumn{8}{|l|}{ Melastomataceae } \\
\hline Tibouchina granulosa (Desr.) Cogn. & 61 & 6,57 & 5,4 & 5,98 & A & $\mathrm{P}$ & Ane \\
\hline \multicolumn{8}{|l|}{ Moraceae } \\
\hline Ficus mexiae Standl. & 1 & 0,11 & 0,02 & 0,07 & $\mathrm{~A}$ & $\mathrm{Si}$ & Zoo \\
\hline \multicolumn{8}{|l|}{ Myrtaceae } \\
\hline Psidium cattleianum Afzel. ex Sabine & 2 & 0,22 & 0,05 & 0,14 & A & $\mathrm{P}$ & Zoo \\
\hline Psidium guajava L. & 6 & 0,65 & 0,67 & 0,66 & A & $\mathrm{P}$ & Zoo \\
\hline \multicolumn{8}{|l|}{ Solanaceae } \\
\hline Solanum granulosoleprosum Dunal & 4 & 0,43 & 0,27 & 0,36 & A & $\mathrm{P}$ & Zoo \\
\hline Solanum lycocarpum A. St.-Hil. & 8 & 0,86 & 1,07 & 0,97 & A & $\mathrm{P}$ & Zoo \\
\hline Solanum mauritianum Scop. & 11 & 1,18 & 0,82 & 1,01 & A & $\mathrm{P}$ & Zoo \\
\hline Solanum paniculatum L. & 3 & 0,32 & 0,14 & 0,23 & $\mathrm{~A}$ & $\mathrm{P}$ & Zoo \\
\hline Solanum pseudoquina A. St.-Hil. & 22 & 2,37 & 4,76 & 3,57 & A & $\mathrm{Si}$ & Zoo \\
\hline \multicolumn{8}{|l|}{ Urticaceae } \\
\hline Cecropia glaziovii Snethl. & 11 & 1,18 & 1,07 & 1,13 & A & $\mathrm{P}$ & Zoo \\
\hline Cecropia hololeuca Miq. & 5 & 0,54 & 0,15 & 0,35 & A & $\mathrm{P}$ & Zoo \\
\hline \multicolumn{8}{|l|}{ Verbenaceae } \\
\hline Citharexylum myrianthum Cham. & 82 & 8,83 & 8,26 & 8,54 & A & $\mathrm{Si}$ & Zoo \\
\hline Lantana camara $\mathrm{L}$ & 4 & 0,43 & 0,11 & 0,27 & $\mathrm{~B}$ & $\mathrm{P}$ & Zoo \\
\hline
\end{tabular}

NInd: Número de indivíduos; DeRel: Densidade relativa; DoRel: Dominância relativa; VC (\%): Índice de valor de cobertura; FV: Forma de vida (A: arbórea; B: arbustiva); CS: Categoria sucessional (P: pioneira; Si: 
secundária inicial; St: secundária tardia); SD: Síndrome de dispersão (Ane: anemocoria; Aut: autocoria; Zoo: zoocoria).

\subsection{Atributos funcionais}

A espécie mais abundante na área foi Vernonanthura phosphorica (Vell.) H.Rob com 241 indivíduos, advindos da regeneração natural, representando 25,94\% dos indivíduos deste levantamento. Além disso, as espécies que apresentaram o maior valor de cobertura (VC\%) foram: Vernonanthura phosphorica (20,49\%), Clitoria fairchildiana R.A.Howard (19,87\%), Bauhinia forficata Link (9,08 \%) e Citharexylum myrianthum Cham. (8,54 \%).

No que concerne a riqueza de espécies e síndrome de dispersão, houve predominância de espécies zoocóricas (54,55\%), seguida das anemocóricas $(27,27 \%)$ e autocóricas $(18,18$ $\%$ ), como mostra a figura 2-2A. Quanto a categoria sucessional, as espécies pioneiras se destacaram $(63,64 \%)$, seguidas das secundárias iniciais $(30,30 \%)$ e secundárias tardias $(6,06$ $\%$ ), conforme figura $2-2 \mathrm{~B}$. 
Figura 2-2. Distribuição de espécies e indivíduos em: Categoria Sucessional e Síndrome de Dispersão
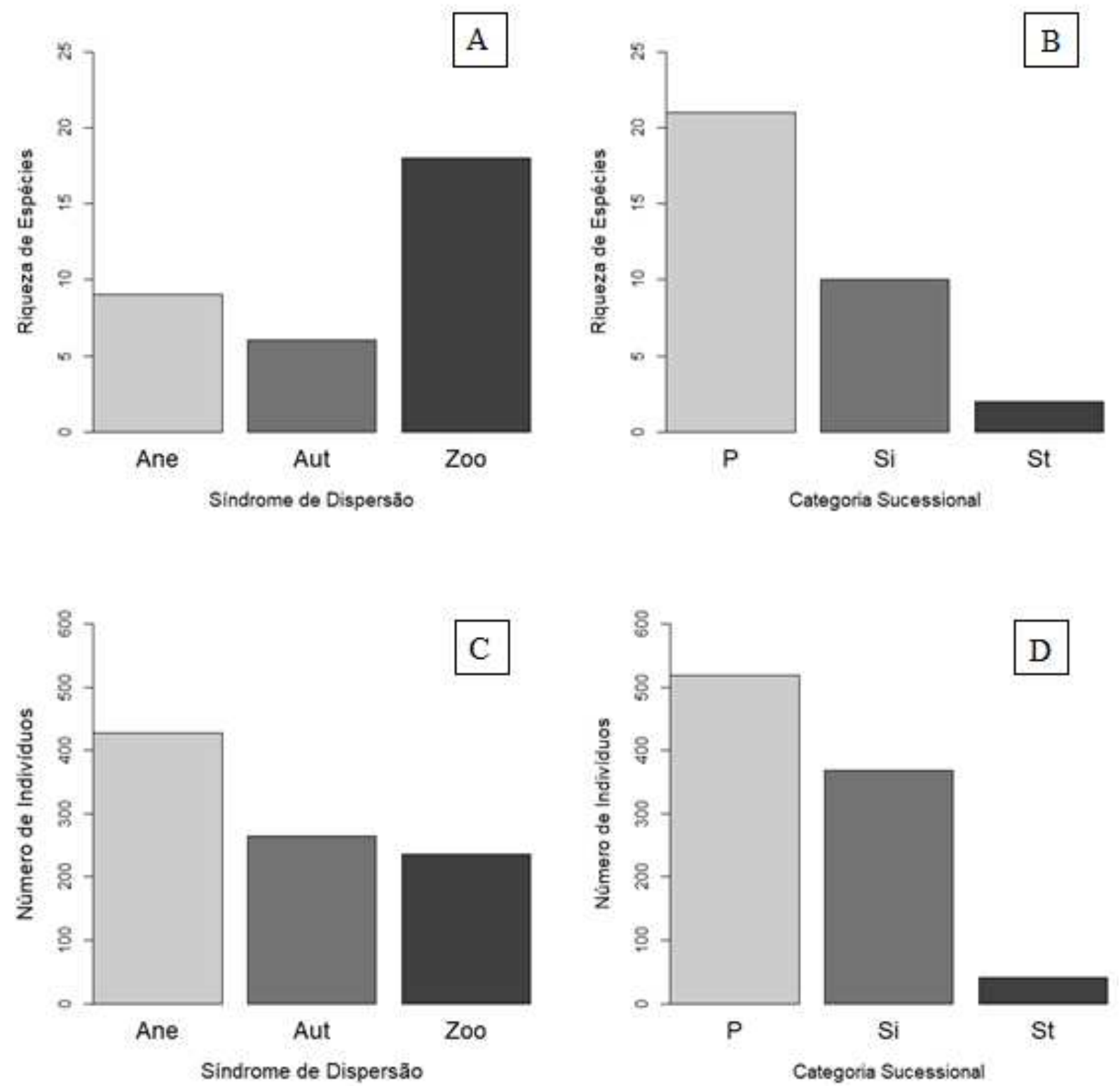

Categoria Sucessional (P: pioneira; Si: secundária inicial; St: secundária tardia), Síndrome de dispersão (Ane: anemocoria; Aut: autocoria; Zoo: zoocoria); Riqueza de espécies (A e B); Número de indivíduos (C e D).

Quanto à abundância, descaram-se os indivíduos anemocóricos (46,07\%), seguidos dos autocóricos $(28,53 \%)$ e zoocóricos $(25,40 \%)$, conforme figura 2-2C. Em relação à categoria sucessional, os indivíduos pioneiros representam 55,87\% do total, seguido dos secundários iniciais $(39,72 \%)$ e secundários tardios $(4,41 \%)$, figura 2-2D.

De acordo com a Tabela 2-4, as famílias mais representativas em termo de densidade de indivíduos foram: Fabaceae (28,96\%), Asteraceae (26,61\%) e Bignoniaceae (11,84\%). 
Quanto à riqueza de espécies, destacam-se as famílias: Fabaceae $(21,21 \%)$; Solanaceae $(15,15 \%)$ e Bignoniaceae $(12,12 \%)$.

Tabela 2-4. Parâmetros fitossociológicos das famílias botânicas encontradas na área de estudo.

\begin{tabular}{ccccccc}
\hline Famílias & NInd & NSpp & \%Spp & DeRel & DoRel & VC (\%) \\
\hline Fabaceae & 269 & 7 & 21,21 & 28,96 & 42,18 & 35,57 \\
Asteraceae & 250 & 2 & 6,06 & 26,91 & 15,46 & 21,19 \\
Bignoniaceae & 110 & 4 & 12,12 & 11,84 & 6,04 & 8,94 \\
Verbenaceae & 86 & 2 & 6,06 & 9,26 & 8,36 & 8,81 \\
Cannabaceae & 56 & 1 & 3,03 & 6,03 & 9,86 & 7,95 \\
Solanaceae & 48 & 5 & 15,15 & 5,17 & 7,07 & 6,12 \\
Melastomataceae & 61 & 1 & 3,03 & 6,57 & 5,4 & 5,98 \\
Urticaceae & 16 & 2 & 6,06 & 1,72 & 1,21 & 1,47 \\
Euphorbiaceae & 14 & 3 & 9,09 & 1,51 & 0,87 & 1,19 \\
Myrtaceae & 8 & 2 & 6,06 & 0,86 & 0,72 & 0,79 \\
Arecaceae & 6 & 1 & 3,03 & 0,65 & 2,64 & 1,65 \\
Anacardiaceae & 2 & 1 & 3,03 & 0,22 & 0,1 & 0,16 \\
Malvaceae & 2 & 1 & 3,03 & 0,22 & 0,06 & 0,14 \\
Moraceae & 1 & 1 & 3,03 & 0,11 & 0,02 & 0,07 \\
\hline Total & 929 & 33 & 1000 & 100 & 100 & 100
\end{tabular}

NInd: Número de indivíduos; NSpp: Número de espécies; \%Spp: Percentual de espécie; DeRel: Densidade relativa; DoRel: Dominância relativa; VC (\%): Índice de valor de cobertura.

Quanto aos parâmetros fitossociológicos encontrados na tabela 2-4, a família Fabaceae apresentou o maior valor de cobertura (CV), representando um percentual de $35,57 \%$ de toda a comunidade, e além disso, apresentou a maior riqueza de espécies $(21,21 \%)$. Desse modo, pode-se inferir que esta família apresenta uma boa adaptação em estágios iniciais, além de bom crescimento e acúmulo de biomassa nesta área de estudo.

\subsection{Atributos físicos}

Quanto a resistência à penetração, maiores valores foram observados na medição realizada em solo exposto, após a retirada das estruturas administrativas no início de 2017 , ou seja, naquela situação o sub-solo estava mais compactado. Observa-se que a profundidade máxima registrada por meio do penetrômetro digital foi $10 \mathrm{~cm}$, demonstrando uma grande 
limitação para o crescimento e desenvolvimento das mudas. Em contrapartida, após a implantação de técnicas de preparo do solo, como a subsolagem com ripper, e com o desenvolvimento da vegetação na área, constatou-se que a profundidade máxima registrada aumentou consideravelmente $(40 \mathrm{~cm})$, conforme a figura 2-3.

Figura 2-3. Resistência à penetração de um Latossolo Vermelho-Amarelo distrófico típico, em diferentes épocas: 2017 (solo exposto) e 2021 (após a implantação de técnicas de restauração ecológica).

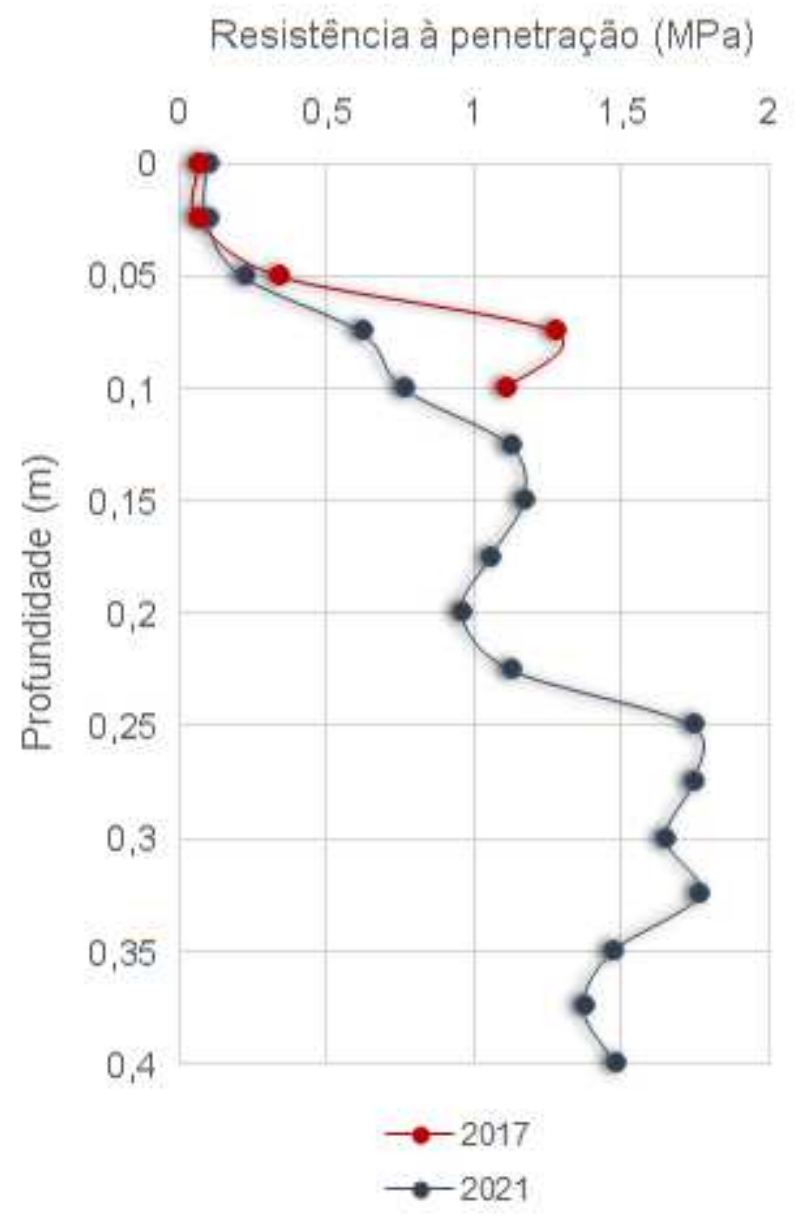

\subsection{Similaridade Florística}

Os padrões de similaridade florística entre as comunidades de espécies arbustivoarbóreas estudadas nas áreas no ambiente de mineração de bauxita estão representados pelo dendrograma da Figura 2-4. O coeficiente de correlação cofenética para este agrupamento foi de 0,81 , considerado adequado conforme Sokal e Rohlf(1962). 
Figura 2-4. Similaridade florística entre diferentes estudos realizados em ambiente de mineração de bauxita, na região.

\section{Cluster Dendrogram (UPGMA)}

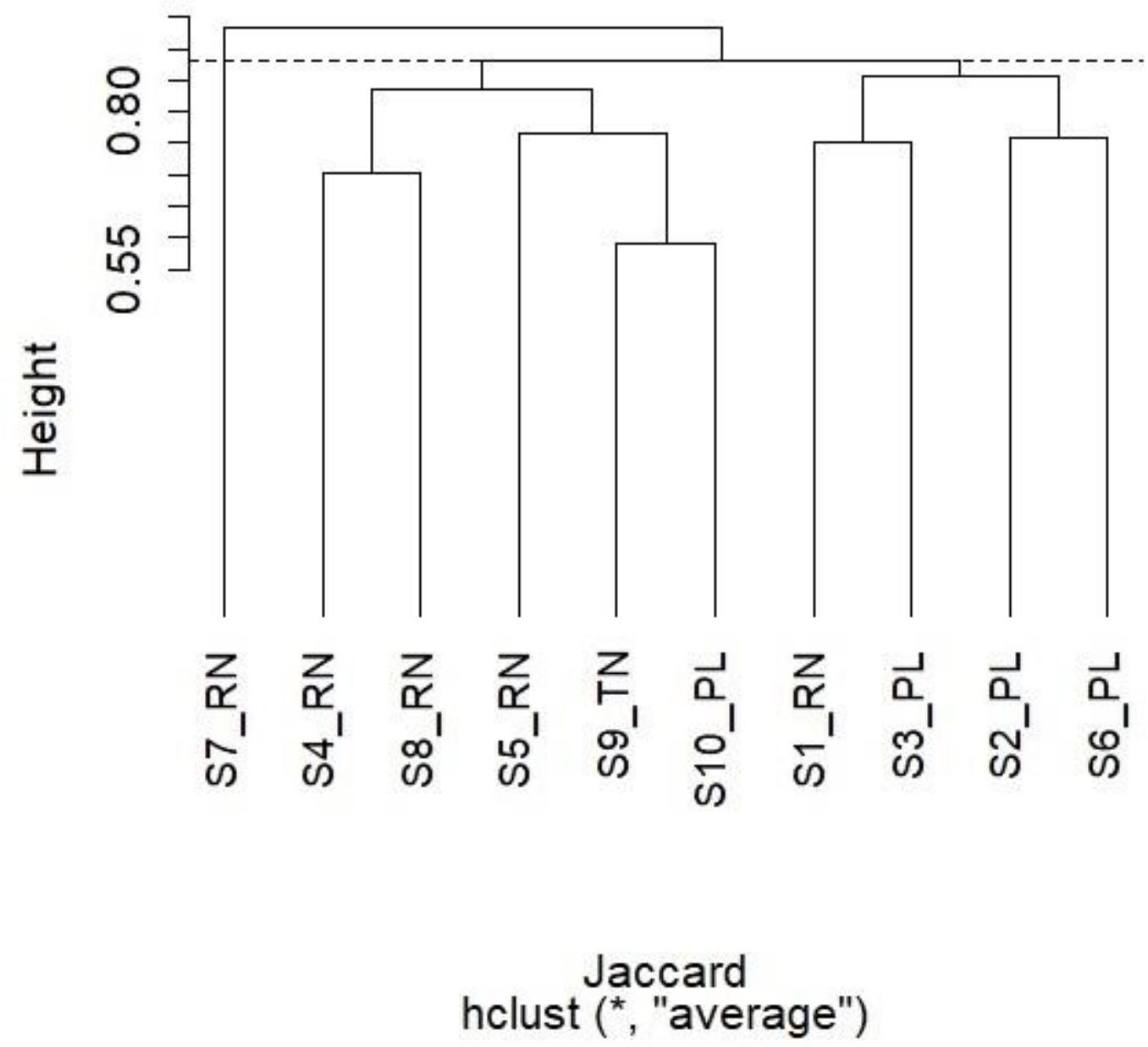

Desse modo, ao analisar a similaridade florística foi verificada uma maior semelhança entre S10_PL (plantio + regeneração natural) e S9_TN (técnicas de nucleação), ambos levantamentos realizados após 4 anos da implantação das técnicas de restauração, em MiraíMG. Além disso, foi verificada a semelhança florística entre o referido grupo com S5_RN, área com 6 anos de restauração por meio da condução da regeneração natural em São Sebastião da Vargem Alegre - MG. Além disso, observou-se agrupamento dos estudos S1_RN e S3_PL, realizados em Descoberto-MG, após 10 e 14 anos de restauração, respectivamente. 
A maior dissimilaridade foi verificada entre S7_RN (área de floresta secundária preservada) e os demais estudos em áreas em restauração no ambiente de mineração de bauxita. Ademais, adotando-se ponto de corte no dendrograma na altura 0,88, observou-se arranjo em dois grupos, com tendência ao agrupamento de estudos que avaliaram a mesma técnica de restauração, com exceção para os estudos S1_RN e S10_PL.

\section{DISCUSSÃO}

\subsection{Diversidade}

A área em processo de restauração apresentou boa diversidade, evidenciada pelos índices de Shannon $\left(\mathrm{H}^{\prime}=2,620\right)$ e Equabilidade de Pielou $\left(\mathrm{J}^{\prime}\right)=0,749$. Estes índices de diversidade verificados neste estudo corroboram com os estudos de Guimarães (2015), no qual avaliou-se três áreas em processo de restauração ecológica, em diferentes idades e com Silva et al (2018a), na avaliação da regeneração natural, ambos realizados em áreas pósmineração de bauxita. Neste contexto, valores inferiores de diversidade também foram relatados por Balestrin (2018), na mesma região deste estudo em área em restauração por regeneração natural, após 6 anos da mineração de bauxita.

Em contrapartida, resultados superiores foram registrados em áreas em restauração no ambiente de mineração de bauxita (Miranda-Neto et al 2014; Lopes et al 2018; Balestrin et al 2019) e em florestas estacionais semideciduais, na região de estudo (Braga et al 2011; Miranda-Neto et al 2012). Cabe destacar que estes estudos apresentaram maior tempo de restauração com estágios sucessionais mais avançados. Sendo assim, apesar das diferenças metodológicas e critérios de inclusão adotados em cada estudo, constata-se que o tempo de restauração é determinante na diversidade estrutural e de espécies (Teixeira et al 2020).

\subsection{Atributos funcionais}

Em relação à densidade de indivíduos, a predominância de Vernonanthura phosphorica $($ DeRel $=25,94 \%)$ destaca a importância da regeneração natural na recuperação da diversidade de espécies no bioma Mata Atlântica, principalmente em estágios iniciais de sucessão (Piaia et al 2020). Assim sendo, a presença desta espécie é relatada em diversos estudos conduzidos em áreas em restauração pós-mineração de bauxita na região (Balestrin 2018; Lopes et al 2018; Silva et al 2021; Martins et al 2021) e em demais áreas em restauração em Minas Gerais (Kunz \& Martins 2013; Ávila et al 2021). 
Vernonanthura phosphorica é uma espécie pioneira, da família Asteraceae, que apresenta boa adaptação às áreas perturbadas e que possui síndrome de dispersão anemocórica, com estratégia de sobrevivência baseada em um ciclo de vida rápido e uma produção abundante de sementes, que são facilmente dispersas pelo vento (Silva et al 2021; Martins et al 2021). Dessa forma, a rusticidade às condições edafoclimáticas e o seu caráter heliófito contribuem para a rápida colonização e, consequentemente, cobertura do solo e proteção contra processos erosivos (Balestrin 2018; Silva et al 2021). Sendo assim, devido ao maior número de indivíduos mensurados, $V$. phosphorica destacou-se também em parâmetros de cobertura do solo $(\mathrm{VC}=20,49 \%)$ e colaborou para a maior abundância de indivíduos anemocóricos $(46,07 \%)$.

Clitoria fairchildiana também se destacou sendo a segunda espécie com maior valor de cobertura $(\mathrm{VC}=19,87 \%)$, principalmente devido a influência da área basal e do número de bifurcações. C. fairchildiana é uma espécie secundária inicial da família Fabaceae, rústica e de rápido crescimento, com grande potencial para cobertura do solo, diante disso é uma espécie indicada para projetos de recuperação de áreas degradadas (Costa et al 2014; Lorenzi et al 2020).

Em nível de família botânica, a maior riqueza de espécies $(21,21 \%)$ e abundância de indivíduos $(28,96 \%)$ da família Fabaceae explicam os maiores valores dos parâmetros fitossociológicos avaliados neste levantamento. Nesse seguimento, Fabaceae se destaca como uma família importante em áreas com solos degradados, visto que muitas espécies podem realizar a fixação biológica de nitrogênio, melhorar as condições edáficas e assim facilitar o desenvolvimento de outras espécies, de modo a contribuir para o processo sucessional (Lorenzi et al 2020; Barbosa et al 2021).

A maior proporção de espécies e indivíduos da categoria sucessional pioneira evidencia que a área se encontra em estágio inicial e corrobora com diversos estudos sobre restauração em áreas de mineração de bauxita (Silva et al 2016; Silva et al 2018a; Balestrin 2018; Silva et al 2021) e na região (Guimarães 2015; Martins et al 2020c). Nesse contexto, as espécies pioneiras são fundamentais, pois apresentam rápido estabelecimento em condições de maior luminosidade, alta plasticidade, ou seja, adaptação às diferentes condições, além disso apresentam floração e frutificação precoces. Nesse sentido, Viani et al (2015) e Camargo et al (2020) ressaltaram que árvores pioneiras dispersas por animais aumentam a regeneração inicial em áreas em processo de restauração da Mata Atlântica. 
Em consonância, a espécie pioneira com dispersão zoocórica mais abundante neste estudo foi Trema micrantha (L.) Blume, com 56 indivíduos. Este resultado está relacionado ao fato de ser uma espécie nucleadora que possui produção precoce e contínua de frutos, dispersos principalmente por aves (Martins et al 2021). Ademais, devido às características morfométricas da copa, é indicada como uma espécie do grupo de preenchimento na restauração ecológica (Martins et al 2021). Além de T. micrantha, pertencente à família Cannabaceae, destacaram-se as espécies dos gêneros Solanum sp. (Solanaceae) e Cecropia sp. (Urticaceae). Sendo assim, estas famílias são fundamentais na resiliência do ecossistema e consideradas famílias-chave em projetos de restauração de áreas no ambiente de mineração de bauxita (Martins et al 2021; Barbosa et al 2021).

Nessa perspectiva, a predominância de espécies com dispersão zoocórica é um bom indicador, tendo em vista a atração da fauna dispersora de sementes (Silva et al 2016). Dessa maneira, os animais dispersores de sementes possuem papel fundamental, tanto para o sucesso individual da planta quanto para a dinâmica de populações e das comunidades vegetais (Volpato et al 2015; Rigacci et al 2021). Assim sendo, colaboram para o aumento da complexidade de interações ecológicas e para acelerar a sucessão ecológica da área em restauração (Corlett 2017; Gardner et al 2019).

Em virtude disto, o conhecimento dos atributos funcionais das espécies é essencial para o planejamento e execução de projetos de restauração ecológica (Rother et al 2019), principalmente em áreas em restauração no ambiente de mineração de bauxita (Martins et al 2020a; Barbosa et al 2021). Desse modo, é possível definir de modo rápido e eficaz as melhores metodologias e técnicas para cada cenário, verificar a necessidade de modificação na trajetória do projeto e determinar o estágio em que a área apresenta equilíbrio nas relações funcionais (Balestrin et al 2019; Londe et al 2020).

\subsection{Atributos físicos}

As técnicas de preparo do solo em área total, principalmente a subsolagem através de um ripper, foram fundamentais para romper a camada compactada e homogeneizar a superfície do solo. De acordo com Moraes et al (2014), a resistência do solo à penetração é um importante indicador da qualidade física do solo, sendo o limite crítico de $2 \mathrm{MPa}$, considerado ideal para permitir o crescimento e desenvolvimento radicular. Sendo assim, os valores de resistência à penetração, encontrados na área em estudo, não são limitantes para o crescimento radicular. 
Além disso, as técnicas de restauração ecológica proporcionaram melhorias na estrutura física, principalmente devido à deposição de serapilheira das mudas plantadas, e ao aumento dos teores de matéria orgânica fresca na superfície do solo (Sayer et al 2006). Em estudo conduzido em área no ambiente de mineração de bauxita no Sudeste do Brasil, 5 anos após o plantio de mudas, Silva et al (2018b) afirmaram que quanto maior a serapilheira acumulada, menor é a resistência do solo à penetração. Desse modo, a matéria orgânica do solo atua aumentando a estabilidade dos agregados e o volume dos poros, e consequentemente aumenta a aeração do solo e melhora a capacidade de retenção e armazenamento de água, favorecendo o crescimento e desenvolvimento radicular (Bonini \& Alves 2011).

\subsection{Similaridade florística}

A maior similaridade florística verificada entre a vegetação do presente estudo (S10_PL) e S9_TN pode ser explicada pelo fato de ambos estudos serem realizados na mesma área, em ambiente de mineração de bauxita, em Miraí-MG. Observou-se semelhança entre estes estudos com S5_RN, área em restauração por meio de regeneração natural, distante 4,6 $\mathrm{Km}$ da área do presente estudo (S10_PL). Nesse seguimento, destaca-se também o agrupamento entre os estudos S1_RN e S3_PL, ambos conduzidos na mesma área em Descoberto-MG, após 10 e 14 anos de restauração, respectivamente. Esta correlação entre similaridade florística e localização geográfica corrobora com estudos realizados na região (Miranda Neto et al 2017; Balestrin et al 2019).

Além disso, a similaridade florística entre os agrupamentos supracitados pode estar relacionada ao tempo de restauração. Nesse sentido, os estudos S9_TN e S10_PL, apresentam estágio inicial de sucessão (4 anos de restauração), com predomínio de espécies e indivíduos pioneiros. Ademais, em virtude dos estudos S1_RN e S3_PL serem realizados em área com maior tempo de restauração, possivelmente podem apresentar semelhanças quanto a estrutura, composição do dossel e distribuição das espécies (Miranda Neto et al 2017).

A dissimilaridade florística verificada entre S7_RN (área de floresta secundária preservada) e os demais estudos (áreas em restauração no ambiente de mineração de bauxita), possivelmente indica que existem diferentes estágios sucessionais entre estes estudos, conforme evidenciado pelo arranjo do dendrograma (Figura 2-4). Assim sendo, quanto maior o tempo de restauração, espera-se um avanço no estágio sucessional da floresta e aumento da diversidade de espécies (Schuldt et al 2019; Moreno-Mateos et al 2020). Isto ressalta a 
importância dos projetos de restauração ecológica, tendo em vista o reestabelecimento das relações ecológicas e funcionais das espécies na região (Martins et al 2020a).

Outros fatores importantes que podem influenciar nestes arranjos do dendrograma de similaridade florística (Figura 2-4), são a técnica de restauração adotada e o tipo de levantamento, seja na avaliação do plantio (PL), regeneração natural $(\mathrm{RN})$ ou técnicas de nucleação (TN) (Balestrin et al 2019).

Nesse sentido, adotando um ponto de corte no dendrograma na altura 0,88 observou-se um arranjo em dois grupos, o primeiro com tendência ao agrupamento de estudos que avaliaram a diversidade de espécies na regeneração natural e técnicas de nucleação (S4_RN, S8_RN, S5_RN e S9_TN) e outro agrupamento com estudos baseados na avaliação do plantio (S3_PL, S2_PL e S6_PL). A exceção neste agrupamento é o estudo S1_RN, arranjado no grupo do plantio e S10_PL pertencente ao agrupamento da regeneração natural + técnicas de nucleação. Este comportamento é justificável devido à proximidade geográfica com outros estudos, conforme explicado anteriormente.

Nessa perspectiva, é importante ressaltar que as áreas em restauração apresentam diferentes trajetórias (Martins 2018; Balestrin et al 2019), desafios específicos (RodríguezUña et al 2020) e características únicas (Stuble et al 2017). Assim sendo, a diversidade florística em áreas no ambiente de mineração de bauxita pode ser influenciada por inúmeros fatores, tais como: técnica de restauração adotada, resiliência do local e da paisagem, adaptabilidade das espécies às novas condições e proximidade a fragmentos florestais preservados (Martins et al 2020a). Em suma, os agrupamentos do dendrograma referentes à similaridade florística dos estudos comparados neste trabalho foram influenciados principalmente pela localização geográfica, técnica e idade de restauração.

\section{CONCLUSÃO}

A vegetação da área em processo de restauração apresentou boa diversidade, baixa dominância ecológica no contexto de área em início de sucessão, sendo considerada floristicamente heterogênea de acordo com índices de Shannon e Equabilidade de Pielou.

O conhecimento dos atributos funcionais das espécies é essencial para o planejamento e execução de projetos de restauração ecológica. Sendo assim, foi possível definir as metodologias e técnicas mais adequadas para cada cenário no ambiente de mineração de 
bauxita. Nesse sentido, os parâmetros fitossociologicos indicam que em estágios inicias, as famílias Fabaceae e Asteraceae (recobrimento do solo) e Cannabaceae, Solanaceae, Urticaceae (atração da fauna dispersora) apresentam grande potencial para colaborar no avanço sucessional, sendo consideradas "famílias-chave".

A análise de agrupamento de Cluster revela que a similaridade florística entre áreas no ambiente de mineração de bauxita foi influenciada principalmente pela localização geográfica, técnica de restauração e idade de restauração das áreas. Além disso, as ações de recuperação e conservação do solo, plantio de mudas e aplicação de técnicas alternativas de restauração, bem como a preservação de fragmentos florestais na paisagem, realizados pela empresa foram fundamentais para os resultados positivos encontrados.

\section{AGRADECIMENTOS}

Os autores agradecem à Coordenação de Aperfeiçoamento de Pessoal de Nível Superior (CAPES) pela bolsa de mestrado para Wesley Fonseca, ao CNPq pela bolsa de produtividade em pesquisa do orientador prof. Sebastião V. Martins e a Companhia Brasileira de Alumínio (CBA) pela infraestrutura e apoio financeiro ao projeto.

\section{REFERÊNCIAS}

ABAL. (2017). Relatório Bauxita no Brasil - Mineração Responsável e Competitividade. 1 st ed. São Paulo: Associação Brasileira de Alumínio, 66p.

Angiosperm Phylogeny Group IV. (2016). An update of the Angiosperm Phylogeny Group classification for the orders and families of flowering plants. Botanical Journal of the Linnean Society, 181:1-20.

ANM. (2019). Brazilian Mineral Yearbook - Main Metallic Commodities 2018. 1 st ed. Brasília: National Mining Agency.

ANM. (2020). Anuário Mineral Brasileiro Principais Substâncias Metálicas 2020 Prévia: Agência Nacional de Mineração. Disponível em: <https://www.gov.br/anm/pt$\mathrm{br} /$ centrais-de-conteudo/publicacoes/serie-estatisticas-e-economia-mineral/anuariomineral/anuario-mineral-brasileiro>. Acesso em 23 de Agosto de 2020.

Aronson J, Alexander S. (2013). Ecosystem restoration is now a global priority: time to roll up our sleeves. Restoration Ecology 21: 293- 296

Ávila MA, Mota NM, Souza SR, Santos RMD, Nunes YRF. (2021). Diversity and Structure of Natural Regeneration in Swamp Forests in Southeastern Brazil. Floresta e Ambiente, 28(1). 
Balestrin D. (2018). Fitossociologia e dinâmica do solo e da paisagem em áreas sob influência da mineração de bauxita em Minas Gerais-Brasil. 118 f. Tese (Doutorado em Ciência Florestal) - Universidade Federal de Viçosa, Viçosa. 2018.

Balestrin D, Martins SV, Schoorl JM, Lopes AT, de Andrade CF. (2019a). Phytosociological study to define restoration measures in a mined area in Minas Gerais, Brazil. Ecological Engineering, 135, 8-16.

Balestrin D, Martins SV, Fonseca CA. (2020). Ecological restoration and forest coverage advancement in a region influenced by bauxite mining, Minas Gerais, Brazil. In: de Vlieger K. (Ed.). Recent advances in ecological restoration. New York: Nova Science

Publishers, 143-154.

Barbosa RS, Pereira GFM, Ribeiro SS, Hage ALF, Costa GF, Salomão RP, Schwartz G. (2021). Key species selection for forest restoration after bauxite mining in the Eastern Amazon. Ecological Engineering, 162, 106190.

Bastin JF, Finegold Y, Garcia C, Mollicone D, Rezende M, Routh D, ... \& Crowther T. W. (2019). The global tree restoration potential. Science, 365(6448), 76-79.

Benayas JMR, Newton AC, Diaz A, Bullock JM. (2009). Enhancement of biodiversity and ecosystem services by ecological restoration: a meta-analysis. Science, 325(5944), 1121 1124.

Bonini CDSB, Alves MC. (2011). Recovery of soil physical properties by green manure, liming, gypsum and pasture and spontaneous native species. Revista Brasileira de Ciência do Solo, 35(4), 1397-1406.

Braga AJT, Borges EEL, Martins SV. (2011). Florística e estrutura da comunidade arbórea de uma floresta estacional semidecidual secundária em Viçosa, MG. Revista Árvore, 35(3), 493-503.

Budowski G. (1965). Distribution of tropical American Rain Forest species in the light of successional processes. Turrialba, 15:40-42.

Camargo PH, Pizo MA, Brancalion PH, \& Carlo TA. (2020). Fruit traits of pioneer trees structure seed dispersal across distances on tropical deforested landscapes: Implications for restoration. Journal of Applied Ecology, 57(12), 2329-2339.

Chazdon RL. (2008). Beyond deforestation: restoring forests and ecosystem services on degraded lands. Science, 320(5882), 1458-1460.

Corlett RT. (2017). Frugivory and seed dispersal by vertebrates in tropical and subtropical Asia: an update. Global Ecology and Conservation, 11, 1-22.

Costa LG, da Silva AG, \& Gomes DR. (2014). Morphology of fruits, seeds and seedlings and anatomy of seeds of sombreiro (Clitoria fairchildiana). Revista de Ciências Agrárias/Amazonian Journal of Agricultural and Environmental Sciences, 57(4), 414-421.

Gardner CJ, Bicknell JE, Baldwin-Cantello W, Struebig MJ, \& Davies ZG. (2019). Quantifying the impacts of defaunation on natural forest regeneration in a global metaanalysis. Nature communications, 10(1), 1-7. 
Guimarães JCC. (2015). Restauração Ecológica de áreas mineradas de bauxita na Mata Atlântica. 125f. Tese (Doutorado em Ciência Florestal) - Universidade Federal de Lavras, Lavras-MG, 2015

IAI, BAC, Wagner C. (2016). Sustainable Bauxite Mining - A Global Perspective. In: Donaldson D, Raahauge BE. (eds) Essential Readings in Light Metals. Springer, Cham. https://doi.org/10.1007/978-3-319-48176-0_7

IBGE. (2012). Manual Técnico da Vegetação Brasileira. 2nd ed. Manuais Técnicos em Geociências. Rio de Janeiro: Instituto Brasileiro de Geografia e Estatística.

Gandolfi S, Leitão Filho HF, Bezerra CLF. (1995). Levantamento florístico e caráter sucessional das espécies arbustivo-arbóreas de uma floresta mesófila semidecídua no município de Guarulhos, SP. Revista Brasileira de Biologia, 55:753-767.

Kaiser-Bunbury CN, Mougal J, Whittington AE, Valentin T, Gabriel R, Olesen JM, \& Blüthgen N. (2017). Ecosystem restoration strengthens pollination network resilience and function. Nature, 542(7640), 223-227.

Kamble PH \& Bhosale SM. (2019). Assessment of Impact of Bauxite Mining on Environment. i-Manager's Journal on Future Engineering and Technology. 14(4):14-21

Kassambara A. (2017). Practical guide to cluster analysis in R: Unsupervised machine learning. 1 st. Sthda, 189.

Köppen W. (1948). Climatologia: con un estudio de los climas de la tierra. México: Fondo de Cultura Econômica.

Kunz SH \& Martins SV. (2013). Regeneração natural de floresta estacional semidecidual em diferentes estágios sucessionais (Zona da Mata, MG, Brasil). Floresta, 44(1), 111-124.

Londe V, Farah FT, Rodrigues RR, Martins FR. (2020). Reference and comparison values for ecological indicators in assessing restoration areas in the Atlantic Forest. Ecological Indicators, 110, 105928.

Lopes BM, Martins SV, Lopes AT, Silva KA. (2018). Fitossociologia e estrutura de floresta em restauração, em área minerada, São Sebastião da Vargem Alegre, MG. MG. Biota, $10,46-60$.

Lorenzi H. (2020). Árvores Brasileiras: manual de identificação e cultivo de plantas arbóreas nativas do Brasil. 8. ed. Nova Odessa: Plantarum, 384 p. (v. 1).

Martin DM \& Lyons JE. (2018). Monitoring the social benefits of ecological restoration. Restoration Ecology, 26(6), 1045-1050.

Martins SV. (2018). Alternative Forest Restoration Techniques. In: Viana H, editor. New Perspectives in Forest Science. 1st ed. London: IntechOpen; p. 131-148.

Martins SV, Cosimo LHE, Balestrin D, Fonseca WS, Andrade CF, Barros RS. (2020a). Restoration of Tree and Shrub Diversity Post Bauxite Mining, in the Southeastern Region of Minas Gerais, Brazil. In: Kristian de Vlieger. (Org.). Recent Advances in Ecological Restoration. 1ed. United States: Nova, 2020, v.1, p. 33-62. 
Martins WBR, Lima MDR, Junior UDOB, Amorim LSVB, de Assis Oliveira F, Schwartz G. (2020b). Ecological methods and indicators for recovering and monitoring ecosystems after mining: A global literature review. Ecological Engineering, 145, 105707.

Martins SV, Villa PM, Nabeta FH, Da Silva LF, Kruschewsky GC, Dias AA. (2020c). Study on site preparation and restoration techniques for forest restoration in mining tailings of Mariana, Brazil. Research in Ecology, 2(4), 42-52.

Martins SV, Fonseca WS, Cosimo LHE, Balestrin D. (2021). Soil Seed Banks in Two Environments of Forest Restoration Post Bauxite Mining: Native Tree Plantation and Natural Regeneration. Research in Ecology, [S.1.], v. 3, n. 1, apr. ISSN 2661-3379.

Melo CES \& Sánchez LE. (2020). Evaluation of environmental rehabilitation practices in bauxite mining at the plateau of Poços de Caldas. REM-International Engineering Journal, 73(2), 247-252.

Miranda Neto A, Martins SV, Silva KA, Gleriani JM. Florística e estrutura do estrato arbustivo-arbóreo de uma floresta restaurada com 40 anos, Viçosa, MG. Revista Árvore, v.36, n.5, p. 869-878, 2012.

Miranda-Neto A, Martins SV, Silva KA, Lopes AT, Demolinari RDA. (2014). Natural regeneration in a restored bauxite mine in southeast Brazil. Bosque, 35(3), 377-389.

Miranda Neto A, Martins SV, Silva KDA, Lopes AT \& Demolinari RDA. (2017). Banco de sementes em mina de bauxita restaurada no Sudeste do Brasil. Floresta e Ambiente, 24.

MME. (2020). Mineral Sector Bulletin. 2 nd ed. Ministério de Minas e Energia. Brasília: National Mining Agency

Moraes MTD, Debiasi H, Carlesso R, Franchini JC, Silva VRD. (2014). Critical limits of soil penetration resistance in a rhodic Eutrudox. Revista Brasileira de Ciência do Solo, 38(1), 288-298.

Moreno-Mateos D, Alberdi A, Morriën E, van der Putten WH, Rodríguez-Uña A, \& Montoya D. (2020). The long-term restoration of ecosystem complexity. Nature ecology \& evolution, 4(5), 676-685.

Mueller-Dombois D \& Ellenberg H. (1974). Aims and methods of vegetation ecology. New York: John Wiley \& Sons, 580.

Piaia BB, Rovedder APM, Procknow D, Camargo B, Gazzola MD, Croda JP, \& de Moraes Stefanello M. (2020). Natural regeneration as an indicator of ecological restoration by applied nucleation and passive restoration. Ecological Engineering, 157, 105991.

R-Core Team. (2019). R: A language and environment for statistical computing. R Foundation for Statistical Computing, Vienna, Austria. https://www.R-project.org. [accessed 01 november 2019].

Rigacci EDB, Paes ND, Félix GM, Silva WR. (2021). The resilient frugivorous fauna of an urban forest fragment and its potential role in vegetation enrichment. Urban Ecosystems, $1-16$. 
Rodríguez-Uña A, Cruz-Alonso V, Rohrer Z, \& Martínez-Baroja L. (2020). Fresh perspectives for classic forest restoration challenges. Restoration Ecology. 28(1): 12-15

Rother DC, Liboni AP, Magnago LFS, Chao A, Chazdon RL, \& Rodrigues RR. (2019). Ecological restoration increases conservation of taxonomic and functional beta diversity of woody plants in a tropical fragmented landscape. Forest Ecology and Management, 451, 117538.

Santos HG, Jacomine PKT, Anjos LHC, Oliveira VA, Lumbreras JF, Coelho MR, Almeida JA, Araujo Filho JC, Oliveira JB, Cunha TJF. (2018). Sistema brasileiro de classificação de solos. Brasília (DF): Embrapa.

Sayer EJ, Tanner EVJ \& Cheesman AW (2006) Increased litterfall changes fine root distribution in a moist tropical forest. Plant and Soil 281: 5-13.

Schuldt A, Ebeling A, Kunz M, Staab M, Guimarães-Steinicke C, Bachmann D, ... \& Eisenhauer N. (2019). Multiple plant diversity components drive consumer communities across ecosystems. Nature communications, 10(1), 1-11.

Silva KDA, Martins SV, Miranda Neto A, Demolinari RDA, \& Lopes AT. (2016). Restauração florestal de uma mina de bauxita: avaliação do desenvolvimento das espécies arbóreas plantadas. Floresta e Ambiente, 23(3), 309-319.

Silva KDA, Martins SV, Lopes AT, Miranda Neto A, Balestrin D. (2018a). A regeneração natural como indicador da restauração ecológica de uma área minerada de bauxita. MG. Biota, 10, 4-17.

Silva KDA, Martins SV, Miranda Neto A, Lopes AT. (2018b). Estoque de serapilheira em uma floresta em processo de restauração após mineração de bauxita. Rodriguésia, 69(2), 853-861.

Silva KDA, Martins SV, Miranda Neto A. (2021). Influence of Environmental Variables on the Natural Regeneration of a Forest under Restoration after Bauxite Mining and in a Reference Ecosystem in Southeastern Brazil. Research in Ecology, [S.1.], v. 2, n. 4, feb. ISSN 2661-3379.

Sokal RR, Rohlf FJ. 1962. The comparison of dendrograms by objective methods. Taxon. 11(2):33-40.

Shepherd GJ, 2010. Fitopac 2.1 - Campinas, Brasil. Departamento de Botânica, Universidade Estadual de Campinas.

Stuble KL, Fick SE, Young TP. (2017). Every restoration is unique: testing year effects and site effects as drivers of initial restoration trajectories. Journal of Applied Ecology, 54(4), 1051-1057.

Teixeira HM, Cardoso IM, Bianchi FJ, da Cruz Silva A, Jamme D, \& Peña-Claros M. (2020). Linking vegetation and soil functions during secondary forest succession in the Atlantic forest. Forest Ecology and Management, 457, 117696.

USGS. (2020). Mineral Commodity Summaries 2020: United States Geological Survey. Reilly II JF, diretor. 1 st ed. Reston (VA): 200 p., https://doi.org/10.3133/mcs2020.

van der Pijl L (1982). Principles of dispersal in higher plants. 3rd ed. Berlin and New York: Springer-Verlag, 214. 
Viani RAG, Vidas NB, Pardi MM, Castro DCV, Gusson E, \& Brancalion PH. (2015). Animal-dispersed pioneer trees enhance the early regeneration in Atlantic Forest restoration plantations. Natureza \& Conservação, 13(1), 41-46.

Viani RA, Holl KD, Padovezi A, Strassburg BB, Farah FT, Garcia LC., ... \& Brancalion, PH. (2017). Protocol for monitoring tropical forest restoration: perspectives from the Atlantic Forest Restoration Pact in Brazil. Tropical Conservation Science, 10, 1940082917697265.

Volpato GH, Anjos L, Lopes EV, Martins SV. (2015). O papel das aves dispersoras de sementes na restauração ecológica. In: Sebastião Venâncio Martins. (Org.). Restauração ecológica de ecossistemas degradados. Restauração ecológica de ecossistemas degradados. 2ed.Viçosa, MG: Editora UFV, v. 1, p. 191-211.

Wortley L, J-M. Hero and M. Howes. (2013). Evaluating Ecological Restoration Success: A Review of the Literature. Restoration Ecology 21:537-543. 


\section{CAPÍtULO 3 - TÉCNICAS ALTERNATIVAS PARA A RESTAURAÇÃO ECOLÓGICA DE ÁrEA NO AMBIENTE DE MINERAÇÃo DE BAUXITA NO SUDESTE DO BRASIL}

RESUMO: O objetivo desse estudo foi avaliar o processo de restauração ecológica através de uma análise comparativa de técnicas alternativas de restauração em uma área no ambiente de mineração de bauxita. O estudo foi realizado em uma área de 2 ha, onde até o ano 2016 funcionava o setor administrativo da Companhia Brasileira de Alumínio - CBA, localizada no município de Miraí, Minas Gerais. Devido a mudança do setor administrativo da empresa, todas as construções foram removidas deixando o subsolo exposto, compactado e de baixa fertilidade. Esta área de estudo foi incluída no programa de compensação ambiental da empresa pela mineração de bauxita. Foram alocadas 40 parcelas de $1 \times 1 \mathrm{~m}$, nas quais foram testados quatro tratamentos compostos por dez repetições cada, distribuídas por meio de delineamento inteiramente casualizado. O tratamento T1 - Transposição de banco de sementes e da serapilheira; T2 - Semeadura direta de 15 espécies arbóreas nativas; T3 Poleiros artificiais e T4 - Regeneração natural (Controle). As médias de riqueza de espécies, abundância de indivíduos e taxa de cobertura do solo nos tratamentos foram comparadas através do teste de Tukey para amostras independentes $(\mathrm{p}<0,05)$. Além disso, foram calculados os índices de diversidade da comunidade vegetal (Shannon e Equabilidade de Pielou) através do software Fitopac 2.1. Na área em processo de restauração, o Índice de Shannon $\left(\mathrm{H}^{\prime}\right)=2,415$ evidencia uma média diversidade florística e a Equabilidade (J') = 0,781 demonstra que a área é floristicamente heterogênea e com baixa dominância ecológica. Em T1 foram registrados 93 indivíduos pertencentes a 13 espécies, em T2 foram 104 indivíduos pertencentes a 12 espécies, em T3 foram 2 indivíduos pertencentes a 1 espécie e em T4, foram 4 indivíduos pertencentes a 1 espécie. Houve diferença significativa $(P \leq 0,05)$ pelo teste $\mathrm{F}$ para os valores das médias de indivíduos e de espécies entre os tratamentos. De acordo com o teste Tukey, os tratamentos T1 e T2 são estatisticamente iguais, no que se refere a riqueza e abundância de indivíduos, e estatisticamente diferentes dos demais tratamentos. Sendo assim, a semeadura direta e a transposição de solo e serapilheira se destacaram como técnicas alternativas para a restauração ecológica de áreas em ambiente de mineração de bauxita, desde que sejam adotadas ações de recuperação e conservação do solo, assim como preservação de fragmentos florestais na paisagem, como já vem sendo realizado pela empresa.

Palavras-chaves: Nucleação, Preparo do solo, Floresta Atlântica, Biodiversidade, Mineração sustentável, Floresta tropical 
ABSTRACT: The objective of this study was to evaluate the ecological restoration process through a comparative analysis of alternative restoration techniques in an area in the bauxite mining environment. The study was carried out in a 2 ha area, where until the year 2016 the administrative sector of Companhia Brasileira de Alumínio - CBA, located in Miraí, Minas Gerais, operated. Due to the change in the company's administrative sector, all the buildings were removed leaving the subsoil exposed, compacted and with low fertility. This study area was included in the company's environmental compensation program for bauxite mining. 40 plots of 1 x $1 \mathrm{~m}$ were allocated, in which four treatments were tested, consisting of ten replicates each, distributed through a completely randomized design. The T1 treatment - Litter and soil seed bank transposition; T2 - Direct seeding of 15 native tree species; T3 - Artificial perches and T4 - Natural regeneration (Control). The means of species richness, abundance of individuals and soil cover rate in the treatments were compared using the Tukey test for independent samples $(\mathrm{p}<0.05)$. In addition, the diversity indexes of the plant community (Shannon and Equabilidade Pielou) were calculated using the Fitopac 2.1 software. In the area undergoing restoration, the Shannon Index $\left(\mathrm{H}^{\prime}\right)=2.415$ shows an average floristic diversity and Equability $\left(\mathrm{J}^{\prime}\right)=0.781$ demonstrates that the area is floristically heterogeneous and with low ecological dominance. In T1, 93 individuals belonging to 13 species were registered, in T2, 104 individuals belonging to 12 species, in T3, 2 individuals belonging to 1 species and in T4, 4 individuals belonging to 1 species. There was a significant difference $(P \leq 0.05)$ by the $\mathrm{F}$ test for the values of the average of individuals and of regenerating species between treatments. According to the Tukey test, the T1 and T2 treatments are statistically equal, regarding to the wealth and abundance of individuals, and statistically different from the other treatments. Thus, alternative techniques for the ecological restoration of areas in a bauxite mining environment, provided that soil recovery and conservation actions are adopted, as well as the preservation of forest fragments in the landscape, as has already been done by the company.

Keywords: Nucleation, Soil preparation, Atlantic Forest, Biodiversity, Sustainable mining, Tropical forest

\section{INTRODUÇÃO}

O Brasil possui uma posição de destaque no cenário mundial, tanto na produção quanto na exploração de reservas minerais existente em seu território (MME 2020). Desse 
modo, a mineração além de gerar importantes receitas e possuir relevante participação no Produto Interno Bruto Nacional (PIB), também promove o desenvolvimento socioeconômico regional, através da geração de empregos diretos e indiretos para a comunidade local (ANM 2019).

Nesse cenário, a bauxita é um importante minério do qual se obtêm o alumínio, terceiro elemento em maior abundância na crosta terrestre (ABAL 2017). Este mineral é encontrado em grande quantidade e qualidade $\left(>40 \% \mathrm{Al}_{2} \mathrm{O}_{3}\right)$ nas reservas brasileiras, (ANM 2019) e, para sua exploração é necessário remover a camada superficial do solo, podendo gerar impactos ambientais localizados (Kamble \& Bhosale 2019).

Todavia, esses impactos são pontuais e não ocupam grandes extensões territoriais, como agricultura e pecuária, além disso, como este minério é encontrado geralmente em camadas próximas à superfície do solo, os impactos podem ser controlados e corrigidos de forma que a recuperação das áreas sob influência da mineração de bauxita seja relativamente rápida e ocorra de forma sustentável, por meio de técnicas de restauração ecológica (ABAL 2017; Balestrin et al 2019a; Melo \& Sánchez 2020; Balestrin et al 2020; Martins et al 2020).

Conforme salientado por Martins (2018) não existe uma "receita universal", um único modelo ou técnica de restauração que possa ser aplicada em todas as áreas. Dessa forma, é necessário adequar os projetos de restauração ecológica aos múltiplos filtros ambientais regionais e às diversas oportunidades ecológicas das paisagens, de modo a aproveitar o potencial remanescente de regeneração do ecossistema e colaborar para o avanço do processo ecológico (Martins 2018).

Tendo em vista a crise contemporânea da biodiversidade (Miller et al 2017; Gann et al 2019; Rodríguez-Uña et al 2020), uma nova tendência em projetos de restauração ecológica são modelos com foco na conservação da biofuncionalidade (Reis et al 2010) e na conectividade de paisagens fragmentadas. Dessa maneira, a integração da paisagem pode melhorar os serviços ecossistêmicos e assim expandir os resultados da restauração para escalas maiores do que o local de restauração (Benayas et al 2009; Miller et al 2017).

Nessa perspectiva, a restauração ecológica de ecossistemas é uma prioridade global diante das metas e desafios assumidos em acordos internacionais (UN 2021). Assim, a comparação de estratégias de restauração ativa e passiva é fundamental para a melhor compreensão do processo de restauração, tendo em vista que diferentes métodos influenciam a recuperação de diferentes componentes do ecossistema (Reid et al 2018; Campanharo et al 
2021). A restauração ativa consiste na aplicação de técnicas com intervenção humana direta como plantio de mudas, semeadura direta e técnicas de nucleação (Martins 2018). A restauração passiva, também conhecida como regeneração natural, consiste no isolamento de uma área dos fatores de degradação, de modo a promover a recuperação espontânea da sua diversidade, estrutura e funções (Crouzeilles et al 2017).

Nesse sentido, a escolha de técnicas eficientes de restauração não é uma atividade fácil, pois depende de características intrínsecas de cada área e de como esses elementos estão correlacionados. Assim, uma alternativa ao padrão tradicional de plantio de mudas é o uso de técnicas de nucleação, como: núcleos de diversidade, poleiros, transposição de solo e serapilheira, banco de sementes, semeadura direta e adubos verdes (Reis et al 2014; Martins 2018).

Sendo assim, a nucleação se destaca pois é uma técnica biocêntrica inspirada na teoria ecológica da facilitação (Yarranton e Morrison 1974), que visa aumentar a probabilidade de rotas alternativas de sucessão. Nessa perspectiva, a nucleação aplicada em áreas no contexto da mineração de bauxita é inovadora (Martins 2018) pois promove gatilhos ecológicos que serão responsáveis não apenas pelo restabelecimento da cobertura vegetal, mas também por desencadear processos de sucessão natural, aumentar as interações funcionais entre fauna e flora, e consequentemente restaurar a complexidade do ecossistema, de modo que o ambiente se torne autossustentável, dispensando intervenções externas (Reis et al 2014; Gann et al 2019).

Diante disso, embora seja necessário comparar as técnicas de restauração ecológica em diferentes contextos ambientais (Martins 2018), a nucleação é uma estratégia promissora para a restauração de ambientes tropicais degradados, pois essas técnicas facilitam a regeneração natural e assim promovem a recuperação da diversidade estrutural, funcional e de espécies (Corbin \& Holl 2012; Holl et al 2017; Rojas-Botero et al 2020). Além disso, o uso dessas técnicas alternativas reduz os custos com plantio de árvores (Holl et al 2017; Bechara et al 2021).

Portanto, os modelos e técnicas de restauração são importantes tanto do ponto de vista ecológico quanto socioeconômico, visto que auxiliam no retorno do ecossistema a uma condição não degradada (Martins 2018). Dessa forma, o desafio da restauração ecológica é adaptar as técnicas mais apropriadas para cada cenário. Assim, este estudo teve como objetivo avaliar o processo de restauração ecológica através de uma análise comparativa de técnicas de 
nucleação empregadas em uma área no ambiente de mineração de bauxita no Sudeste do Brasil.

\section{MATERIAL E MÉTODOS}

\subsection{Local de Estudo}

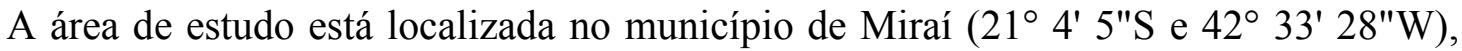
em altitude de 715 m, na região denominada Zona da Mata no Sudeste do estado de Minas Gerais - Brasil (Figura 3-1). A área tem 2 ha e até o ano 2016 era destinada ao setor administrativo da Companhia Brasileira de Alumínio - CBA.

Figura 3-1. Localização da área de estudo, em Miraí-MG, Brasil

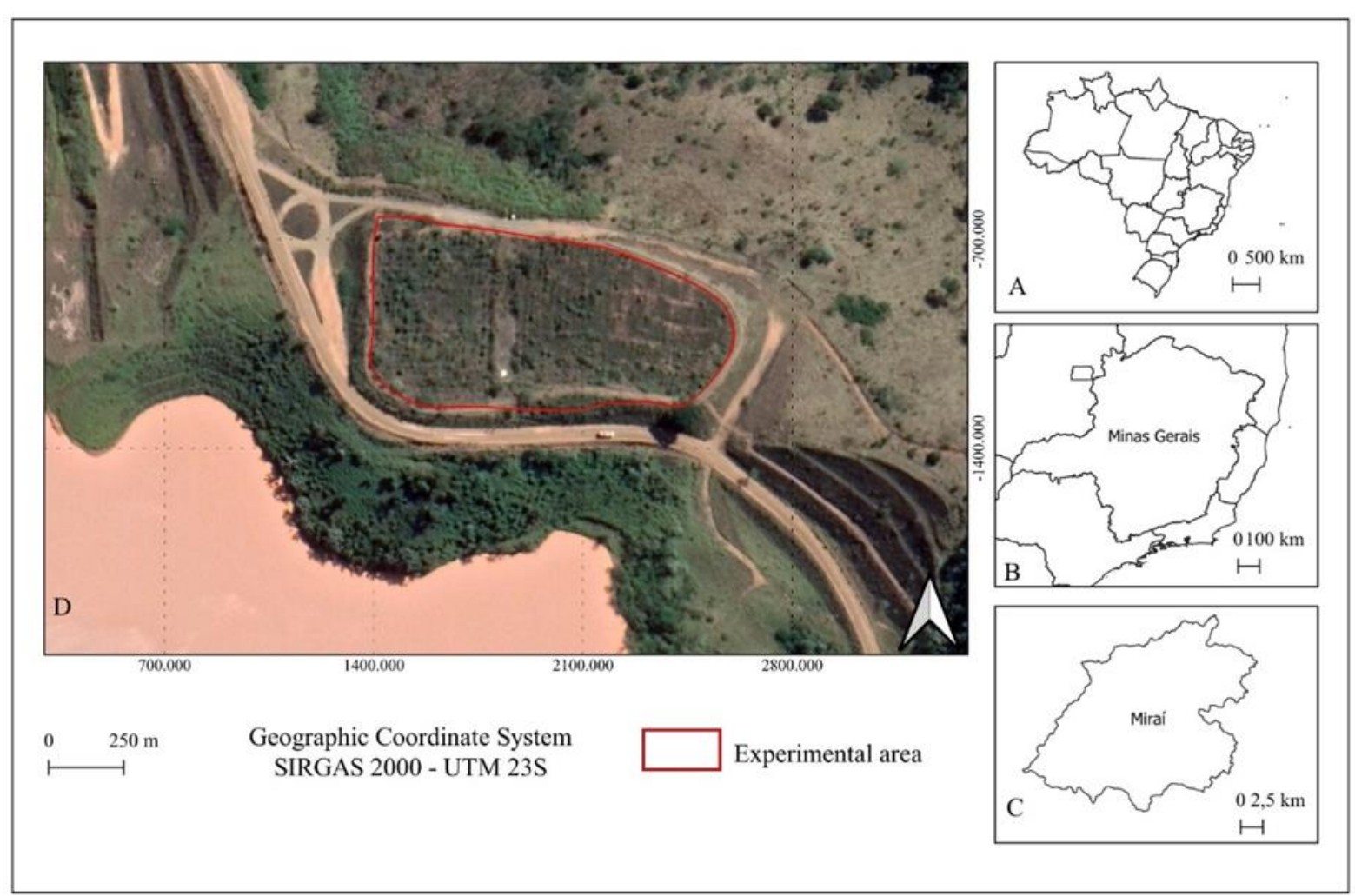

A vegetação característica da região é classificada como Floresta Estacional Semidecidual Montana, inserida no Domínio Floresta Atlântica (IBGE, 2012). De acordo com o Sistema Brasileiro de Classificação de Solos (Santos et al 2018), o solo predominante na região é o Latossolo Vermelho-Amarelo distrófico típico. Segundo a classificação de Köppen 
(1948), o clima da região é do tipo Cwa, clima temperado úmido com inverno seco e verão quente.

No entorno dessa área em restauração existem pastagens com Urochloa decumbens (Stapf) R. D. Webster (Brachiaria), manchas de Pennisetum purpureum Schumach. (Capimelefante), áreas em processo de restauração com diferentes idades e fragmentos florestais preservados.

Devido a mudança do setor administrativo da empresa, todas as construções foram removidas deixando o subsolo exposto, compactado e de baixa fertilidade. Esta área de estudo foi incluída no programa de compensação ambiental da empresa pela mineração de bauxita e a nucleação foi a técnica de restauração ecológica escolhida para a área. Em sequência, foi realizado o preparo do solo em área total através de um subsolador ripper e o cercamento da área.

\subsection{Avaliação florística e Procedimentos de campo}

Foram alocadas 40 parcelas de $1 \times 1 \mathrm{~m}$, nas quais foram testados quatro tratamentos compostos por dez repetições cada, distribuídas por meio de delineamento inteiramente casualizado. O tratamento T1 - Transposição de banco de sementes (composto por uma camada de serapilheira e solo superficial de $5 \mathrm{~cm}$ ); T2 - Semeadura direta de 15 espécies arbóreas nativas (Tabela 3-1), na forma de "muvuca", com 10 sementes por espécies por repetição, totalizando 150 sementes por $\mathrm{m}^{2}$; T3 - Poleiros artificiais (instalação de 10 poleiros de bambu) e T4 - Controle (regeneração natural, realizando apenas a delimitação da parcela).

Tabela 3-1. Lista de espécies arbóreas utilizadas no tratamento T2 - semeadura direta.

\begin{tabular}{llcc}
\hline \multicolumn{1}{c}{ Família } & \multicolumn{1}{c}{ Espécies } & CS & SD \\
\hline Anacardiaceae & Schinus terebinthifolia Raddi & $\mathrm{P}$ & Zoo \\
Bignoniaceae & Handroanthus albus (Cham.) Mattos & $\mathrm{St}$ & Ane \\
Bignoniaceae & Handroanthus impetiginosus (Mart. ex DC.) Mattos & $\mathrm{St}$ & Ane \\
Fabaceae & Anadenanthera colubrina (Vell.) Brenan & $\mathrm{Si}$ & Aut \\
& Caesalpinia pluviosa DC & $\mathrm{Si}$ & Aut \\
& Hymenaea courbaril L. & $\mathrm{St}$ & Zoo \\
& Libidibia ferrea (Mart. Ex Tul.) LP Queiroz & $\mathrm{St}$ & Zoo \\
& Piptadenia gonoacantha (Mart.) JFMacbr & $\mathrm{Si}$ & Aut \\
& Senna macranthera (Collad.) HSIrwin e Barneby & $\mathrm{P}$ & Zoo
\end{tabular}


Lamiacea

Aegiphila sellowiana Cham.

$\mathrm{Si} \quad \mathrm{Zoo}$

Malvaceae

Luehea grandiflora Mart.

$\mathrm{Si} \quad$ Ane

Melastomataceae Tibouchina granulosa (Desr.) Cogn.

P Ane

Primulaceae

Myrsine coriacea (Sw.) R

R. Br. ex.Roem. \& Schult.

$\mathrm{Si} \quad \mathrm{Zoo}$

Sapindaceae

Sapindus saponaria L.

St Aut

Urticaceae

Cecropia hololeuca Miq

P Zoo

CS: Categoria sucessional (P: Pioneira, Si: Secundária inicial, St: Secundária tardia, SD: Síndrome de dispersão (Zoo: Zoocórica, Ane: Anemocórica, Aut: Autocórica)

Para análise das técnicas de restauração, todos os indivíduos arbustivos e arbóreos foram identificados e medidos a altura e o diâmetro ao nível do solo (DNS). Os indivíduos foram classificados em famílias e nomenclatura científica de acordo com o Angiosperm Phylogeny Group (APG IV 2016) e, as espécies encontradas foram classificadas em categorias sucessionais de acordo com Budowski (1965) e adaptadas por Gandolfi et al., (1995) para florestas secundárias brasileiras em: pioneiras (P), secundária inicial (Si) e secundária tardia $(\mathrm{St})$. Quanto a síndrome de dispersão de propágulos, as espécies foram classificadas em: zoocóricas (Zoo), anemocóricas (Ane), autocóricas (Aut) (Pijl 1982), quanto a forma de vida em arbórea (A) ou arbustiva (B).

Além disso, foi mensurada a taxa de cobertura do solo em diferentes anos (2018 e 2020), através da avaliação visual das parcelas por meio da escala percentual, na qual a nota 0 correspondeu à ausência de cobertura vegetal do solo e a nota 100 correspondeu a cobertura completa do solo.

\subsection{Processamento e análise de dados}

As médias da riqueza de espécies, abundância de indivíduos e dos valores de cobertura do solo nos tratamentos foram comparadas através do teste de Tukey para amostras independentes $(\mathrm{p}<0,05)$. Para a realização das análises e avaliação estatística, foi utilizado o software R (R Core Team, 2016). Além disso, os índices de diversidade da comunidade vegetal (Shannon-Wiener e Equabilidade Pielou) foram calculados através do software Fitopac 2.1.

\section{RESULTADOS}

$\mathrm{Na}$ área em processo de restauração por meio de técnicas de nucleação foram registrados 203 indivíduos, pertencentes a 22 espécies e 13 famílias botânicas (Tabela 3-2). O Índice de Shannon-Wiener $\left(H^{\prime}\right)=2,415$ evidencia uma média diversidade florística e o Índice 
de Equabilidade de Pielou $\left(\mathrm{J}^{\prime}\right)=0,781$ demonstra que a área é floristicamente heterogênea e com baixa dominância ecológica. Houve predominância de espécies e indivíduos arbóreos nativos com dispersão zoocórica e categoria sucessional pioneira.

Tabela 3-2. Florística e distribuição das espécies arbustivas e arbóreas encontradas em cada tratamento

\begin{tabular}{|c|c|c|c|c|c|c|c|c|}
\hline \multirow{2}{*}{ Famílias / Espécies } & \multicolumn{5}{|c|}{ Tratamentos } & \multirow[b]{2}{*}{ OR } & \multirow[b]{2}{*}{$\mathrm{CS}$} & \multirow[b]{2}{*}{ SD } \\
\hline & $\mathbf{T 1}$ & $\mathbf{T 2}$ & T3 & $\mathbf{T C}$ & $\mathrm{FV}$ & & & \\
\hline \multicolumn{9}{|l|}{ ANACARDIACEAE } \\
\hline Schinus terebinthifolia Raddi & & 1 & & & A & $\mathrm{N}$ & $\mathrm{P}$ & Zoo \\
\hline \multicolumn{9}{|l|}{ ARECACEAE } \\
\hline Syagrus romanzoffiana (Cham.) Glassman & 3 & & & & A & $\mathrm{N}$ & St & Zoo \\
\hline \multicolumn{9}{|l|}{ ASTERACEAE } \\
\hline Baccharis dracunculifolia DC. & & 2 & & & $\mathrm{~B}$ & $\mathrm{~N}$ & $\mathrm{P}$ & Ane \\
\hline Vernonanthura phosphorica (Vell.) H.Rob. & 9 & 3 & & 4 & A & $\mathrm{N}$ & $\mathrm{P}$ & Ane \\
\hline \multicolumn{9}{|l|}{ BIGNONIACEAE } \\
\hline Handroanthus impetiginosus (Mart. ex DC.) Mattos & & 20 & & & A & $\mathrm{N}$ & St & Ane \\
\hline \multicolumn{9}{|l|}{ CANNABACEAE } \\
\hline Trema micrantha (L.) Blume & 5 & & 2 & & A & $\mathrm{N}$ & $\mathrm{P}$ & Zoo \\
\hline \multicolumn{9}{|l|}{ EUPHORBIACEAE } \\
\hline Croton urucurana Baill. & 3 & & & & A & $\mathrm{N}$ & $\mathrm{P}$ & Aut \\
\hline \multicolumn{9}{|l|}{ FABACEAE } \\
\hline Caesalpinia pluviosa DC & & 15 & & & A & $\mathrm{N}$ & $\mathrm{Si}$ & Aut \\
\hline Dalbergia nigra (Vell.) Benth & & 3 & & & A & $\mathrm{N}$ & $\mathrm{Si}$ & Ane \\
\hline Hymenaea courbaril L & & 29 & & & A & $\mathrm{N}$ & St & Zoo \\
\hline Inga marginata Willd & & 1 & & & A & $\mathrm{N}$ & $\mathrm{Si}$ & Zoo \\
\hline Piptadenia gonoacantha (Mart.) JFMacbr & 1 & 13 & & & A & $\mathrm{N}$ & $\mathrm{Si}$ & Ane \\
\hline Senegalia polyphylla (DC.) Britton \& Killipa & 1 & & & & A & $\mathrm{N}$ & $\mathrm{P}$ & Aut \\
\hline Senna macranthera (Collad.) HSIrwin e Barneby & & 6 & & & A & $\mathrm{N}$ & $\mathrm{P}$ & Zoo \\
\hline Senna multijuga (Rich.) HSIrwin e Barneby & 11 & & & & A & $\mathrm{N}$ & $\mathrm{Si}$ & Aut \\
\hline \multicolumn{9}{|l|}{ LAURACEAE } \\
\hline Nectandra oppositifolia Nees \& Mart. & 1 & & & & A & $\mathrm{N}$ & St & Zoo \\
\hline \multicolumn{9}{|l|}{ MELASTOMATACEAE } \\
\hline Miconia cinnamomifolia (DC.) Naudin & 1 & & & & A & $\mathrm{N}$ & $\mathrm{P}$ & Zoo \\
\hline \multicolumn{9}{|l|}{ SAPINDACEAE } \\
\hline Matayba elaeagnoides Radlk & 1 & 10 & & & $\mathrm{~A}$ & $\mathrm{~N}$ & $\mathrm{Si}$ & Zoo \\
\hline \multicolumn{9}{|l|}{ SOLANACEAE } \\
\hline Solanum mauritianum Scop & 55 & & & & A & $\mathrm{N}$ & $\mathrm{P}$ & Zoo \\
\hline \multicolumn{9}{|l|}{ URTICACEAE } \\
\hline Cecropia glaziovii Snethl & 1 & & & & A & $\mathrm{N}$ & $\mathrm{P}$ & Zoo \\
\hline Cecropia hololeuca Miq & 1 & & & & A & $\mathrm{N}$ & $\mathrm{P}$ & Zoo \\
\hline \multicolumn{9}{|l|}{ VERBENACEAE } \\
\hline Lantana camara L. & & 1 & & & $\mathrm{~B}$ & $\mathrm{~N}$ & $\mathrm{P}$ & Zoo \\
\hline
\end{tabular}


Categoria Sucessional (P: Pioneira, Si: Secundária Inicial, St: Secundária Tardia); SD= Síndrome de Dispersão (Ane: Anemocórica, Aut: Autocórica, Zoo: Zoocórica).

No tratamento T1 - Transposição de solo e serapilheira foram registrados 94 indivíduos $\left(9,4\right.$ ind. $\left.\mathrm{m}^{-2}\right)$, pertencentes a 13 espécies e 10 famílias botânicas. As espécies mais abundantes foram: Solanum mauritianum Scop. com 55 indivíduos; Senna multijuga (Rich.) HSIrwin e Barneby (11) e Vernonanthura phosphorica (Vell.) H.Rob. (9). Em T1, a maioria das espécies $(61,54 \%)$ e dos indivíduos (72,12\%) apresentaram dispersão zoocórica. Quanto a classe sucessional, houve predominância de espécies $(61,54 \%)$ e de indivíduos $(81,72 \%)$ pioneiros. Todos as espécies apresentaram forma de vida arbórea.

No tratamento T2 - Semeadura direta foram registrados 104 indivíduos $\left(10,4\right.$ ind. $\mathrm{m}^{-}$ ${ }^{2}$ ), pertencentes a 12 espécies e 6 famílias botânicas. As espécies mais abundantes foram: Hymenaea courbaril L. com 29 indivíduos; Handroanthus impetiginosus (Mart. ex DC.) Mattos (20) e Caesalpinia pluviosa DC (15). Em T2 houve predominância da síndrome de dispersão zoocórica, tanto para espécies $(50,00 \%)$ quanto para indivíduos $(46,15 \%)$. No que concerne a classe sucessional, houve predominância de indivíduos secundários tardios (47,12\%), principalmente devido a contribuição das espécies $H$. courbaril e $H$. impetiginosus. Quanto a forma de vida, houve predominância do hábito arbóreo, tanto para espécies (75\%), quanto para indivíduos $(96,15 \%)$.

No tratamento T3 - Poleiros artificiais foram registrados apenas 2 indivíduos (0,2 ind. $\mathrm{m}^{-2}$ ) da espécie Trema micrantha. Essa espécie apresenta síndrome de dispersão zoocórica, apresentando dispersão de propágulos principalmente pela avifauna. No tratamento T4 Regeneração natural foram registrados 4 indivíduos $\left(0,4\right.$ ind. $\left.\mathrm{m}^{-2}\right)$, pertencentes à espécie Vernonanthura phosphorica.

\subsection{Riqueza de espécies e abundância de indivíduos}

A média da riqueza de espécies e a média da abundância de indivíduos entre os tratamentos foram comparadas através do teste Tukey para amostras independentes ao nível de $5 \%$ de significância $(\mathrm{p}<0,05)$. Houve diferença estatística $(\mathrm{p}<0,05)$ entre os quatro tratamentos. Os tratamentos T1 e T2 apresentaram os melhores resultados e são estatisticamente iguais, no que se refere a riqueza e abundância, e estatisticamente diferentes dos demais tratamentos (Figura 3-2A e 3-2B). 

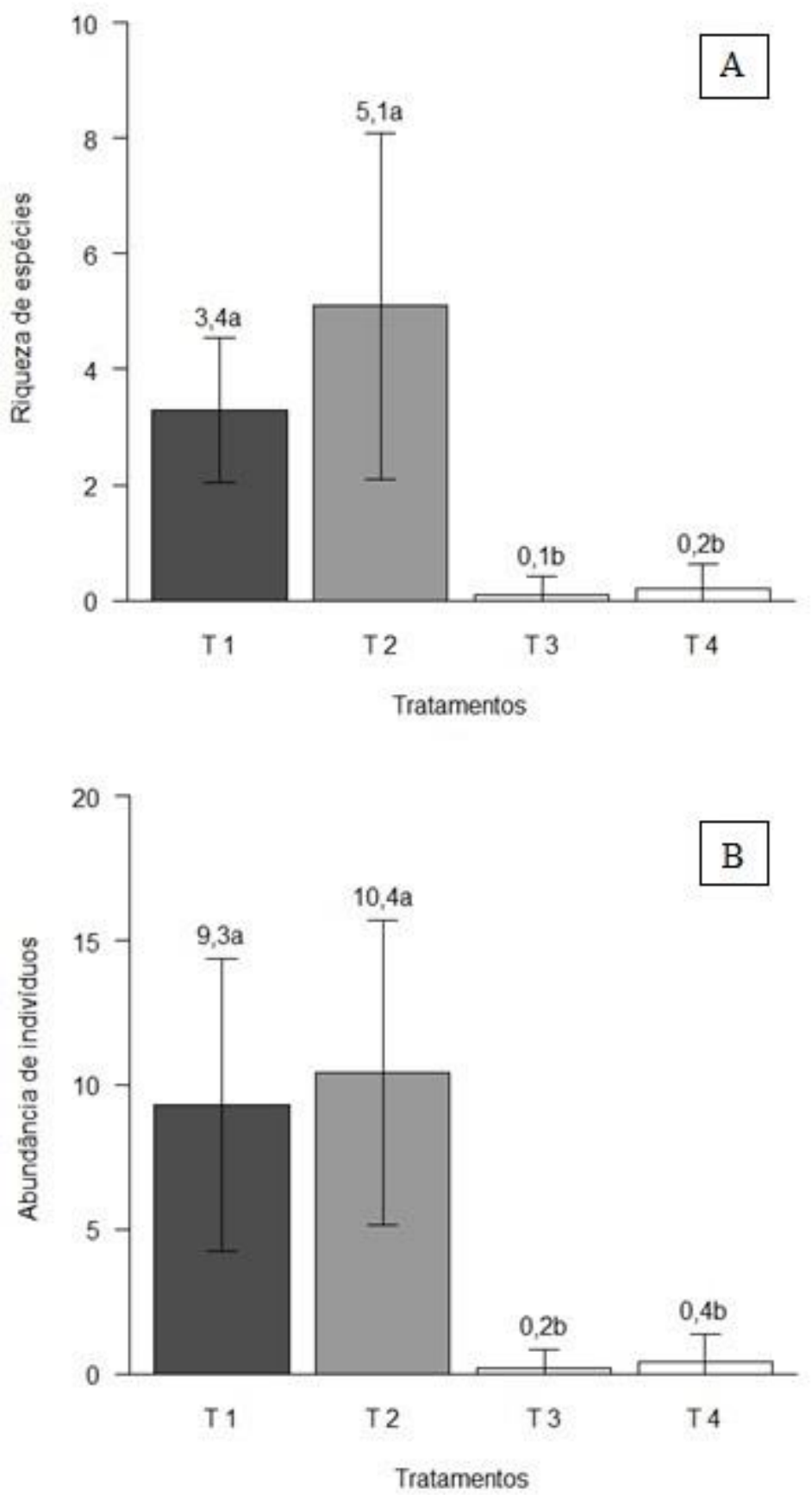

Figura 3-2. Barplot de A) riqueza de espécies e B) abundância de indivíduos. Números seguidos de letras diferentes são estatisticamente diferentes $p \leq 0.05$ (Tukey). T1= Transposição de banco de sementes, $\mathrm{T} 2=$ Semeadura direta, $\mathrm{T} 3=$ Poleiros artificiais, $\mathrm{T} 4=$ Controle.

\subsection{Cobertura do solo}

A cobertura do solo avaliada em 2018 mostrou que não houve diferenças estatísticas entre os tratamentos T1 $(49 \%)$ e T2 $(31 \%)$ ao nível de 5\% de significância $(\mathrm{p}<0,05)$ e os 
tratamentos T3 e T4 não apresentaram cobertura de solo (Figura 3-3). Em sequência, a avaliação realizada em 2020 revelou que houve acréscimo no recobrimento do solo em todos os tratamentos. Os tratamentos T1 (87\%) e T2 (86\%) mantiveram o mesmo comportamento e são estatisticamente superiores aos demais tratamentos. O tratamento T4 (23,5\%), no qual foi realizado apenas a delimitação da parcela apresentou a menor cobertura de solo, sendo estatisticamente inferior aos demais tratamentos.

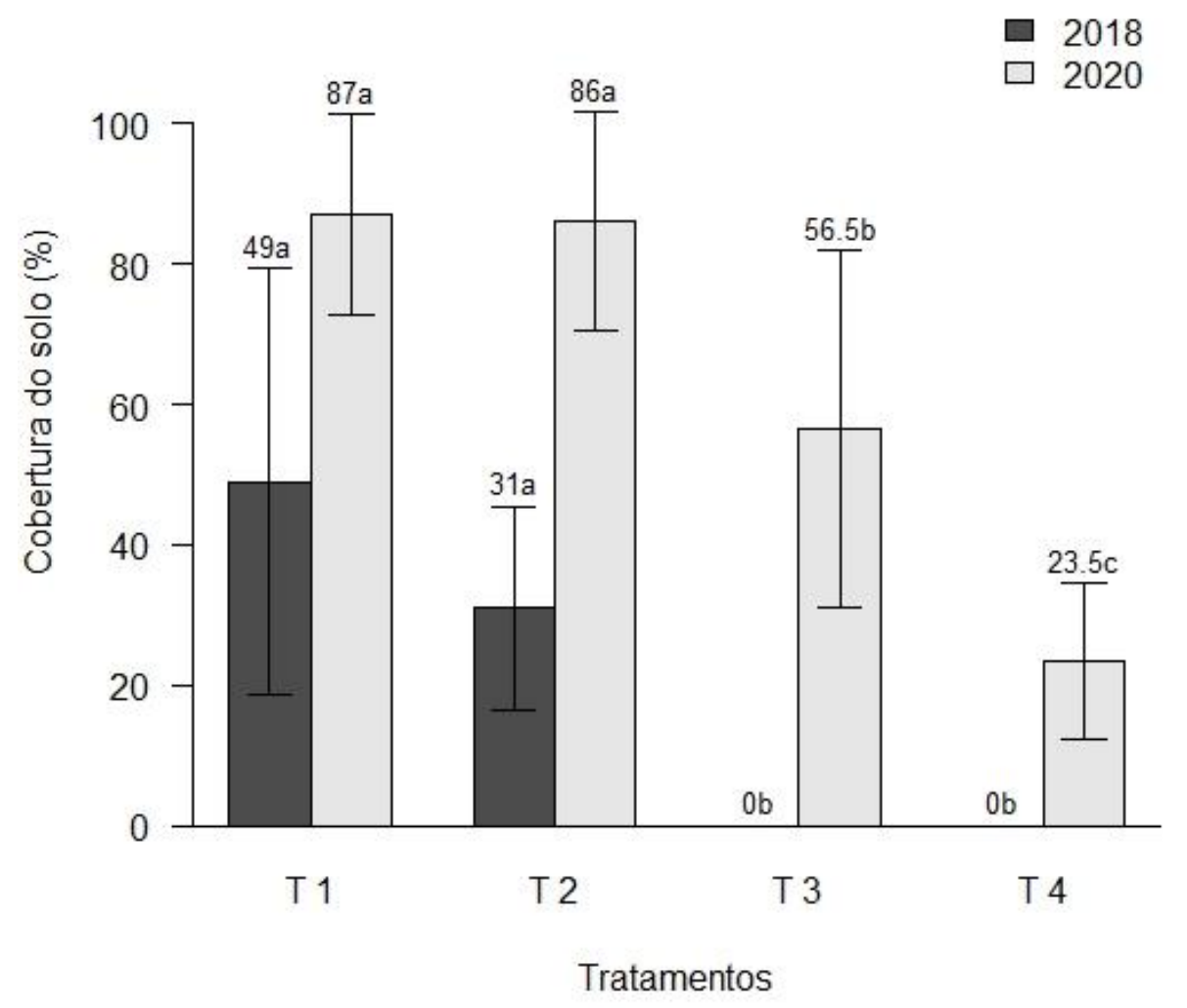

Figura 3-3. Barplot da cobertura do solo nos tratamentos de nucleação, nos anos 2018 e 2020. $\mathrm{T} 1=$ Transposição de banco de sementes, $\mathrm{T} 2=$ Semeadura direta, $\mathrm{T} 3=$ Poleiros artificiais, $\mathrm{T} 4=$ Controle.

\section{DISCUSSÃO}

A área em restauração por meio de técnicas de nucleação apresentou boa diversidade florística, conforme os índices de Shannon $\left(\mathrm{H}^{\prime}=2,415\right)$ e Equabilidade de Pielou $\left(\mathrm{J}^{\prime}\right)=0,781$. Estes índices de diversidade são superiores aos verificados em estudos de comparação de técnicas de nucleação no bioma Mata Atlântica (Trentin et al 2018; Piaia et al 2020).

A maior riqueza de espécies e abundância de indivíduos da família Fabaceae é um indicador importante, visto que muitas espécies são capazes de realizar a fixação biológica de 
nitrogênio, e consequentemente, promover melhorias nos parâmetros edáficos (Barbosa et al 2021). Em consonância o predomínio da síndrome de dispersão zoocórica e da categoria sucessional pioneira, em nível de espécies e indivíduos, contribui para o avanço do processo sucessional (Camargo et al 2020).

Neste contexto, as espécies pioneiras são consideradas facilitadoras do processo sucessional devido ao rápido crescimento, rusticidade e melhoria das condições edáficas, além disso, a floração e frutificação precoce garante um maior recobrimento do solo e redução dos processos erosivos (Martins et al 2021). Em complemento, as espécies zoocóricas podem atrair a fauna dispersora de sementes e colaborar para o aumento da complexidade de interações ecológicas na área em restauração (Silva et al 2016; Corlett 2017; Gardner et al 2019). Desse modo, as árvores pioneiras dispersas por animas podem aumentar a regeneração em estágios iniciais, conforme estudos na Mata Atlântica (Viani et al 2015; Camargo et al 2020).

\subsection{Riqueza de espécies e abundância de indivíduos}

As técnicas transposição de banco de sementes (T1) e semeadura direta (T2) se destacaram como alternativas para recuperação do ambiente, apresentando as maiores riquezas de espécies e abundâncias de indivíduos, além de maiores valores de cobertura do solo, nas duas análises realizadas. Nessa perspectiva, a nucleação é capaz de superar a limitação inicial por sementes e consequentemente aumentar o número de espécies, de modo a promover a recuperação da diversidade funcional e de espécies na área degradada (RojasBotero et al 2020).

Nesse sentido, o tratamento T1 se destacou quanto a abundância de indivíduos $(9,3$ ind. $\mathrm{m}^{-2}$ ), principalmente devido à influência de Solanum mauritianum, espécie pioneira de rápido crescimento (Silva et al 2016; Martins et al 2021). No entanto, esse valor foi inferior ao verificado por Neto et al 2010 (11,1 ind. $\left.\mathrm{m}^{-2}\right)$, em experimento de transposição do banco de sementes em pastagem abandonada na Floresta Estacional Semidecidual. Essa diferença pode estar relacionada à resiliência do ambiente e às condições edáficas, principalmente influenciadas pela ausência da camada fértil do solo na área deste estudo.

A eficiência da transposição do banco de sementes como estratégia de restauração no aumento da diversidade de espécies é descrita em diversos estudos; em diferentes regiões tropicais (Neto et al 2010; Boanares \& de Azevedo 2014; Silva et al 2015; Martins 2018; Ribeiro et al 2018) e em áreas de mineração de bauxita (Martins et al 2018; Onésimo et al 
2021). Além disso, estudos indicam que essa técnica é capaz de: estimular a sucessão (Rodrigues et al 2010); aumentar a fertilidade e a ciclagem de nutrientes no solo (Silva et al 2015); depositar estruturas reprodutivas com capacidade de rebrota (Martins et al 2015); reduzir a infestação de espécies invasoras e incorporar microrganismos edáficos, como fungos e bactérias (Schmidt et al 2020), entre outros benefícios.

Nessa perspectiva, o objetivo principal desta técnica é aproveitar o potencial de resiliência das áreas, de modo a colaborar para o avanço do processo sucessional (Martins et al 2015; Martins 2018). Assim, a transposição de solo e serapilheira em áreas no ambiente da mineração é uma alternativa para aumentar a diversidade de plantas e o restabelecimento de espécies nativas, de forma economicamente viável (Hall et al 2010). Em T2, quanto a abundância de indivíduos, o valor encontrado na semeadura direta $\left(10,4\right.$ ind. $\left.\mathrm{m}^{-2}\right)$ foi superior ao indicado por Silva et al 2015 (7,2 ind. $\left.\mathrm{m}^{-2}\right)$, em experimentos conduzidos em solos degradados, na mesma região e tipologia florestal da área de estudo, após 2 anos da semeadura. Em complemento, os autores destacaram que a combinação das técnicas semeadura direta e transposição de serapilheira potencializaram os benefícios na emergência e desenvolvimento de plântulas.

Nesse sentido, a semeadura direta apresentou a maior média de riqueza de espécies entre os tratamentos, mostrando-se uma técnica eficiente na recuperação da diversidade de espécies na fase inicial da restauração ecológica. Além disso, o potencial da semeadura direta na redução dos custos da restauração em comparação ao plantio de mudas e no acúmulo de biomassa acima do solo é confirmado em diversos estudos atuais (Meli et al 2018; Freitas et al 2019; Rodrigues et al 2019; Greet et al 2020; Raupp et al 2020; Figueiredo et al 2021; Campanharo et al 2021).

Em contrapartida, existem limitações para a utilização dessa técnica em larga escala e de forma exclusiva na restauração de uma área impactada. Embora a semeadura direta possa ser uma alternativa viável economicamente, alguns estudos apontaram baixa emergência e estabelecimento (Souza \& Engel 2018), maior infestação de plantas indesejáveis (Passaretti et al 2020) e dificuldades na obtenção de grandes quantidades de sementes viáveis (Ceccon et al 2016).

Desse modo, tais limitações podem comprometer a aplicabilidade desta técnica em algumas regiões, pois os resultados são diretamente relacionados às condições edafoclimáticas, espécies utilizadas na semeadura, mecanismos de quebra de dormência 
(quando necessário), tamanho da semente, condições edáficas, dinâmica da paisagem, entre outros (Palma \& Laurance 2015). Sendo assim, a utilização da semeadura direta como técnica complementar ao plantio de mudas pode proporcionar resultados mais satisfatórios, e em menor tempo, tendo em vista a recuperação estrutural e a diversidade funcional de espécies (Ceccon et al 2016; Souza \& Engel 2018).

Os poleiros artificiais (T3) foram ineficientes na recuperação da diversidade vegetal na área em foco, tendo em vista o baixo estabelecimento de mudas, e consequentemente a baixa riqueza de espécies e abundância de indivíduos $\left(0,2\right.$ ind. $\left.\mathrm{m}^{-2}\right)$. Esse resultado corrobora com estudos realizados no bioma Mata Atlântica, demonstrando eficiência limitada dessa técnica de forma isolada na recuperação de áreas degradadas (Almeida et al 2016; Iguatemy et al 2020). Apesar da comprovada utilização dos poleiros artificiais pela avifauna e da chegada de sementes, a germinação, estabelecimento e desenvolvimento de mudas é drasticamente limitado pelas condições edáficas, comprometendo a eficácia dessa técnica. Este comportamento também foi observado em projetos de restauração ecológica em outras regiões tropicais do mundo (Graham \& Page 2012; Freeman et al 2021).

Apesar disso, a presença de Trema micrantha no tratamento de poleiros artificiais é um indicador muito importante, pois é uma espécie nucleadora, pioneira de rápido crescimento em condições adversas e que apresenta uma produção precoce e contínua de sementes ortodoxas (Miranda Neto et al 2017). Além disso, a espécie possui associação com animais, principalmente à avifauna, colaborando para dispersão dos propágulos e, os eficientes mecanismos de dormência garantem alta longevidade das sementes (Martins et al 2021). Assim, a espécie desempenha um importante papel na resiliência dos ecossistemas, sendo considerada uma espécie chave para viabilizar a restauração de áreas degradadas (Miranda Neto et al 2021).

Em T4 observou-se baixa riqueza de espécies e baixa abundância de indivíduos na regeneração natural $\left(0,4\right.$ ind. $\left.\mathrm{m}^{-2}\right)$, em comparação às técnicas de transposição de solo e semeadura direta. Nesse sentido, a comparação das técnicas de restauração ativa versus passiva por meio de meta-análises é uma tendência diante das metas globais de restauração de ecossistemas (Crouzeilles et al 2017; Meli et al 2017; Reid et al 2018; Atkinson \& Bonser 2020). Assim, o sucesso de projetos de restauração ecológica em ambientes tropicais geralmente é associado à técnica de restauração passiva, por meio da regeneração natural, com enfoque na biodiversidade e a estrutura da vegetação (Crouzeilles et al 2017). 
Em contraste, Reid et al (2018) sugerem que existe um viés de seleção positivo inerente para a escolha da regeneração natural. Desse modo, apontaram incompatibilidade entre o conjunto de estudos, na maioria dos casos os estudos de restauração ativa e regeneração natural foram conduzidos em diferentes locais, dificultando assim a comparação. Além disso, os autores indicam que o preparo do solo tem relação direta com a caracterização da técnica (ativa ou passiva) e com os resultados encontrados, apesar de muitos estudos desconsiderarem essa abordagem (Meli et al 2017; Reid et al 2018; Atkinson \& Bonser 2020).

Desse modo, a escolha de estratégias de restauração em determinada área é altamente dependente do grau de degradação ambiental (Reid et al 2018; Atkinson \& Bonser 2020; Campanharo et al 2021). Nessa perspectiva, a baixa regeneração natural no tratamento controle (T4) ressalta a importância do banco de sementes da camada superficial do solo para o estabelecimento inicial de espécies pioneiras arbóreas (Balestrin et al 2019b; Martins et al 2021), banco este que foi perdido nessa área devido ao tipo de uso do solo. Além disso, a ausência da camada superficial do solo (fértil) inviabiliza a escolha da regeneração natural como técnica exclusiva para a recuperação da biodiversidade nesta área de estudo.

\subsection{Taxa de cobertura do solo}

Os tratamentos $\mathrm{T} 1$ e $\mathrm{T} 2$ foram estatisticamente superiores aos demais, nas duas análises realizadas, mostrando grande potencial para cobertura do solo e confirmando estudos realizados por Pilon et al 2018. O tratamento T3 sugere que neste caso, os poleiros artificiais contribuíram muito pouco para o aumento na riqueza de espécies e o recobrimento do solo. Além disso, a baixa cobertura do solo em T4, reforça a necessidade de implementação de técnicas que visem a proteção física do solo e o recobrimento em menor tempo.

Nessa perspectiva, a rápida cobertura do solo é essencial para o controle dos processos erosivos, tendo em vista que a erosão do solo é uma grande ameaça à viabilidade de um ecossistema (Jiang et al 2020). Em consonância, uma recente meta-análise de dados globais indica que o Brasil apresenta situação crítica, pois a perda de solo no país é superior à média global e estimada em 4 t. ha ${ }^{-1}$.ano ${ }^{-1}$, a mais que em países vizinhos (Wuepper et al 2020).

Desse modo, as médias de cobertura do solo em T1 e T2 após 3 anos de experimento foram superiores a 85\%, demonstrando que além da superioridade na recuperação da diversidade funcional e de espécies, essas técnicas foram mais eficientes na cobertura do solo, minimizando os impactos dos processos erosivos. Sendo assim, essas técnicas de nucleação apresentam potencial para o recobrimento do solo, em projetos de restauração ecológica. 
Portanto, embora os aspectos positivos da restauração ativa por meio do plantio de mudas não possam ser negligenciados, a sinergia com as técnicas de nucleação: transposição de banco de semente e serapilheira e semeadura direta, potencializa os benefícios sendo uma alternativa para a restauração ecológica de áreas no ambiente de mineração de bauxita. Cabe destacar a necessidade de adaptar essas técnicas aos múltiplos filtros ambientais regionais e às características ecológicas das paisagens de modo a aproveitar a resiliência do ambiente (Bechara et al 2016; Martins 2018; Reid et al 2018; Rojas-Botero et al 2020).

\section{CONCLUSÃO}

A semeadura direta e a transposição de solo e serapilheira se destacaram como técnicas alternativas para a restauração ecológica da área em ambiente de mineração de bauxita, devido: às contribuições na recuperação dos serviços ecossistêmicos, o aumento da diversidade funcional e de espécies e ao potencial de recobrimento do solo, em escala local. No entanto, cabe salientar que é necessário que as potencialidades do ambiente permitam esta flexibilização e que sejam adotadas ações de recuperação e conservação do solo, bem como a preservação de fragmentos florestais na paisagem, como já vem sendo realizado pela empresa.

Embora o uso de poleiros e a restauração passiva, não tenham produzido os efeitos esperados, devido ao estado de degradação do solo e, não sejam indicadas como técnicas isoladas de restauração de áreas com estas condições, podem auxiliar o processo de restauração como técnicas complementares de enriquecimento.

\section{AGRADECIMENTOS}

Os autores agradecem à Coordenação de Aperfeiçoamento de Pessoal de Nível Superior (CAPES) pela bolsa de mestrado para Wesley Fonseca, ao CNPq pela bolsa de produtividade em pesquisa do orientador prof. Sebastião V. Martins e a Companhia Brasileira de Alumínio (CBA) pela infraestrutura e apoio financeiro ao projeto.

\section{REFERÊNCIAS}

ABAL. (2017). Relatório Bauxita no Brasil - Mineração Responsável e Competitividade. 1 st ed. São Paulo: Associação Brasileira de Alumínio, 66p. 
Almeida A, Marques MC, Ceccon-Valente, MF, Vicente-Silva J, Mikich SB. (2016). Limited effectiveness of artificial bird perches for the establishment of seedlings and the restoration of Brazil's Atlantic Forest. Journal for Nature Conservation, 34, 24-32.

ANM. (2019). Brazilian Mineral Yearbook - Main Metallic Commodities 2018. 1 st ed. Brasília: National Mining Agency.

Angiosperm Phylogeny Group IV. (2016). An update of the Angiosperm Phylogeny Group classification for the orders and families of flowering plants. Bot J Linn Soc. 181:1-20.

Atkinson J \& Bonser SP. (2020). "Active" and "passive" ecological restoration strategies in meta-analysis. Restoration Ecology, 28(5), 1032-1035.

Balestrin D, Martins SV, Schoorl JM, Lopes AT, de Andrade CF. (2019a). Phytosociological study to define restoration measures in a mined area in Minas Gerais, Brazil. Ecological Engineering, 135, 8-16.

Balestrin D, Martins SV, Fonseca WS, Cosimo LHE. (2019b). Relationship between soil seed bank and canopy coverage in a mined area. Revista Árvore, 43(4):e430403

Balestrin D, Martins SV, Fonseca CA, (2020). Ecological restoration and forest coverage advancement in a region influenced by bauxite mining, Minas Gerais, Brazil. In: de Vlieger K. (Ed.). Recent advances in ecological restoration. New York: Nova Science

Publishers, 143-154.

Bechara FC, Dickens SJ, Farrer EC, Larios L, Spotswood EN, Mariotte P, \& Suding K. N. (2016). Neotropical rainforest restoration: comparing passive, plantation and nucleation approaches. Biodiversity and Conservation, 25(11), 2021-2034.

Bechara FC, Trentin BE, Engel VL, Estevan DA, \& Ticktin T. (2021). Performance and cost of applied nucleation versus high-diversity plantations for tropical forest restoration. Forest Ecology and Management, 491, 119088.

Benayas JMR, Newton AC, Diaz A, Bullock JM. (2009). Enhancement of biodiversity and ecosystem services by ecological restoration: a meta-analysis. science, 325(5944), 11211124.

Boanares D \& de Azevedo CS. (2014). The use of nucleation techniques to restore the environment: a bibliometric analysis. Natureza \& Conservação, 12(2), 93-98.

Budowski G. 1965. Distribution of tropical American Rain Forest species in the light of successional processes. Turrialba. 15:40-42.

Camargo PH, Pizo MA, Brancalion PH, Carlo TA. (2020). Fruit traits of pioneer trees structure seed dispersal across distances on tropical deforested landscapes: Implications for restoration. Journal of Applied Ecology, 57(12), 2329-2339.

Campanharo IF, Martins SV, Villa PM, Kruschewsky GC, Dias AA, \& Nabeta F. (2021). Forest restoration methods, seasonality, and penetration resistance does not influence aboveground biomass stock on mining tailings in Mariana, Brazil. Anais da Academia Brasileira de Ciências, 93(1).

Ceccon E, González EJ, Martorell C. (2016). Is direct seeding a biologically viable strategy for restoring forest ecosystems? Evidences from a Meta-analysis. Land Degradation \& Development, 27(3), 511-520. 
Corbin JD \& Holl KD. (2012). Applied nucleation as a forest restoration strategy. Forest Ecology and Management, 265, 37-46.

Corlett RT. (2017). Frugivory and seed dispersal by vertebrates in tropical and subtropical Asia: an update. Global Ecology and Conservation, 11, 1-22.

Crouzeilles R, Ferreira MS, Chazdon RL, Lindenmayer DB, Sansevero JB, Monteiro L, ... \& Strassburg BB. (2017). Ecological restoration success is higher for natural regeneration than for active restoration in tropical forests. Science advances, 3(11), e1701345.

Figueiredo MA, Messias MCTB, Leite MGP, Kozovits AR. (2021). Direct seeding in the restoration of post-mined campo rupestre: germination and establishment of 14 native species. Flora, 151772.

Freeman AN, Freebody K, Montenero M, Moran C, Shoo LP, \& Catterall CP. (2021). Enhancing bird-mediated seed dispersal to increase rainforest regeneration in disused pastureA restoration experiment. Forest Ecology and Management, 479, 118536.

Freitas MG, Rodrigues SB, Campos-Filho EM, do Carmo GHP, da Veiga JM, Junqueira RGP, \& Vieira DLM. (2019). Evaluating the success of direct seeding for tropical forest restoration over ten years. Forest ecology and management, 438, 224-232.

Gandolfi S, Leitão Filho HF, Bezerra CLF. 1995. Levantamento florístico e caráter sucessional das espécies arbustivo-arbóreas de uma floresta semidecídua no município de Guarulhos, SP. Rev Bras Biol. 55:753-767

Gann GD, McDonald T, Walder B, Aronson J, Nelson CR, Jonson J, ... \& Hua F. (2019). International principles and standards for the practice of ecological restoration. Restoration Ecology, 27, S1-S46.

Gardner CJ, Bicknell JE, Baldwin-Cantello W, Struebig MJ, \& Davies ZG. (2019). Quantifying the impacts of defaunation on natural forest regeneration in a global metaanalysis. Nature communications, 10(1), 1-7.

Graham LL \& Page SE. (2012). Artificial bird perches for the regeneration of degraded tropical peat swamp forest: a restoration tool with limited potential. Restoration Ecology, 20(5), 631-637.

Greet J, Ede F, Robertson D, \& McKendrick S. (2020). Should I plant or should I sow? Restoration outcomes compared across seven riparian revegetation projects (Vol. 21, No. 1, pp. 58-65).

Hall SL, Barton CD, Baskin CC. (2010). Topsoil seed bank of an Oak-Hickory forest in eastern Kentucky as a restoration tool on surface mines. Restoration Ecology, 18(6), 834842.

Holl KD, Reid JL, Chaves-Fallas JM, Oviedo-Brenes F, Zahawi RA. (2017). Local tropical forest restoration strategies affect tree recruitment more strongly than does landscape forest cover. Journal of Applied Ecology 54:1091-1099

IBGE. (2012). Manual Técnico da Vegetação Brasileira. 2nd ed. Manuais Técnicos em Geociências. Rio de Janeiro: Instituto Brasileiro de Geografia e Estatística.

Iguatemy MDA, Vilarinhos JA, Oda GAM, Conde MDMS, \& Zaú AS. (2020). Artificial perches: ecological and functional aspects of its contribution in the Atlantic forest. Floresta e Ambiente, 27(2). 
Jiang C, Zhao L, Dai J, Liu H, Li Z, Wang X, ... \& Wang J. (2020). Examining the soil erosion responses to ecological restoration programs and landscape drivers: A spatial econometric perspective. Journal of Arid Environments, 183, 104255.

Kamble PH \& Bhosale SM. (2019). Assessment of Impact of Bauxite Mining on Environment. i-Manager's Journal on Future Engineering and Technology. 14(4):14-21

Köppen W. (1948). Climatologia: con un estudio de los climas de la tierra. México: Fondo de Cultura Econômica.

Martins SV, Miranda Neto A, Ribeiro TM. (2015). Uma abordagem sobre diversidade e técnicas de restauração ecológica. In: Sebastião Venâncio Martins. (Org.). Restauração ecológica de ecossistemas degradados. Restauração ecológica de ecossistemas degradados. 1ed.Viçosa, MG: Editora UFV, 2015, v. 1, p. 19-41.

Martins SV. (2018). Alternative Forest Restoration Techniques. In: Viana H, editor. New Perspectives in Forest Science. 1st ed. London: IntechOpen; p. 131-148.

Martins WBR, Ferreira GC, Oliveira, FA. (2018). Deposição de serapilheira e nutrientes em áreas de mineração submetidas a métodos de restauração florestal em Paragominas, Pará. Floresta, 48(1), 37-48.

Martins SV, Cosimo LHE, Balestrin D, Fonseca WS, Andrade CF, Barros RS. (2020). Restoration of Tree and Shrub Diversity Post Bauxite Mining, in the Southeastern Region of Minas Gerais, Brazil. In: Kristian de Vlieger. (Org.). Recent Advances in Ecological Restoration. 1ed.Estados Unidos: Nova, v.1, p. 33-62.

Martins SV, Fonseca WS, Cosimo LHE, Balestrin D. (2021). Soil Seed Banks in Two Environments of Forest Restoration Post Bauxite Mining: Native Tree Plantation and Natural Regeneration. Research in Ecology, [S.1.], v. 3, n. 1, apr. ISSN 2661-3379.

Meli P, Holl KD, Rey Benayas JM, Jones HP, Jones PC, Montoya D, \& Moreno Mateos D. (2017). A global review of past land use, climate, and active vs. passive restoration effects on forest recovery. Plos one, 12(2), e0171368.

Meli P, Isernhagen I, Brancalion PH, Isernhagen EC, Behling M, \& Rodrigues RR. (2018). Optimizing seeding density of fast-growing native trees for restoring the Brazilian Atlantic Forest. Restoration Ecology, 26(2), 212-219.

Melo CES, \& Sánchez LE. (2020). Evaluation of environmental rehabilitation practices in bauxite mining at the plateau of Poços de Caldas. REM-International Engineering Journal, 73(2), 247-252.

Miller BP, Sinclair EA, Menz MH, Elliott CP, Bunn E, Commander LE, ... \& Golos PJ. (2017). A framework for the practical science necessary to restore sustainable, resilient, and biodiverse ecosystems. Restoration Ecology, 25(4), 605-617.

Miranda Neto A, Martins SV, Silva KDA, Lopes AT, \& Demolinari RDA. (2017). Banco de sementes em mina de bauxita restaurada no Sudeste do Brasil. Floresta e Ambiente, 24.

Miranda Neto A, Martins SV, Silva KDA. (2021). Soil seed banks in different environments: initial forest, mature forest, Pinus and Eucalyptus abandoned stands. Plant Biosystems-An International Journal Dealing with all Aspects of Plant Biology, 155(1), 128135. 
MME. (2020). Mineral Sector Bulletin. 2 nd ed. Ministério de Minas e Energia. Brasília: National Mining Agency

Neto AM, Kunz SH, Martins SV, Silva KDA, Silva DAD. (2010). Transposição do banco de sementes do solo como metodologia de restauração florestal de pastagem abandonada em Viçosa, MG. Revista Árvore, 34(6), 1035-1043.

Onésimo CM, Dias DD, Vale Beirão M, Kozovits AR, \& Messias MCT. (2021). Ecological succession in areas degraded by bauxite mining indicates successful use of topsoil. Restoration Ecology, 29(1), e13303.

Palma AC \& Laurance SG. (2015). A review of the use of direct seeding and seedling plantings in restoration: what do we know and where should we go?. Applied Vegetation Science, 18(4), 561-568.

Passaretti RA, Pilon NA, Durigan G. (2020). Weed control, large seeds and deep roots: Drivers of success in direct seeding for savanna restoration. Applied Vegetation Science, 23(3), 406-416.

Piaia BB, Rovedder APM, Procknow D, Camargo B, Gazzola MD, Croda JP, \& de Moraes Stefanello M. (2020). Natural regeneration as an indicator of ecological restoration by applied nucleation and passive restoration. Ecological Engineering, 157, 105991.

Pilon NAL, Buisson E, Durigan G. (2018). Restoring Brazilian savanna ground layer vegetation by topsoil and hay transfer. Restoration Ecology, 26(1), 73-81.

R Development Core Team. 2018. R: A language and environment for statistical computing. Version 3.5.1. Vienna (AT): R Foundation for Statistical Computing.

Raupp PP, Ferreira MC, Alves M, Campos-Filho EM, Sartorelli PAR, Consolaro HN, \& Vieira DLM. (2020). Direct seeding reduces the costs of tree planting for forest and savanna restoration. Ecological Engineering, 148, 105788.

Reid JL, Fagan ME, Zahawi RA. (2018). Positive site selection bias in meta-analyses comparing natural regeneration to active forest restoration. Science advances, 4(5), eaas9143.

Reis A, Bechara FC, Tres DR. (2010). Nucleation in tropical ecological restoration. Scientia Agricola, 67(2), 244-250.

Reis A, Bechara FC, Tres DR, Trentin BE. (2014). Nucleation: Biocentric conception for the ecological restoration. Ciência Florestal, 24(2):509-519.

Ribeiro RA, Giannini TC, Gastauer M, Awade M, \& Siqueira JO. (2018). Topsoil application during the rehabilitation of a manganese tailing dam increases plant taxonomic, phylogenetic and functional diversity. Journal of environmental management, 227, 386-394.

Rodrigues BD, Martins SV, Leite HG. (2010). Avaliação do potencial da transposição da serapilheira e do banco de sementes do solo para restauração florestal em áreas degradadas. Revista Árvore, 34(1), 65-73.

Rodrigues SB, Freitas MG, Campos-Filho EM, do Carmo GHP, da Veiga JM, Junqueira RGP, \& Vieira DLM. (2019). Direct seeded and colonizing species guarantee successful early restoration of South Amazon forests. Forest Ecology and Management, 451, 117559.

Rodríguez-Uña A, Cruz-Alonso V, Rohrer Z, Martínez-Baroja L. (2020). Fresh perspectives for classic forest restoration challenges. Restoration Ecology. 28(1): 12-15 
Rojas-Botero S, Solorza-Bejarano J, Kollmann J, Teixeira LH. (2020). Nucleation increases understory species and functional diversity in early tropical forest restoration. Ecological Engineering, 158, 106031.

Santos HG, Jacomine PKT, Anjos LHC, Oliveira VA, Lumbreras JF, Coelho MR, Almeida JA, Araujo Filho JC, Oliveira JB, Cunha TJF. (2018). Sistema brasileiro de classificação de solos. Brasília (DF): Embrapa.

Schmidt KT, Maltz M, Ta P, Khalili B, Weihe C, Phillips M, ... \& Kimball S. (2020). Identifying mechanisms for successful ecological restoration with salvaged topsoil in coastal sage scrub communities. Diversity, 12(4), 150.

Silva KDA, Martins SV, Miranda Neto A, Campos WH. (2015). Semeadura direta com transposição de serapilheira como metodologia de restauração ecológical. Revista Árvore, 39(5), 811-820.

Silva KDA, Martins SV, Miranda Neto A, Demolinari RDA, Lopes AT. (2016). Restauração florestal de uma mina de bauxita: avaliação do desenvolvimento das espécies arbóreas plantadas. Floresta e Ambiente, 23(3), 309-319.

Shepherd GJ. 2010. Fitopac. Version 2.1. Campinas (Brasil): Departamento de Botânica, Universidade Estadual de Campinas.

Souza DC \& Engel VL. (2018). Direct seeding reduces costs, but it is not promising for restoring tropical seasonal forests. Ecological Engineering, 116, 35-44.

Stuble, KL, Fick SE, Young TP. (2017). Every restoration is unique: testing year effects and site effects as drivers of initial restoration trajectories. Journal of Applied Ecology, 54(4), 1051-1057.

Trentin BE, Estevan DA, Rossetto EFS, Gorenstein MR, Brizola GP, \& Bechara FC. (2018). Restauração florestal na Mata Atlântica: passiva, nucleação e plantio de alta diversidade. Ciência Florestal, 28(1), 160-174.

van der Pijl L. 1982. Principles of dispersal in higher plants. 3rd ed. Berlin and New York: Springer-Verlag.

Viani RAG, Vidas NB, Pardi MM, Castro DCV, Gusson E, \& Brancalion PH. (2015). Animal-dispersed pioneer trees enhance the early regeneration in Atlantic Forest restoration plantations. Natureza \& Conservação, 13(1), 41-46.

Wuepper D, Borrelli P, Finger R. (2020). Countries and the global rate of soil erosion. Nature Sustainability, 3(1), 51-55.

Yarranton GA \& Morrison RG. (1974) Spatial dynamics of a primary succession: nucleation. Journal of Ecology, 62, 417-428. 


\section{CAPÍTULO 4 - MONITORAMENTO DE FAUNA COMO INDICADOR DE RESTAURAÇÃO ECOLÓGICA DE UMA ÁREA EM AMBIENTE DE MINERAÇÃO DE BAUXITA NA ZONA DA MATA MINEIRA}

RESUMO: A Mata Atlântica é um dos biomas tropicais mais ricos em biodiversidade, considerado hotspot global por possuir elevados índices de endemismo, alta fragmentação de habitat e por abrigar espécies ameaçadas de extinção da fauna e flora. Neste cenário, os projetos de restauração ecológica neste bioma são fundamentais para a preservação e conservação da biodiversidade. A fauna de diferentes níveis tróficos desempenha papeis fundamentais que auxiliam no restabelecimento de um ecossistema funcional, contudo a recolonização da fauna em áreas em restauração é menos estudada do que da flora. Sendo assim, este estudo teve como objetivo apresentar novas perspectivas para o monitoramento da fauna na restauração ecológica da área no ambiente de mineração de bauxita. A pesquisa foi realizada em uma área de 2 ha, na qual funcionava o setor administrativo da Companhia Brasileira de Alumínio, em Miraí, Minas Gerais, Sudeste do Brasil. Nesse local, as construções foram removidas deixando o subsolo exposto, compactado e com baixa fertilidade. O solo foi preparado com um subsolador ripper e foram plantadas mudas de espécies nativas. Em complemento, também foram implementadas técnicas alternativas de restauração, como transposição de solo e serapilheira, instalação de poleiros artificiais, semeadura direta de espécies nativas e a semeadura de adubos verdes. Três anos após o início do projeto de restauração, três armadilhas fotográficas foram instaladas para monitorar a vida selvagem (janeiro/2020 - janeiro/2021). As câmeras ficaram ativas e programadas para capturar imagens 24 horas por dia, a qualquer movimento. Além disso, foi realizado o método de busca ativa para identificação de todos os animais pertencentes às classes: Amphibia, Reptilia, Aves e Mammalia. As espécies foram classificadas de acordo com: hábitos alimentares, sociabilidade, padrão de atividade e nível de ameaça (IUCN). Foram identificadas 24 espécies de aves, 4 mamíferos, 3 répteis e 1 anfíbio. Constatou-se predomínio de espécies onívoras $(34,38 \%)$, padrão de atividade diurna $(78,1 \%)$ e comportamento gregário (50,0\%). Quanto à classificação da IUCN, destacaram-se as espécies Chrysocyon brachyurus (Lobo-guará) e Strix hylophila (Coruja-listrada) classificadas como "quase ameaçada". No que tange o comportamento das espécies no ambiente, os principais registros estão relacionados: à alimentação, forrageamento, utilização de poleiros naturais e artificiais, cuidado paternal e interações sociais através do canto. Portanto, as armadilhas fotográficas forneceram uma abordagem inovadora no contexto da restauração ecológica para avaliar a 
relação fauna-flora e aspectos da ecologia comportamental das espécies. A presença da fauna de diferentes classes, níveis tróficos e padrões de sociabilidade indica que com o avanço do processo sucessional espera-se que aumente a complexidade das interações ecológicas intraespecíficas e interespecíficas. Em complemento, as técnicas de restauração, recuperação do solo e ações de conservação realizadas pela empresa, bem como a restauração e preservação de fragmentos florestais na paisagem, têm se mostrado eficientes e desempenham um papel importante na conservação da biodiversidade regional.

Palavras-chave: Biodiversidade, Floresta Atlântica, Bioindicadores, Bauxita, Biomonitoramento, Sustentabilidade, Ecologia comportamental

ABSTRACT: The Atlantic Forest is one of the tropical biomes richest in biodiversity, considered a global hotspot for having high levels of endemism, high habitat fragmentation and for harboring endangered species of fauna and flora. In this scenario, ecological restoration projects in this biome are essential for the biodiversity preservation and conservation. The fauna of different trophic levels plays fundamental roles which help to reestablish a functional ecosystem, however the recolonization of fauna in areas which are undergoing restoration is less studied than that of flora. Therefore, this study aimed to present new perspectives for fauna monitoring in the ecological restoration of the area in the bauxite mining environment. The research was carried out in a 2 ha area, in which the administrative sector of Companhia Brasileira de Alumínio operated, in Miraí, Minas Gerais, southeastern of Brazil. In this location, the buildings were removed leaving the subsoil exposed, compacted and with low fertility. The soil was prepared with a ripper subsoiler and seedlings of native species were planted. In addition, alternative restoration techniques were also implemented, such as transposition of soil and litter, installation of artificial perches, direct sowing of native species and sowing of green manure. Three years after the start of the restoration project, three camera traps were installed to monitor wildlife (from January, 2020 to January, 2021). The cameras were active and programmed to capture images 24 hours a day, at any movement. In addition, the active search method was carried out to identify all animals belonging to the classes: Amphibia, Reptilia, Birds and Mammalia. The species were classified according to eating habits, sociability, activity pattern and threat level (IUCN). 24 species of birds, 4 mammals, 3 reptiles and 1 amphibian were identified. There was a predominance of omnivorous species (34.38\%), daytime activity pattern $(78.1 \%)$ and gregarious behavior (50.0\%). As for the IUCN classification, the species Chrysocyon 
brachyurus (maned wolf) and Strix hylophila (striped owl) were classified as "near threatened". Regarding the behavior of species in the environment, the main records are related to feeding, foraging, use of natural and artificial perches, paternal care and social interactions through singing. Therefore, camera traps provided an innovative approach in the context of ecological restoration to assess the fauna-floral relationship and aspects of the species' behavioral ecology. The presence of fauna from different classes, trophic levels and sociability patterns indicates that with the advancement of the succession process it is expected that the complexity of intraspecific and interspecific ecological interactions will increase. In addition, the restoration techniques, soil recovery and conservation actions carried out by the company, as well as the restoration and preservation of forest fragments in the landscape, have proven to be efficient and play an important role in the conservation of regional biodiversity.

Keywords: Biodiversity, Atlantic Forest, Bioindicators, Bauxite, Biomonitoring, Sustainability, Behavioral ecology

\section{INTRODUÇÃO}

A Mata Atlântica é um dos biomas tropicais mais ricos em biodiversidade e mais ameaçados do mundo sendo considerado hotspot global por possuir elevados índices de endemismo e alta fragmentação do habitat (Rezende et al 2018). Nessa perspectiva, os sucessivos impactos da expansão agrícola, urbanização e industrialização causaram uma redução drástica da cobertura vegetal natural (Zachos e Habel 2011; Nanni et al 2019). Por conseguinte, a Mata Atlântica é considerada área prioritária para conservação, visto que a perda e fragmentação do habitat são as principais ameaças à biodiversidade em todo o mundo (Maxwell et al 2016; Püttker et al 2020; Strassburg et al 2020).

Este domínio fitogeográfico possui grande relevância para o Brasil, além de abrigar espécies ameaçadas de extinção da fauna e flora, é o lar de mais de 125 milhões de brasileiros, destacando o bioma Mata Atlântica também no âmbito econômico pela contribuição em 70\% do Produto Interno Bruto Nacional (PIB) (Scarano \& Ceotto 2015; Rezende et al 2018).

Nesse cenário, a mineração de bauxita é uma das atividades industriais que contribui para o desenvolvimento socioeconômico do país, devido a geração de empregos diretos e indiretos para a comunidade local e influência no Índice de Desenvolvimento Humano Municipal (IDH-M) (ANM 2019). Contudo, a mineração de bauxita provoca impactos 
pontuais, que não ocupam grandes extensões territoriais como agricultura e pecuária (Barros et al. 2012; Kamble \& Bhosale 2019; Balestrin et al 2020). Desse modo, para que a mineração seja sustentável são necessárias ações de restauração nas áreas direta e indiretamente afetadas (Martins et al 2020; Balestrin et al 2020).

Nessa perspectiva, a demanda global pela conversão de paisagens degradadas ou alteradas à ecossistemas resilientes ressalta a importância da restauração ecológica como uma ferramenta essencial contra a crise contemporânea da biodiversidade (Miller et al 2017; Gann et al 2019; Brancalion et al 2019; Bastin et a 2019). Desse modo, o período de 2021-2030 foi reconhecido pela ONU como a Década das Nações Unidas de Restauração de Ecossistemas, visando combater as mudanças climáticas, melhorar a segurança alimentar, a conservação da biodiversidade e fornecimento de água (UNGA 2019).

Sendo assim, é importante que o processo de restauração ecológica vise o restabelecimento das estruturas naturais e dos processos internos, garantindo estabilidade no longo prazo e que seja autossustentável, de modo a equilibrar as relações funcionais entre fauna e flora (Gann et al 2019).

Neste contexto, a efetividade de um projeto de restauração ecológica geralmente é baseada em indicadores de avaliação e monitoramento (Brancalion et al 2015). Entretanto, para que este processo seja mais eficaz são necessários avanços tecnológicos, com novas abordagens de gerenciamento afim de expandir a capacidade de avaliar o desempenho da restauração ecológica em escalas temporais e espaciais, de modo a contemplar indicadores da vegetação e também indicadores de fauna (Cross et al 2019a; Almeida et al 2020; Bessone et al 2020).

Existem evidências que comprovam que a fauna de diferentes níveis tróficos desempenha papeis cruciais para restaurar o equilíbrio do ecossistema (Ritchie et al 2017; Cross et al 2019b), principalmente no que tange a funcionalidade e a diversidade (Gagic et al 2015). Entretanto, historicamente a fauna tem sido negligenciada, visto que a maioria dos projetos de restauração ecológica tem sua abordagem baseada na flora (Cristescu et al 2012; Cross et al 2019b), com ênfase na estrutura da vegetação, estudos fitossociológicos e em parâmetros edáficos (McAlpine et al. 2016; Holl 2017; Viani et al 2018; Balestrin et al 2019a; Heringer et al 2020). 
Assim sendo, a fauna é um importante bioindicador da restauração ecológica, tendo em vista que a funcionalidade do ecossistema está intimamente relacionada à diversidade de fauna (Gagic et al 2015; Cross et al 2019b). Nessa perspectiva, os estudos comportamentais podem contribuir para uma melhor compreensão das relações fauna-flora (Burton et al 2015); comportamento reprodutivo das espécies (Berger-Tal et al 2011); dispersão (Delisle et al 2021) e principais atividades desempenhadas no ambiente (Hale et al 2020). Além disso, através de respostas individuais e em grupos da fauna, esses estudos permitem avaliar a efetividade das técnicas de restauração utilizadas (Caravaggi et al 2017; Hale et al 2020).

Diante disso, avaliar o comportamento animal sem o viés do pesquisador é um grande desafio (Caravaggi et al 2017; Luciano et al 2020). Dessa forma, as armadilhas fotográficas se destacam como importantes ferramentas para o monitoramento de fauna, visto que oferecem abordagens inovadoras para a obtenção de distribuição, estrutura e comportamento da comunidade de espécies de modo econômico e de forma minimamente invasiva (Rovero \& Zimmermann, 2016; Bessone et al 2020). Assim, este estudo tem como objetivo apresentar novas perspectivas para o monitoramento da restauração ecológica de uma área no ambiente de mineração de bauxita, na Mata Atlântica, através do uso de armadilhas fotográficas.

\section{MATERIAIS E MÉTODOS}

\subsection{Caracterização da área de estudo}

O estudo foi realizado no município de Miraí $\left(21^{\circ} 4^{\prime} 5^{\prime \prime} \mathrm{S}\right.$ e $\left.42^{\circ} 33^{\prime} 28^{\prime \prime} \mathrm{W}\right)$ localizado na região denominada Zona da Mata, no Sudeste do Estado de Minas Gerais, Brasil (Figura 41). A área de estudo tem 2 ha e altitude de $715 \mathrm{~m}$, e até o ano 2016 era destinada ao setor administrativo da Companhia Brasileira de Alumínio - CBA. 
Figura 4-1. Localização da área de estudo, Miraí - MG, Brasil

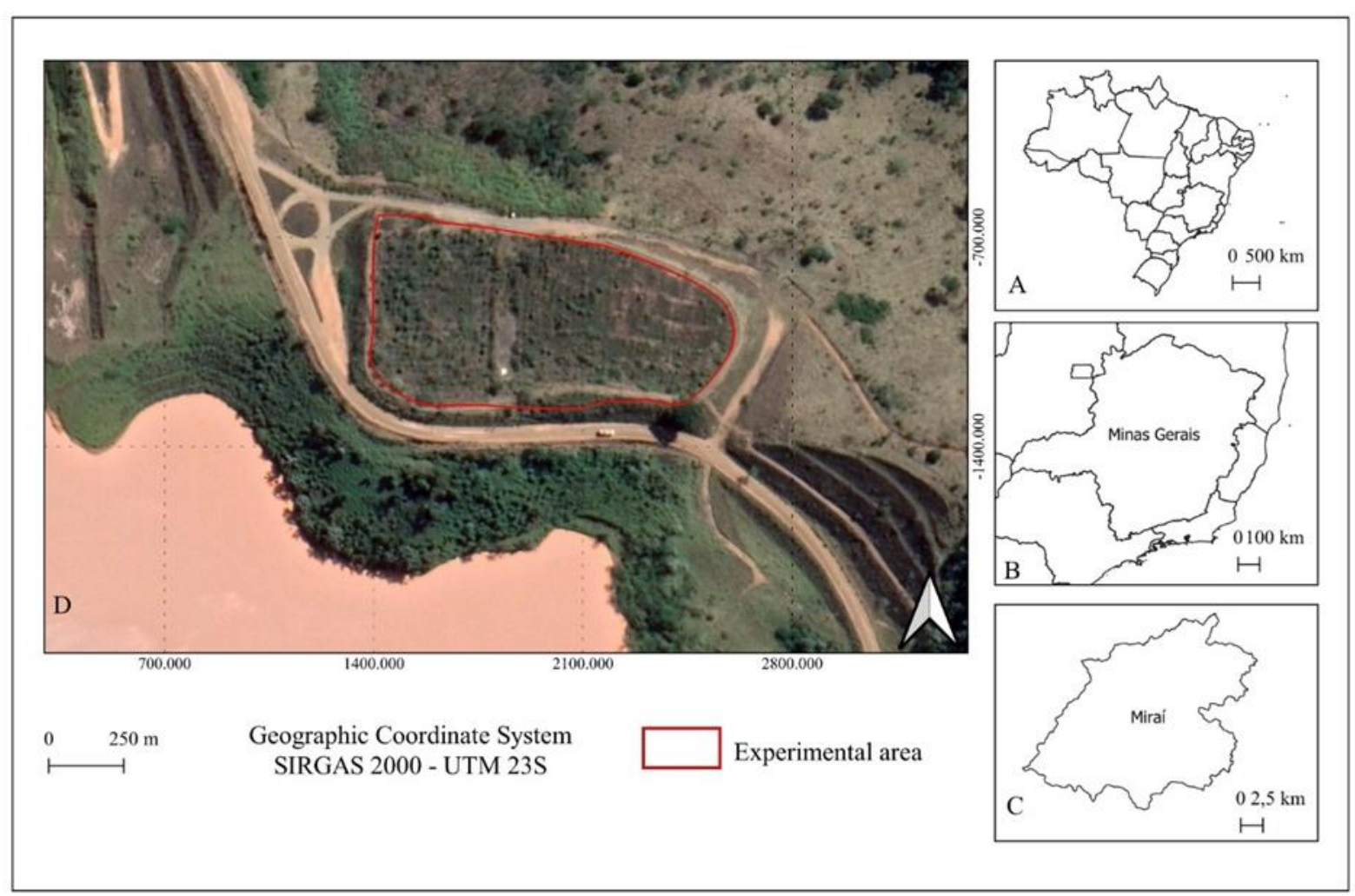

A classificação climática da região é do tipo Cwa, clima temperado úmido com inverno seco e verão quente (Köppen 1948). De acordo com o Sistema Brasileiro de Classificação de Solos, o solo predominante na região é o Latossolo Vermelho-Amarelo distrófico típico (Santos et al 2018). A vegetação característica da região é classificada como Floresta Estacional Semidecidual Montana, inserida no Domínio Floresta Atlântica (IBGE 2012)

Devido a mudança do setor administrativo da empresa, todas as construções foram removidas deixando o subsolo exposto, compactado e de baixa fertilidade. Esta área de estudo foi incluída no programa de compensação ambiental da empresa pela mineração de bauxita.

Desse modo, foi realizado o preparo do solo através de um subsolador ripper, o plantio de mudas de espécies nativas e o cercamento da área. Em complemento, também foram implantadas técnicas alternativas de restauração, como transposição de solo e serapilheira, instalação de poleiros de bambu, semeadura direta de espécies nativas da Mata Atlântica e a semeadura de adubos verdes. 


\subsection{Procedimentos de campo e processamento dos dados}

Foram instaladas 3 câmeras scouting digital (Bushnell Trophy Cam HD Aggressor) para o monitoramento contínuo da fauna. As câmeras estavam ativas e programadas para fotografar e filmar $24 \mathrm{~h} /$ dia e com o sensor de sensibilidade no modo "high", para aumentar a sensibilidade do infravermelho e registrar movimentos da fauna em qualquer gatilho. A cada 15 dias, os registros fotográficos foram transferidos para um computador e analisados. Em complemento, foram realizadas buscas ativas para o registro dos animais do filo chordata presentes na área em processo de restauração.

Os dados das armadilhas fotográficas foram coletados entre janeiro de 2020 e janeiro de 2021, de modo a realizar um inventário da biodiversidade em área no ambiente da mineração de bauxita. Para evitar perturbações e interferências causadas pela passagem de equipes de campo e veículos, as câmeras foram sistematicamente posicionadas a $50 \mathrm{~m}$ da borda da área e orientadas a $0,3 \mathrm{~m}$ acima do solo.

Os registros fotográficos e vídeos das câmeras de monitoramento foram analisados minuciosamente de modo a identificar quaisquer movimentos e/ou vocalização da fauna. Os animais foram classificados nas classes: Amphibia, Reptilia, Aves e Mammalia.

\subsection{Classificação das espécies}

Quanto ao hábito alimentar, as espécies foram classificadas em: insetívoros (Ins), dieta composta principalmente por insetos e outros artrópodes; onívoros (Oni), por insetos, artrópodes e frutos; frugívoros (Fru), por frutos; granívoros (Gra) por grãos e/ou sementes; carnívoros (Car): por vertebrados vivos e detritívoros (Det): por matéria orgânica em decomposição. Algumas espécies foram classificadas em Fru/Gra, com dieta alimentar composta por frutas e grãos e Fru/Ins, por frutas e insetos.

O status de conservação da espécie foi classificado de acordo com os critérios propostos pela International Union for Conservation of Nature - IUCN, em Least Concern LC (baixo risco ou pouco preocupante) e em Near Threatened - NT (para as espécies quase ameaçadas). Em complemento, as espécies foram classificadas de acordo com a tendência populacional, por meio dos símbolos: $\downarrow$ (decrescente); - (estável); $\uparrow$ (crescente) e Nc (Não classificadas ou desconhecido). No que tange a sociabilidade e o comportamento no ambiente, as espécies foram classificadas em: gregária $(\mathrm{G})$, solitária $(\mathrm{S})$, ou em pares (P). Além disso as espécies foram classificadas conforme o seu padrão de atividade em: diurnas (D), noturnas (N) ou crepuscular/noturno $(\mathrm{C} / \mathrm{N})$. 


\section{RESULTADOS}

No levantamento da fauna realizado por meio de armadilhas fotográficas e busca ativa entre Jan/2020 a Jan/2021 na área em processo de restauração ecológica, foram registradas 32 espécies de animais, pertencentes a 21 famílias, sendo 24 espécies de aves, 4 mamíferos, 3 répteis e 1 anfíbio (Tabela 4-1).

Tabela 4-1. Lista de espécies da fauna, presentes na área em restauração ecológica, no ambiente de mineração de bauxita, em Miraí-MG, Brasil

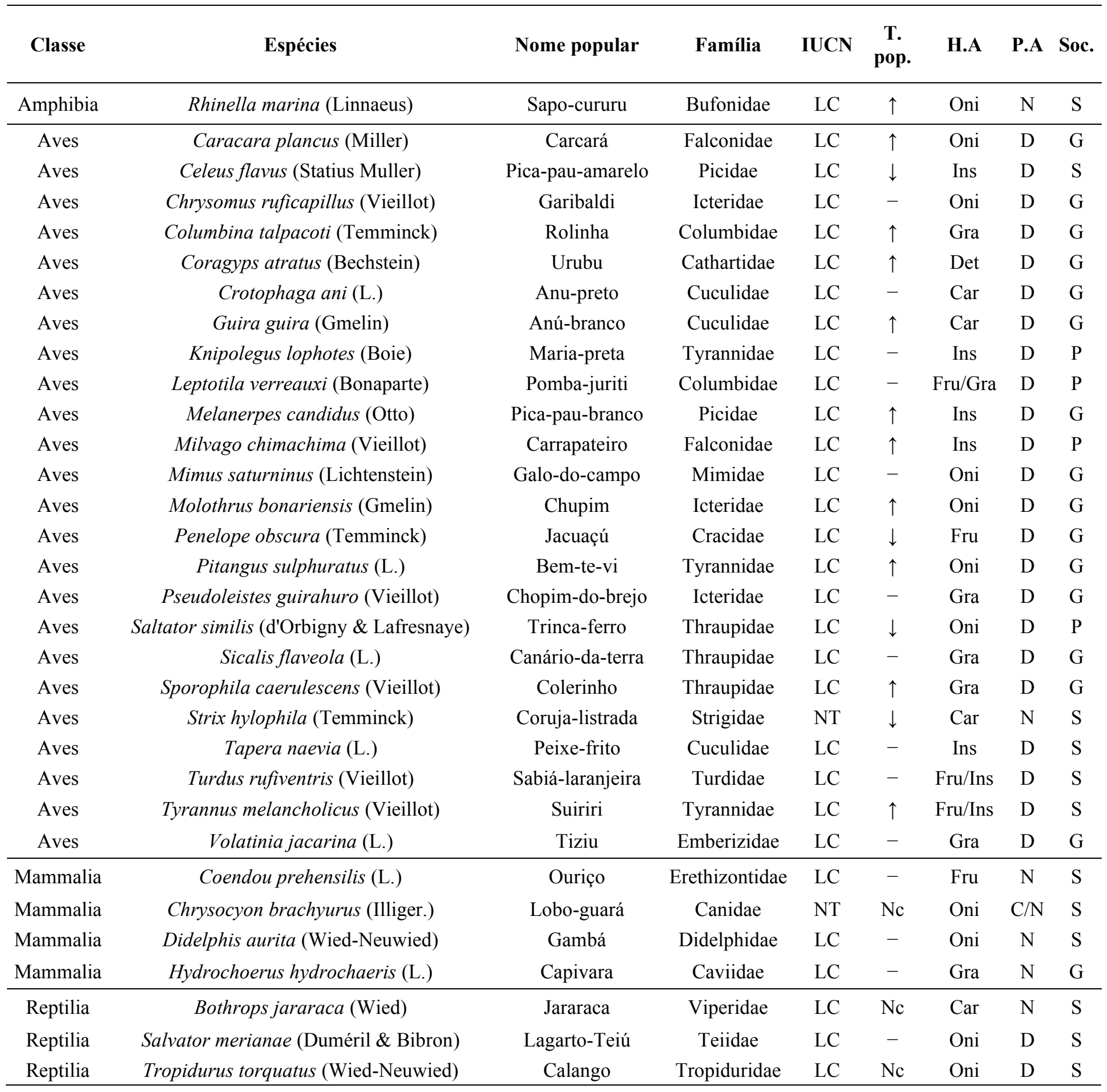


IUCN: International Union for Conservation of Nature (LC: Least Concern, NT: Near Threatened); T.pop: Tendência populacional ( $\downarrow$ decrescente, - estável, $\uparrow$ crescente, Nc: Não classificado ou Desconhecido); H.A: Hábito alimentar (Ins: insetívoros, Oni: onívoros, Fru: frugívoros, Gra: granívoros, Car: carnívoros, Det: detritívoros, Fru/Ins: frugívoro/insetívoro, Fru/Gra: frugívoro/granívoro) P.A: Padrão de atividade em (D: diurno, N: noturno, C/N: crepuscular/noturno) e Soc.: Sociabilidade (G: gregária, S: solitária, P: em pares).

De acordo com a tabela 4-1, houve predominância da classe Aves, sendo responsável por $75 \%$ das espécies encontradas neste levantamento. Quanto às famílias, as mais representativas dessa classe foram: Icteridae e Thraupidae, ambas com 3 espécies cada.

Quanto ao hábito alimentar, destacaram-se as espécies onívoras $(34,38 \%)$, ou seja, espécies que apresentam dieta alimentar diversificada com capacidade de metabolizar alimentos de origem animal e vegetal. Em sequência as espécies: granívoras (18,75\%); insetívoras $(15,63 \%)$; carnívoras $(12,50 \%)$; frugívoras $(6,25 \%)$; frugívoras/insetívoras $(6,25 \%)$; frugívoras/granívoras $(3,13 \%)$ e detritívoras $(3,13 \%)$.

No que concerne à sociabilidade, as espécies gregárias (50\%) foram as mais representativas, ou seja, animais que vivem em bandos ou em grupos. Em seguida, as espécies com comportamento solitário $(37,5 \%)$ e àquelas que apresentam organização social em pares $(12,5 \%)$.

Quanto ao padrão de atividade, houve predominância de espécies diurnas (78,13\%), principalmente pela contribuição da avifauna, tendo em vista que a maior parte das aves geralmente apresenta atividade diurna. Em complemento, as espécies noturnas representaram $18,75 \%$ do total de espécies e 3,13\% foram classificadas com padrão crepuscular/noturno, ou seja, que são primariamente ativas durante o crepúsculo (amanhecer e no anoitecer).

De acordo com a Lista vermelha de espécies ameaçadas da IUCN, 93,75\% das espécies neste monitoramento foram classificadas como não ameaçadas (LC). Apesar desta classificação, é observada uma tendência decrescente no Sudeste do Brasil nas populações das espécies: Celeus flavus Statius Muller (Pica-pau amarelo), Penelope obscura Temminck (Jacuaçú), Saltator similis d'Orbigny \& Lafresnaye (Trinca-ferro).

Além disso, cabe destacar que as espécies Chrysocyon brachyurus Illiger. (Loboguará) e Strix hylophila Temminck (Coruja-listrada) apresentaram status de conservação "quase ameaçadas" (NT) (Figura 4-2). Sendo assim, apesar da área em restauração apresentar 
estágio sucessional inicial (4 anos), ela já está colaborando para a preservação e conservação de espécies com certo grau de ameaça e/ou com taxa populacional decrescente.

Figura 4-2. Registro das armadilhas fotográficas de espécies "quase ameaçadas" de extinção segundo IUCN: A) Chrysocyon brachyurus Illiger. (Lobo-guará) e B) Strix hylophila Temminck (Coruja-listrada).
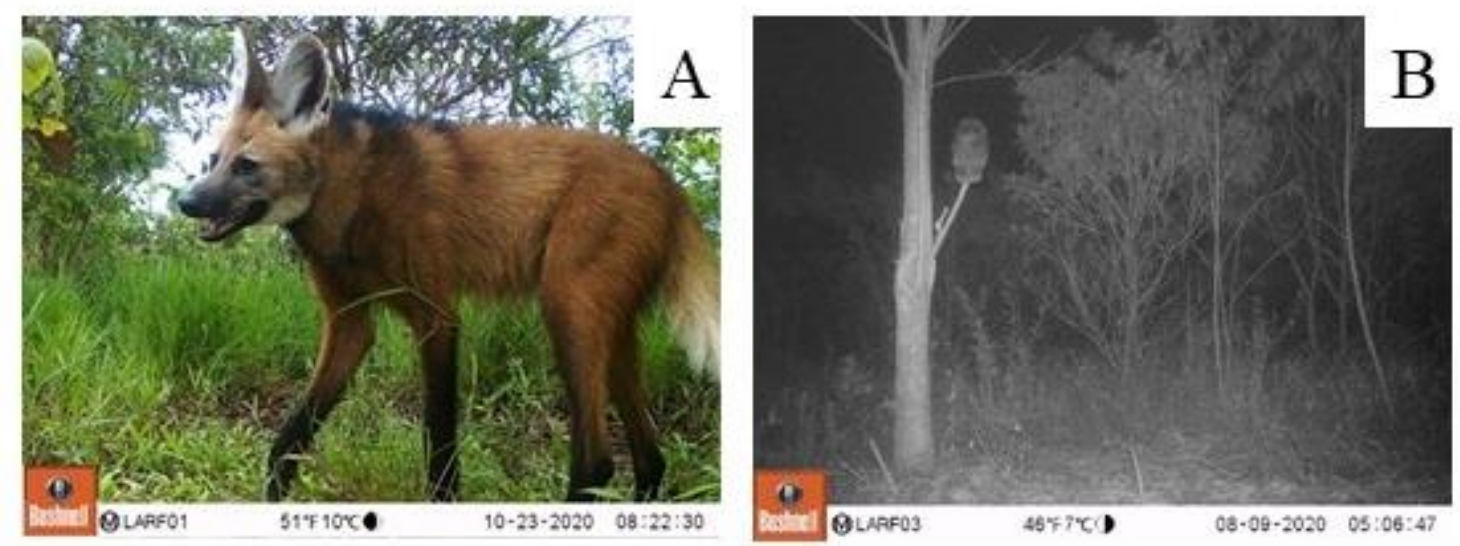

Assim, é importante identificar o papel ecológico e funcional das espécies no ambiente, bem como as inter-relações entre fauna-flora. Nesse cenário, destacam-se a espécie Penelope obscura (Jacuaçú), uma ave galliforme da família Cracidae e Coendou prehensilis (Ouriço), um roedor arborícola da família Erethizontidae. Ambas espécies são frugívoras e desempenham funções importantes para a dinâmica sucessional da área através da dispersão de sementes (Figura 4-3).

Figura 4-3. Registro das armadilhas fotográficas das espécies frugívoras: A) Penelope obscura Temminck (Jacuaçú) e B) Coendou prehensilis (Ouriço).
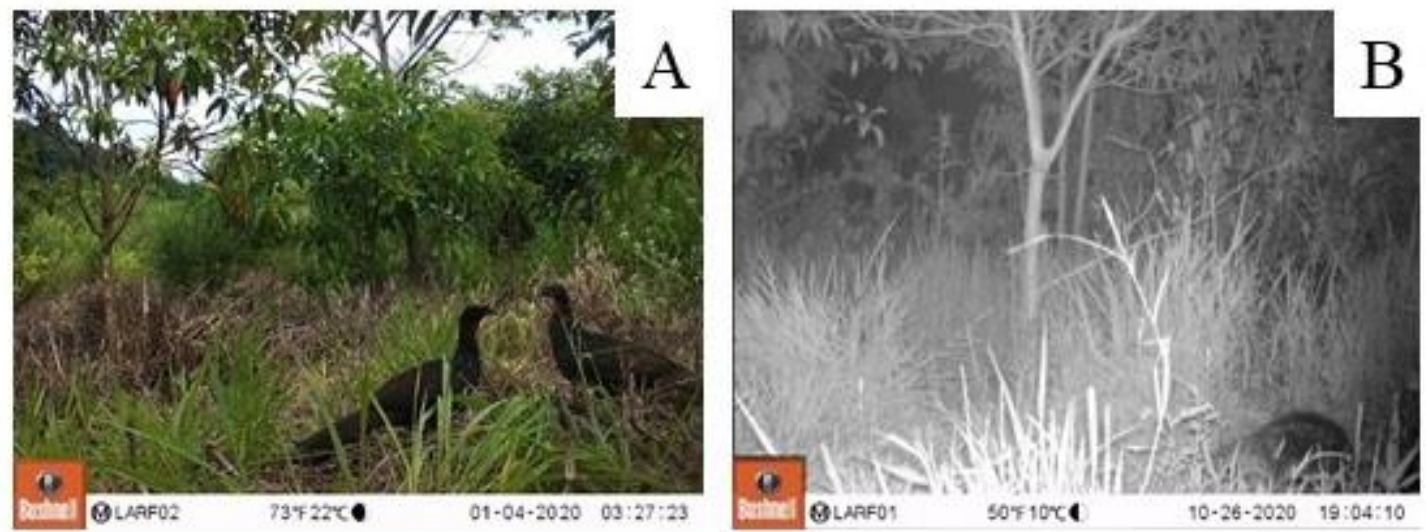

Em suma, o monitoramento por meio de câmeras digitais e pelo método de busca ativa possibilitaram verificar que as espécies estabeleceram diversas interações no ambiente. Os registros mais frequentes foram relacionados com: 
- Alimentação nas espécies (Penelope obscura, Coragyps atratus, Leptotila verreauxi, Chrysocyon brachyurus, Didelphis aurita, Celeus flavus, Caracara plancus, Milvago chimachima ; (Figura 4-4)

- Regulação térmica corporal (Tropidurus torquatus);

- Estratégia de caça (Caracara plancus);

- Reprodução e cuidado paternal (P. obscura);

- Interações sociais através do canto (Pitangus sulphuratus, Tapera naevia, Crotophaga ani,

- Utilização de poleiros naturais: Crotophaga ani, Strix hylophila (Figura 2B)

- Utilização de poleiros artificiais: Columbina talpacoti, Crotophaga ani, Pseudoleistes guirahuro, Tyrannus melancholicus, Sicalis flaveola, Knipolegus lophotes (Figura 4$5)$;

- Presença em áreas úmidas: Rhinella marina;

- Forrageamento (Chrysomus ruficapillus, Columbina talpacoti, Sicalis flaveola, Turdus rufiventris, Salvator merianae, Coendou prehensilis), entre outras.

Figura 4-4. Alimentação A) Celeus flavus se alimentando de insetos do tronco e B) Didelphis aurita se alimentando de grãos e frutos.
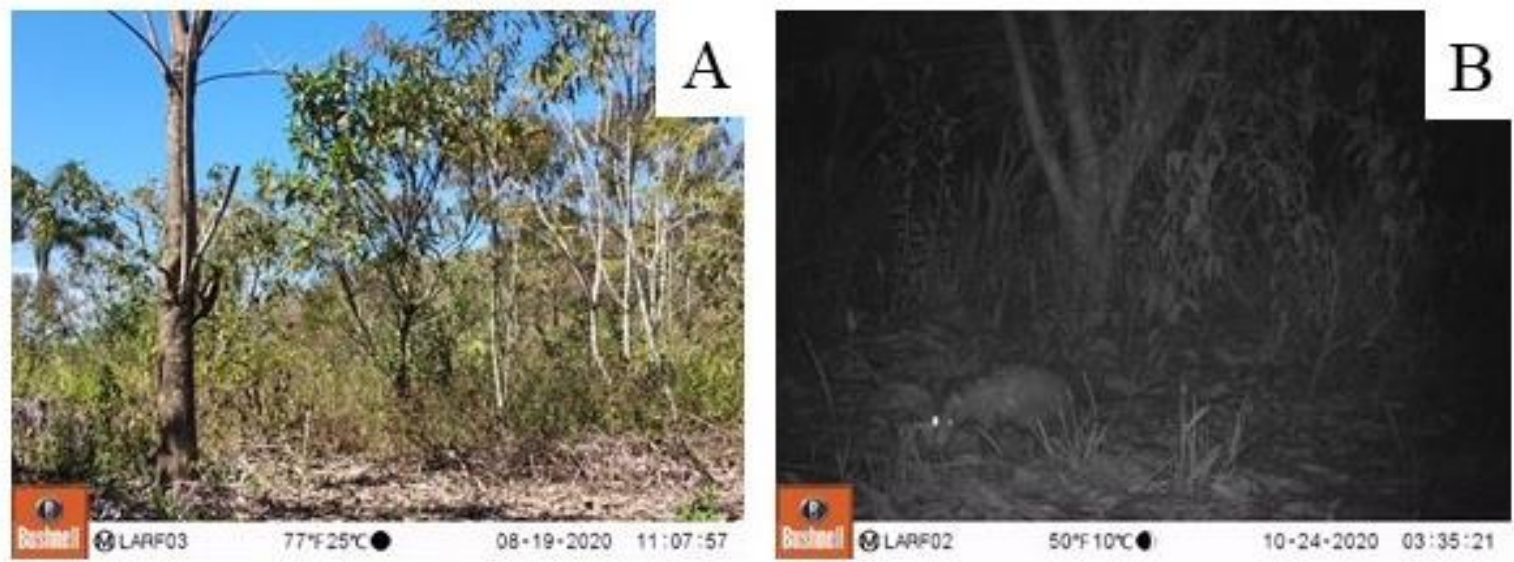
Figura 4-5. Utilização de poleiros artificiais por Sicalis flaveola (A) e Knipolegus lophotes (B)
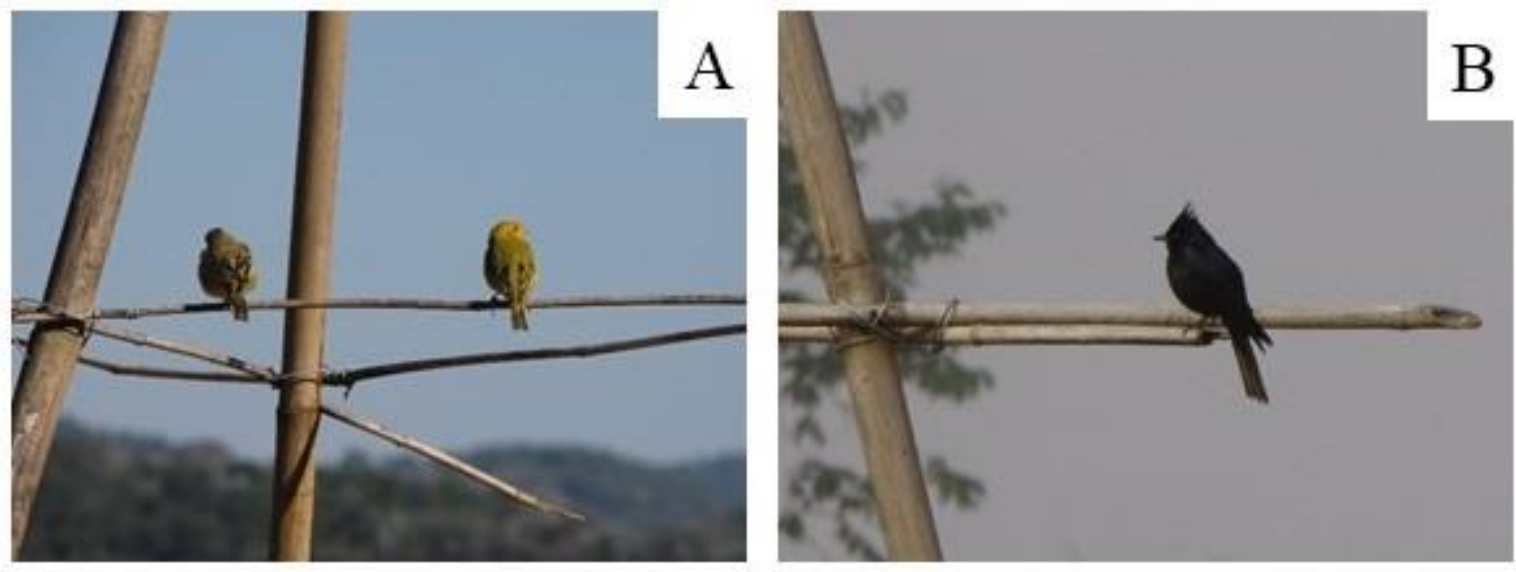

Figura 4-6. Forrageamento de Turdus rufiventris (A) e interações interespecíficas em Molothrus bonariensis (B)
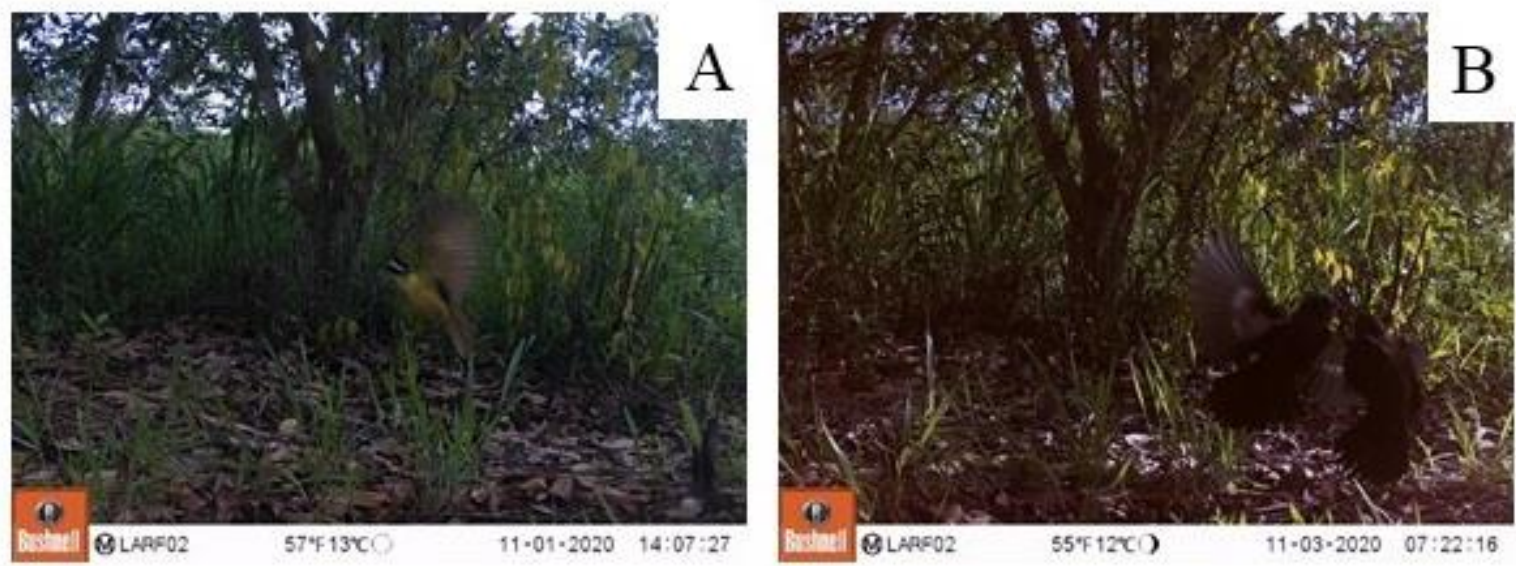

\section{DISCUSSÃO}

O monitoramento da fauna na área em ambiente da mineração de bauxita é fundamental para conhecer a composição e estrutura de comunidades faunísticas, atender às exigências da legislação, além de ser uma ferramenta para verificar a efetividade do projeto de restauração realizado (Almeida et al 2020). Nesse sentido, as armadilhas fotográficas ofereceram uma abordagem inovadora no contexto da restauração ecológica, de modo a permitir o monitoramento contínuo da fauna, e também possibilitaram verificar a distribuição e o comportamento das espécies no ambiente a fim de elucidar as relações fauna-flora (Bessone et al 2020). 
Nesta abordagem, as armadilhas fotográficas se destacaram pois são acionadas por sensores infravermelhos, programados para capturar imagens e vídeos a quaisquer gatilhos e/ou diferenças de temperatura. Ademais, os registros em formato de vídeo com dados de comportamento e interações possibilitaram um estudo da história natural das espécies, algo que seria difícil observar diretamente no campo devido a interferência do pesquisador (Luciano et al 2020). Dessa forma, proporcionam um monitoramento de forma não invasiva, igualmente eficiente na coleta de dados diurnos e noturnos, robusta à variação nas condições edafoclimáticas, além disso, as armadilhas fotográficas podem ser utilizadas para obter informações em locais com limitações de acesso.

A predominância de espécies onívoras é um indicador importante, tendo em vista que esse grupo estabelece diversas relações ecológicas no ecossistema e no que tange à teia alimentar, os onívoros destacam-se por ocupar diferentes níveis tróficos (Loch et al 2020). Dessa maneira, apresentam uma grande vantagem ecológica e possuem maiores probabilidades de sobrevivência, em comparação aos demais grupos, pois possuem adaptações que permitem metabolizar alimentos de origem animal e vegetal. Em suma, a plasticidade alimentar das espécies onívoras promove aumento da complexidade de interações no ambiente (Cross et al 2019b).

Nesse sentido, a maior abundância de espécies com alimentação generalista corrobora com o verificado por Volpato et al (2010), em estudo da avifauna conduzido no Sul do Brasil. Desse modo, as espécies menos especializadas no que tange à alimentação são eficientes na colonização de habitats fragmentados e degradados, e além disso, colaboram quantitativamente na dispersão de sementes e, consequentemente favorecem o processo de restauração (Vogel et al 2015).

Nessa perspectiva, a presença de guildas tróficas granívoras, insetívoras, carnívoras, frugívoras e detritívoras demostra que a área em processo de restauração ecológica apresenta variabilidade na oferta de alimentos. Dentre essas guildas, as espécies frugívoras desempenham papel fundamental na dispersão de sementes e na manutenção da diversidade vegetal (Volpato et al 2018a).

De acordo com Vasconcellos-Neto et al (2015), dentre as aves dispersoras de sementes, as pertencentes à família Cracidae se destacam pelo grande tamanho dos indivíduos $(42-95 \mathrm{~cm})$, e pela contribuição para a regeneração da floresta. Devido ao maior porte dos indivíduos, os cracídeos conseguem se alimentar de frutos maiores e assim contribuir para a 
dispersão de sementes de diversas espécies arbóreas e na cadeia alimentar são fonte de alimento para animais carnívoros. Além disso, são considerados indicadores ecológicos, pois são sensíveis às alterações dos habitats (Brooks 2006).

Nesse sentido, a presença do cracídeo Penelope obscura na área em processo de restauração é um indicador importante, visto que esta espécie é comumente encontrada em habitat florestal e atualmente apresenta uma tendência decrescente na população (IUCN 2021). Assim, essa espécie de ave é um componente-chave para a regulação das comunidades de plantas, principalmente pela capacidade de dispersar grandes quantidades de sementes, outrossim, a espécie não apresenta moela (estrutura do sistema digestivo responsável por triturar os alimentos), ou seja, é um frugívoro típico e não danifica a semente (Brooks 2006).

Em consonância, os registros das armadilhas fotográficas (fotos e vídeos) comprovam que $P$. obscura está se adaptando bem às condições do ambiente em restauração, tendo em vista às inúmeras vezes em que a espécie foi registrada forrageando ou se alimentando de frutos. Além disso, os registros permitiram confirmar o comportamento monogâmico desta espécie e a relação entre pais e filhotes no momento da alimentação. Tais aspectos da ecologia comportamental das espécies é essencial para avaliar a eficácia das técnicas de restauração da funcionalidade do ecossistema (Caravaggi et al 2017; Fontúrbel et al 2021).

Ademais, em relação às espécies frugívoras, os registros possibilitaram a identificação de Coendou prehensilis, um roedor arborícola, notívago e que apresenta comportamento solitário. De acordo com Rocha et al (2015), os mamíferos silvestres da família Erethizontidae colonizam áreas em estágio de sucessão secundária inicial e áreas secundárias tardias.

Contudo, o declínio das populações de espécies frugívoras apresenta uma grande ameaça à biodiversidade, principalmente em regiões neotropicais devido à fragmentação de habitats (Püttker et al 2020). Desse modo, a limitação da dispersão de sementes interfere negativamente na trajetória de restauração, especialmente devido à alteração na composição florística, beneficiando espécies de plantas com dispersão abiótica (Silva et al 2020; Rigacci et al 2021). Sendo assim, os projetos de restauração ecológica são fundamentais para a preservação e conservação de espécies frugívoras.

O predomínio de espécies com padrão de atividade diurno $(78,13 \%)$ e de espécies com comportamento gregário (50\%) se deve principalmente ao maior número de espécies da classe aves. As aves apresentam maior atividade nas primeiras horas da manhã e no final da tarde, ou seja, geralmente a busca por alimentos e a vocalização são realizadas em períodos com 
temperatura mais amena do dia, conforme observado por Fontúrbel et al (2021), em estudos sobre o padrão de atividades de aves, por meio de armadilhas fotográficas.

Em relação ao comportamento social, as espécies gregárias apresentam algumas vantagens devido às interações intraespecíficas como: maior proteção contra predadores, menor probabilidade de predação, maior área de forrageamento, otimização na busca por alimento e facilidade nas interações sociais para reprodução (Hoehne et al 2017; Tucker 2020). Em contrapartida, a organização social em grupos também apresenta algumas desvantagens, principalmente relacionadas à competição pelos mesmos recursos, manutenção da coordenação e tomada de decisões no grupo (Papageorgiou \& Farine 2020).

Desse modo, a observância de aspectos da ecologia comportamental de espécies é fundamental, visto que a fauna desempenha importantes funções em muitos processos ecológicos (Rovero \& Zimmermann, 2016; Caravaggi et al 2017; Cross et al 2019b; Fontúrbel et al 2021). Assim, a melhor compreensão destes processos permite determinar o estágio em que espécies faunísticas recolonizam a área em processo de restauração. De acordo com Nichols \& Nichols (2003), os mamíferos generalistas e as aves foram as primeiras a recolonizar uma área reabilitada, após mineração de bauxita no sudoeste da Austrália.

Neste estudo, após 4 anos da implantação de técnicas de restauração foram registradas 24 espécies de aves. Em estudos da avifauna conduzidos em áreas em processo de restauração pós-mineração de bauxita nessa mesma região foram encontrados maiores valores: 42 espécies de aves após 5 anos de restauração e 53 espécies em área com 12 anos de restauração (Volpato et al 2018b). Contudo, cabe destacar que nestes dois estudos a área minerada e restaurada estava pareada com fragmento florestal em estágio médio de sucessão, já na área do presente estudo, embora existam fragmentos florestais na paisagem, estes não estão no seu entorno. Sendo assim é possível perceber que a composição de aves é diretamente influenciada pela estrutura da paisagem, proximidade de florestas remanescentes e tempo de desenvolvimento da vegetação.

Nessa perspectiva, as aves são consideradas importantes bioindicadores no estágio inicial do processo de restauração ecológica, principalmente devido às diversas estratégias adaptativas, que incluem variação na dieta e estratégias especializadas de forrageamento, que permitem que este grupo recolonize precocemente o ambiente em restauração (Volpato et al 2018a; Roels et al 2019; Chowfin \& Leslie 2021). 
No que tange à mastofauna, além de Coendou prehensilis, foram registradas as espécies Chrysocyon brachyurus, Didelphis aurita e Hydrochoerus hydrochaeris, pertencentes às famílias Canidae, Didelphidae e Caviidae, respectivamente. Segundo Rocha et al (2015), os mamíferos pertencentes à essas famílias tendem a colonizar o ambiente em estágios iniciais de sucessão e permanecerem até estágios mais avançados.

Nesse sentido, cabe destacar que a colonização de mamíferos em uma área é determinada principalmente pela capacidade de dispersão e mobilidade do animal (Rocha et al 2015). Desse modo, a riqueza e a diversidade de espécies de mamíferos possuem uma forte relação com o tamanho da área, integridade do ambiente, grau de isolamento e fitofisionomia (Morcatty et al 2013; Magioli et al 2021).

Diante dessa estreita relação espécie-área, a perda de habitat e fragmentação são as principais ameaças para os mamíferos (Rios et al 2021). Desse modo, os projetos de restauração ecológica têm potencial para conectar fragmentos e permitir a continuidade do fluxo gênico entre as espécies e consequentemente impedir a defaunação de mamíferos na Mata Atlântica (Morcatty et al 2013; Bogoni et al 2020; Marjakangas et al 2020; Galetti et al 2021; Rios et al 2021) e em áreas de mineração (Nichols \& Grant 2007; Lawer et al 2019).

Dentre os vertebrados terrestres, os anfíbios apresentam o maior nível de ameaça, e em regiões neotropicais, o estado de conservação é ainda mais crítico (IUCN 2021). Desse modo, a restauração ecológica de áreas nessas regiões pode contribuir para a recuperação e conservação de anfíbios (Díaz-García et al 2020), visto que o restabelecimento da cobertura vegetal e da estrutura pode melhor as condições para a restabelecimento deste grupo (Thompson e Donnelly, 2018). Assim, os anfíbios geralmente tendem a retornar para a área à medida que as condições ambientais relacionadas à cobertura do dossel, temperatura e umidade estejam em padrões adequados para estas espécies (Thompson e Donnelly, 2018).

Cabe destacar que apesar da área em estudo apresentar estágio inicial de sucessão, foi verificada a presença de Rhinella marina Linnaeus, um anfíbio pertencente à família Bufonidae. Desse modo, é possível afirmar que na área em restauração existem micro-habitats favoráveis ao estabelecimento desta classe, sejam relacionados à oferta de alimento e/ou aos aspectos edafoclimáticos.

Em consonância, os répteis também apresentam maiores exigências quanto a condições e recursos do ambiente. Nesse monitoramento foram registradas as espécies: Salvator merianae Duméril \& Bibron, Tropidurus torquatus e Bothrops jararaca Wied. De 
modo geral, os anfíbios e repteis apresentam maior sensibilidade às mudanças ambientais, devido as maiores exigências ecológicas e limitações fisiológicas (Thompson e Donnelly, 2018). Sendo assim, ambas classes de animais são consideradas bons bioindicadores, e colonizam o ambiente em estágios mais avançados de sucessão.

Nesse seguimento, é importante conhecer as funções desempenhadas por estas espécies e sua contribuição para o processo sucessional. De acordo com Castro \& Galetti (2004), o lagarto S. merianae possui uma alimentação generalista e pode atuar na dispersão de sementes em florestas semidecíduas do Sudeste do Brasil. Em concordância, Valido \& Olesen (2019) ressaltaram a importância dos lagartos na dispersão de sementes e afirmaram que sementes dispersas por lagartos germinaram tão bem quanto sementes dispersas por pássaros frugívoros e mamíferos.

As espécies carnívoras como B. jararaca possuem grande importância ecológica, pois regulam a população de presas de forma natural, e assim influenciam toda a dinâmica do ecossistema (Svenning et al 2016; Svenning et al 2019). Nesse seguimento, Luciano et al (2020) destacaram a importância do uso de armadilhas fotográficas para o registro da predação de anfíbios do gênero Rhinella por Salvator merianae, na Floresta Atlântica brasileira. Ambas espécies foram registradas na área em restauração, desse modo, à medida que houver avanço no estágio sucessional é esperado que as relações ecológicas de predação sejam intensificadas, restaurando também a complexidade funcional do ecossistema.

O monitoramento por meio de câmeras digitais permitiu uma avaliação mais detalhada das relações intraespecíficas e interespecíficas de comunidades faunísticas, bem como das relações ecológicas entre fauna e flora. Nessa perspectiva, destacaram-se as atividades referentes: à alimentação, forrageamento, estratégia de caça, cuidado paternal, utilização de poleiros naturais e interações sociais através do canto. Assim sendo, a compreensão do comportamento animal no ambiente em restauração é importante para que as estratégias de conservação de espécies sejam eficácias (Caravaggi et al 2017).

De acordo com a lista vermelha de espécies ameaçadas da IUCN (2021), a maioria das espécies registradas neste monitoramento apresenta status "pouco preocupante", com tendência a aumento populacional ou estabilidade. Contudo, a presença de espécies com certo grau de ameaça como Chrysocyon brachyurus e Strix hylophila demonstra a importância dos projetos de restauração ecológica conduzidos no bioma Mata Atlântica. 
Dentre as espécies registradas, cabe destacar o lobo-guará (Chrysocyon brachyurus) que é o maior canídeo da América do Sul, originalmente distribuído em áreas abertas de vegetação nativa do bioma Cerrado (Queirolo et al 2011). Contudo, a expansão agrícola na savana brasileira e as modificações nas condições ambientais tem provocado declínio populacional desta espécie (Aximoff et al 2020). Desse modo, as constantes mudanças no uso do solo e fragmentação de habitat são os principais fatores que alteram a distribuição espacial e ameaçam a sobrevivência de $C$. brachyurus no Brasil (Coelho et al 2018; Magioli et al 2021).

Concomitantemente, as mudanças climáticas e de uso do solo atuam sinergicamente na conversão de florestas tropicais em savanas derivadas, por meio de um processo denominado "savanização" (Sales et al 2020). Assim sendo, a Mata Atlântica é um dos principais habitats alternativos para abrigar as populações desta espécie, tendo em vista o aumento no número de registros e da distribuição de Lobo-guará no sudeste do Brasil (Queirolo et al 2011; Aximoff et al 2020).

Nessa perspectiva, é possível afirmar que a restauração ecológica de áreas degradadas e/ou impactadas no Sudeste do Brasil é importante para a conservação do Lobo-guará, tendo em vista sua vulnerabilidade (ICMBio 2018) e que a presença desta espécie pode colaborar para o reestabelecimento da funcionalidade do ecossistema. Outro fator que pode ter contribuído para a expansão e atração do Lobo-guará para esta área em estudo é a presença de frutos da espécie arbórea Solanum lycocarpum A. St. Hil., popularmente conhecida como lobeira. Nesse sentido, apesar do Lobo-guará possuir dieta onívora e hábito alimentar generalista oportunista, é considerado um importante dispersor de sementes, podendo colaborar para a dinâmica sucessional (Aximoff et al 2020).

No contexto de espécies ameaçadas, as armadilhas fotográficas utilizadas permitiram também registrar a espécie Strix hylophila, ave endêmica da Mata Atlântica, popularmente conhecida como Coruja-listrada (Vale et al 2018). De acordo com Morante-Filho et al (2021) a fragmentação de habitats afeta mais as espécies endêmicas de aves do que aquelas mais generalistas de habitat e a principal variável que impacta na presença de uma determinada espécie no fragmento é quantidade de floresta no entorno, ou seja, a matriz florestal. Dessa maneira, a preservação de fragmentos florestais no entorno da área em restauração, realizada pela empresa, são fundamentais para a conservação e preservação de espécies endêmicas da Mata Atlântica. 
Além disso, cabe destacar que a presença de espécies com tendência populacional decrescente no Sudeste do Brasil, como Celeus flavus, Penelope obscura, Saltator similis, demonstra que a área mesmo em estágio inicial está fornecendo abrigo e/ou alimento para a avifauna e assim está desempenhando um importante papel na preservação e conservação da biodiversidade de espécies.

Em suma, a avaliação de projetos de restauração normalmente é baseada em indicadores de vegetação. Dessa maneira, há carência de estudos científicos envolvendo a fauna, que contemple aspectos comportamentais das classes: Amphibia, Reptilia, Aves e Mammalia, sendo assim, o presente estudo é muito importante. Nesse sentido, o uso de armadilhas fotográficas é inovador na avaliação e monitoramento da restauração ecológica de áreas no ambiente da mineração de bauxita, na região da Mata Atlântica. Portanto, são necessárias novas perspectivas para o monitoramento da fauna em projetos de restauração ecológica, com ênfase em parâmetros funcionais e comportamentais, de modo a elucidar as relações entre fauna e flora.

\section{CONCLUSÕES}

As armadilhas fotográficas fornecem uma abordagem inovadora que permite avaliar a relação fauna-flora e aspectos da ecologia comportamental das espécies na área em processo de restauração.

A presença da fauna de diferentes classes, hábitos alimentares, sociabilidade e padrão de atividade é um indicador de que à medida que avançar o processo sucessional é possível que aumente a complexidade das interações ecológicas intraespecíficas e interespecíficas.

As técnicas de restauração e ações de recuperação e conservação do solo, realizadas pela empresa, bem como a preservação de fragmentos florestais na paisagem foram eficientes e estão cumprindo o papel na conservação e recuperação da biodiversidade regional.

\section{AGRADECIMENTOS}

Os autores agradecem à Coordenação de Aperfeiçoamento de Pessoal de Nível Superior (CAPES) pela bolsa de mestrado para Wesley Fonseca, ao CNPq pela bolsa de produtividade em pesquisa do orientador prof. Sebastião V. Martins e a Companhia Brasileira de Alumínio (CBA) pela infraestrutura e apoio financeiro ao projeto. 


\section{REFERÊNCIAS}

Almeida DR, Stark SC, Valbuena R, Broadbent EN, Silva TS, de Resende AF, Ferreira MP, Cardil A, Silva CA, Amazonas N, Zambrano, AM, Brancalion PHS. (2020). A new era in forest restoration monitoring. Restoration Ecology. 28(1):8-11

ANM. (2019). Brazilian Mineral Yearbook - Main Metallic Commodities. 1 st ed. Brasília: National Mining Agency.

Aximoff I, Carvalho WD, Romero D, Esbérard CEL, Guerrero JC, \& Rosalino LM. (2020). Unravelling the drivers of maned wolf activity along an elevational gradient in the Atlantic Forest, south-eastern Brazil. Mammalian Biology, 1-15.

Balestrin D, Martins SV, Schoorl JM, Lopes AT, Andrade CF. (2019a). Phytosociological study to define restoration measures in a mined area in Minas Gerais, Brazil. Ecol Eng. 135(10): 8-16.

Balestrin D, Martins SV, Fonseca CA. (2020). Ecological restoration and forest coverage advancement in a region influenced by bauxite mining, Minas Gerais, Brazil. In: de Vlieger K. (Ed.). Recent advances in ecological restoration. New York: Nova Science

Publishers, 143-154.

Barros DA, Guimarães JCC, Pereira JAA, Borges LAC, Silva RA, Pereira AAS. (2012). Characterization of the bauxite mining of the Poços de Caldas alkaline massif and its socio-environmental impacts. Rev Esc Minas. 65(1):127-133.

Bastin JF, Finegold Y, Garcia C, Mollicone D, Rezende M, Routh D, ... \& Crowther T. W. (2019). The global tree restoration potential. Science, 365(6448), 76-79.

Berger-Tal O, Polak T, Oron A, Lubin Y, Kotler BP, \& Saltz D. (2011). Integrating animal behavior and conservation biology: a conceptual framework. Behavioral Ecology, 22(2), 236-239.

Bessone M, Kühl HS, Hohmann G, Herbinger I, N'Goran KP, Asanzi P, ... \& Iyomi MD. (2020). Drawn out of the shadows: Surveying secretive forest species with camera trap distance sampling. Journal of Applied Ecology. 57(5), 963-974.

Bogoni JA, Peres CA, Ferraz KM. (2020). Extent, intensity and drivers of mammal defaunation: a continental-scale analysis across the Neotropics. Scientific reports, 10(1), 1-16.

Brancalion PHS, Viani RAG, Rodrigues RR, Gandolfi S. (2015). Avaliação e monitoramento de áreas em processo de restauração. In: Martins SV, editor. Restauração ecológica de ecossistemas degradados. 2 nd ed. Viçosa: Editora UFV; p. 262-292.

Brancalion PHS, Niamir A, Broadbent E, Crouzeilles R, Barros FS, Zambrano AMA, ... \& Strassburg BB. (2019). Global restoration opportunities in tropical rainforest landscapes. Science Advances, 5(7), eaav3223.

Brooks DM. (2006). Conserving cracids: the most threatened family of birds in the Americas. Houston: Houston Museum of Natural Science. 169 p. Miscellaneous Publications of the Houston Museum of Natural Science, no. 6.

Burton AC, Neilson E, Moreira D, Ladle A, Steenweg R, Fisher JT, ... \& Boutin S. (2015). Wildlife camera trapping: a review and recommendations for linking surveys to ecological processes. Journal of Applied Ecology, 52(3), 675-685. 
Caravaggi A, Banks PB, Burton AC, Finlay CM, Haswell PM, Hayward MW, ... \& Wood MD. (2017). A review of camera trapping for conservation behaviour research. Remote Sensing in Ecology and Conservation, 3(3), 109-122.

Castro ERD \& Galetti, M. (2004). Frugivoria e dispersão de sementes pelo lagarto teiú Tupinambis merianae (Reptilia: Teiidae). Papéis Avulsos de Zoologia, 44(6), 91-97.

Chowfin SM \& Leslie AJ. (2021). Using birds as biodindicators of forest restoration progress: A preliminary study. Trees, Forests and People, 3, 100048.

Coelho L, Romero D, Queirolo D, Guerrero JC. (2018). Understanding factors affecting the distribution of the maned wolf (Chrysocyon brachyurus) in South America: Spatial dynamics and environmental drivers. Mammalian Biology, 92(1), 54-61.

Cristescu RH, Frère C, Banks PB. (2012). A review of fauna in mine rehabilitation in Australia: current state and future directions. Biological Conservation, 149(1), 60-72.

Cross SL, Tomlinson S, Craig MD, Dixon KW, Bateman PW. (2019a). Overlooked and undervalued: the neglected role of fauna and a global bias in ecological restoration assessments. Pacific Conservation Biology, 25(4), 331-341.

Cross SL, Bateman PW, Cross AT. (2019b). Restoration goals: Why are fauna still overlooked in the process of recovering functioning ecosystems and what can be done about it?. Ecological Management \& Restoration. 21(1):4-8

Delisle ZJ, Flaherty EA, Nobbe MR, Wzientek CM, \& Swihart RK. (2021). NextGeneration Camera Trapping: Systematic Review of Historic Trends Suggests Keys to Expanded Research Applications in Ecology and Conservation. Frontiers in Ecology and Evolution, 9, 97.

Díaz-García JM, López-Barrera F, Toledo-Aceves T, Andresen E, \& Pineda E. (2020). Does forest restoration assist the recovery of threatened species? A study of cloud forest amphibian communities. Biological Conservation, 242, 108400.

Fontúrbel FE, Orellana JI, Rodríguez-Gómez GB, Tabilo CA, Castaño-Villa GJ. (2021). Habitat disturbance can alter forest understory bird activity patterns: A regional-scale assessment with camera-traps. Forest Ecology and Management, 479, 118618.

Gagic V, Bartomeus I, Jonsson T. et al. (2015) Functional identity and diversity of animals predict ecosystem functioning better than species-based indices. Proceedings of the Royal Society B: Biological Sciences 282, 20142620

Galetti M, Gonçalves F, Villar N, Zipparro VB, Paz C, Mendes C, ... \& Bovendorp RS. (2021). Causes and consequences of large-scale defaunation in the Atlantic forest. In The Atlantic Forest (pp. 297-324). Springer, Cham.

Gann GD, McDonald T, Walder B, Aronson J, Nelson CR, Jonson J, ... \& Hua F. (2019). International principles and standards for the practice of ecological restoration. Restoration Ecology, 27, S1-S46.

Hale R, Blumstein DT, Mac Nally R, \& Swearer SE. (2020). Harnessing knowledge of animal behavior to improve habitat restoration outcomes. Ecosphere, 11(4), e03104.

Holl KD. (2017). Restoring tropical forests from the bottom up. Science, 355(6324), 455-456. 
Heringer G, Villa PM, Neri, AV. (2020). Phytosociology in R: a routine to estimate phytosociological parameters. In: Diniz, ES \& Villa PM. Aplicações da Linguagem R em Análises de Vegetação. 1ed.: Atena Editora, p. 20-29. 10.22533/at.ed.3552009033.

Hoehne L, Prestes NP, Piloneto CR. (2017). Organização social dos animais: um fascinante estudo etológico. Revista Caderno Pedagógico, 14(1).

IBGE. (2012). Manual Técnico da Vegetação Brasileira. 2nd ed. Manuais Técnicos em Geociências. Rio de Janeiro: Instituto Brasileiro de Geografia e Estatística.

ICMBio - Instituto Chico Mendes de Conservação da Biodiversidade. 2018. Livro Vermelho da Fauna Brasileira Ameaçada de Extinção: Volume II - Mamíferos. Brasília: ICMBio: p. 622 .

IUCN. (2021). The IUCN Red List of Threatened Species. Version 2021-1. https://www.iucnredlist.org. Acess [27/02/2021].

Kamble PH \& Bhosale SM. (2019). Assessment of Impact of Bauxite Mining on Environment. i-Manager's Journal on Future Engineering and Technology. 14(4):14-21

Lawer EA, Mupepele AC, \& Klein AM. (2019). Responses of small mammals to land restoration after mining. Landscape Ecology, 34(3), 473-485.

Loch JM, Walters LJ, Cook GS. (2020). Recovering trophic structure through habitat restoration: A review. Food Webs, 25, e00162.

Luciano BFL, Ceron K, Bôlla DA, Zocche JJ, \& Carvalho F. (2020). New records of predation attempt on Rhinella spp. in the Atlantic Forest: The importance of camera trap in recording species natural history. Herpetology Notes, 13, 253-256.

Magioli M, de Barros KMPM, Chiarello AG, Galetti M, Setz EZF, Paglia AP, ... \& Ovaskainen O. (2021). Land-use changes lead to functional loss of terrestrial mammals in a Neotropical rainforest. Perspectives in Ecology and Conservation.

Marjakangas EL, Abrego N, Grøtan V, de Lima RA, Bello C, Bovendorp RS, ... \& Ovaskainen O. (2020). Fragmented tropical forests lose mutualistic plant-animal interactions. Diversity and Distributions, 26(2), 154-168.

Martins SV, Cosimo LHE, Balestrin D, Fonseca WS, Andrade CF, Barros RS. (2020). Restoration of Tree and Shrub Diversity Post Bauxite Mining, in the Southeastern Region of Minas Gerais, Brazil. In: Kristian de Vlieger. (Org.). Recent Advances in Ecological Restoration. 1ed.Estados Unidos: Nova, 2020, v.1, p. 33-62.

Maxwell SL, Fuller RA, Brooks TM, Watson JE. (2016). Biodiversity: The ravages of guns, nets and bulldozers. Nature News, 536(7615), 143.

McAlpine C, Catterall CP, Mac Nally RM. et al. (2016) Integrating plant and animalbased perspectives for more effective restoration of biodiversity. Frontiers in Ecology and the Environment 14, 37- 45.

Miller BP, Sinclair EA, Menz MH, Elliott CP, Bunn E, Commander LE, ... \& Golos PJ. (2017). A framework for the practical science necessary to restore sustainable, resilient, and biodiverse ecosystems. Restoration Ecology, 25(4), 605-617.

Morante-Filho JC, Benchimol M, \& Faria D. (2021). Landscape composition is the strongest determinant of bird occupancy patterns in tropical forest patches. Landscape Ecology, 36,105-117 
Morcatty TQ, El Bizri HR, Carneiro HCS., Biasizzo, R. L., de Oliveira Almeri, C. R., da Silva, E. S., ... \& Figueira, J. E. C. (2013). Habitat loss and mammalian extinction patterns: are the reserves in the Quadrilátero Ferrífero, southeastern Brazil, effective in conserving mammals?. Ecological research, 28(6), 935-947.

Nagy-Reis MB, Estevo CA, Setz EZ, Ribeiro MC, Chiarello AG, \& Nichols JD. (2017). Relative importance of anthropogenic landscape characteristics for Neotropical frugivores at multiple scales. Animal Conservation, 20(6), 520-531.

Nanni AS, Sloan S, Aide TM, Graesser J, Edwards D, Grau HR. (2019). The neotropical reforestation hotspots: A biophysical and socioeconomic typology of contemporary forest expansion. Global Environmental Change, 54, 148-159.

Nichols OG \& Nichols FM. (2003). Long-term trends in faunal recolonization after bauxite mining in the jarrah forest of southwestern Australia. Restoration Ecology, 11(3), 261-272.

Nichols OG \& Grant CD. (2007). Vertebrate fauna recolonization of restored bauxite mines-key findings from almost 30 years of monitoring and research. Restoration Ecology, $15, \mathrm{~S} 116-\mathrm{S} 126$.

Papageorgiou D \& Farine DR. (2020). Shared decision-making allows subordinates to lead when dominants monopolize resources. Science advances, 6(48), eaba5881.

Püttker T, Crouzeilles R, Almeida-Gomes M, Schmoeller M, Maurenza D, AlvesPinto H, .. \& Metzger JP. (2020). Indirect effects of habitat loss via habitat fragmentation: A cross-taxa analysis of forest-dependent species. Biological Conservation, 241, 108368.

Queirolo D, Moreira JR, Soler L, Emmons LH, Rodrigues FH, Pautasso AA, ... \& Salvatori V. (2011). Historical and current range of the Near Threatened maned wolf Chrysocyon brachyurus in South America. Oryx, 45(2), 296-303.

Rezende CL, Scarano FR, Assad ED, Joly CA, Metzger JP, Strassburg BBN, ... \& Mittermeier RA. (2018). From hotspot to hopespot: An opportunity for the Brazilian Atlantic Forest. Perspectives in ecology and conservation, 16(4), 208-214.

Rigacci EDB, Paes ND, Félix GM, \& Silva WR. (2021). The resilient frugivorous fauna of an urban forest fragment and its potential role in vegetation enrichment. Urban Ecosystems, 1-16.

Rios, E., Benchimol, M., Dodonov, P., De Vleeschouwer, K., \& Cazetta, E. (2021). Testing the habitat amount hypothesis and fragmentation effects for medium-and large-sized mammals in a biodiversity hotspot. Landscape Ecology, 1-13.

Ritchie AL, Nevill PG, Sinclair EA, Krauss SL. (2017). Does restored plant diversity play a role in the reproductive functionality of Banksia populations? Restoration Ecology 25, 414-423.

Rocha EC, Silva E, Martins SV, Volpato GH. (2015). O papel dos mamíferos silvestres na sucessão e na restauração ecológica. In: Sebastião Venâncio Martins. (Org.). Restauração ecológica de ecossistemas degradados. 2ed.Viçosa, MG: Editora UFV, v.1, 169190.

Roels S, Hannay M, \& Lindell C. (2019). Recovery of bird activity and species richness in an early-stage tropical forest restoration. Avian Conservation and Ecology, 14(1). Article 9, 10.5751/ACE-01330-140109 
Rovero F \& Zimmermann F. (2016). Camera trapping for wildlife research. Exeter, England: Pelagic Publishing Ltd.

Sales LP, Galetti M, \& Pires MM. (2020). Climate and land-use change will lead to a faunal "savannization" on tropical rainforests. Global Change Biology, 26(12), 7036-7044.

Santos HG, Jacomine PKT, Anjos LHC, Oliveira VA, Lumbreras JF, Coelho MR, Almeida JA, Araujo Filho JC, Oliveira JB, Cunha TJF. (2018). Sistema brasileiro de classificação de solos. Brasília (DF): Embrapa.

Scarano FR, Ceotto P. (2015). Brazilian Atlantic forest: impact, vulnerability, and adaptation to climate change. Biodiversity and Conservation, 24(9), 2319-2331.

Silva WR, Zaniratto CP, Ferreira JO, Rigacci ED, Oliveira JF, Morandi ME, ... \& Abreu LB. (2020). Inducing seed dispersal by generalist frugivores: A new technique to overcome dispersal limitation in restoration. Journal of Applied Ecology, 57(12), 2340-2348.

Strassburg BB, Iribarrem A, Beyer HL, Cordeiro CL, Crouzeilles R, Jakovac CC, ... \& Brooks TM. (2020). Global priority areas for ecosystem restoration. Nature, 1-6.

Svenning JC, Pedersen PB, Donlan CJ, Ejrnæs R, Faurby S, Galetti M, ... \& Vera FW. (2016). Science for a wilder Anthropocene: Synthesis and future directions for trophic rewilding research. Proceedings of the National Academy of Sciences, 113(4), 898-906.

Svenning JC, Munk M, Schweiger A. (2019). Trophic rewilding-ecological restoration of top-down trophic interactions to promote self-regulating biodiverse ecosystems. J.T. du Toit, N. Pettorelli, S.M. Durant (Eds.), Rewilding. Ecological Reviews, Cambridge University Press (2019), pp. 73-98

Thompson ME \& Donnelly M. A. (2018). Effects of secondary forest succession on amphibians and reptiles: a review and meta-analysis. Copeia, 106(1), 10-19.

Tucker M. (2020). Social Behaviour: Finding the right size for a group. Elife, 9, e63871.

UNGA (Assembléia Geral das Nações Unidas) (2019) Década das Nações Unidas sobre Restauração de Ecossistemas (2021-2030). Documento da ONU A / RES / 73/284 (6 de agosto de 2020).

Vale MM, Tourinho L, Lorini ML, Rajão H, \& Figueiredo MS. (2018). Endemic birds of the Atlantic Forest: traits, conservation status, and patterns of biodiversity. Journal of Field Ornithology, 89(3), 193-206.

Valido A \& Olesen JM. (2019). Frugivory and seed dispersal by lizards: a global review. Frontiers in Ecology and Evolution, 7, 49.

Vasconcellos-Neto J, Ramos RR, \& Pinto LP. (2015). The impact of anthropogenic food supply on fruit consumption by dusky-legged guan (Penelope obscura Temminck, 1815): potential effects on seed dispersal in an Atlantic forest area. Brazilian Journal of Biology, (AHEAD), 1008-1017.

Viani RA, Holl KD, Padovezi A, Strassburg BB, Farah FT, Garcia LC, .. \& Brancalion, PH. (2017). Protocol for monitoring tropical forest restoration: perspectives from the Atlantic Forest Restoration Pact in Brazil. Tropical Conservation Science, 10, 1940082917697265. 
Vogel HF, Campos JB, \& Bechara FC. (2015). Early bird assemblages under different subtropical forest restoration strategies in Brazil: passive, nucleation and high diversity plantation. Tropical Conservation Science, 8(4), 912-939.

Volpato GH, Miranda Neto A, \& Martins SV. (2018a). Avifauna como bioindicadora para avaliação da restauração florestal: estudo de caso em uma floresta restaurada com 40 anos em viçosa-mg. Ciência Florestal, 28(1), 336-344.

Volpato GH, Martins SV, Cosimo LHE. (2018b). Avifauna em florestas em processo de restauração pós-mineração de bauxita em Minas Gerais. MG. BIOTA, v. 10, p. 18-45, 2018.

Zachos FE, Habel JC. (Eds.). (2011). Biodiversity hotspots: distribution and protection of conservation priority areas. Springer Science \& Business Media. 


\section{CONSIDERAÇÕES FINAIS}

A restauração ecológica de ecossistemas é uma ferramenta importante para combater o aumento global da degradação de ecossistemas e a crise contemporânea da biodiversidade, principalmente no período entre 2021-2030, declarado pela ONU como "Década de Restauração de Ecossistema". Neste cenário, diversas metas e acordos internacionais foram assumidos visando restaurar o equilíbrio do ambiente e retornar à sua trajetória histórica.

Cabe salientar que, cada área perturbada, impactada ou degradada pode sofrer influência variada de diversos fatores, apresentar condições ecológicas únicas e desafios de restauração específicos. Sendo assim, o planejamento, a avaliação e o monitoramento da restauração ecológica não são tarefas simples, visto que é necessário o conhecimento das peculiaridades de cada ambiente e de como estas características ambientais estão correlacionadas.

Nesta perspectiva, este estudo pode ser utilizado com uma ferramenta para subsidiar a tomada de decisões em projetos de restauração, conduzidos em ambiente de mineração de bauxita, além de possibilitar definir o estado atual do projeto, corrigir possíveis falhas e verificar a necessidade de sofrer novas interferências. Assim, a aplicação de bioindicadores é fundamental pois possibilita uma melhor compreensão dos processos ecológicos, das interrelações entre as comunidades vegetais e das relações fauna-flora na área em restauração. Além disso, é importante para gerar informações qualitativas e quantitativas que permitem a comparação com ecossistemas de referência, identificar áreas prioritárias para a restauração e definir metodologias de restauração mais adequadas para cada cenário no ambiente de mineração.

A adubação verde é uma alternativa promissora para a recuperação do solo de áreas no ambiente de mineração de bauxita. Os adubos verdes se destacaram principalmente por promover uma rápida cobertura do solo, minimizar os processos erosivos, auxiliar no controle de gramíneas exóticas invasoras, além de promover aumento dos teores de nutrientes e matéria orgânica do solo, devido ao aporte de fitomassa. Desse modo, a adubação verde melhorou as condições químicas, físicas, biológicas e estruturais do solo, e consequentemente favoreceu os processos ecológicos. 
O conhecimento dos atributos funcionais das espécies, por meio de estudos fitossociológicos é fundamental para o planejamento e execução de projetos de restauração ecológica. Nesse sentido, a análise dos parâmetros fitossociológicos permitiu identificar espécies e "famílias-chave" com potencial de colaborar para o avanço sucessional e assim favorecer o processo de restauração ecológica da área.

As técnicas de nucleação possuem um enfoque biocêntrico e são inspiradas na teoria ecológica da facilitação, que visa promover gatilhos ecológicos e aumentar a probabilidade de rotas alternativas de sucessão. Nessa perspectiva, a nucleação aplicada em áreas no ambiente da mineração de bauxita é inovadora. Este estudo demonstra que embora os aspectos positivos da restauração por meio do plantio de mudas não possam ser negligenciados, a sinergia com as técnicas de nucleação: transposição de banco de sementes e serapilheira e semeadura direta potencializa os benefícios: aumenta as interações funcionais entre fauna e flora, desencadeia processos de sucessão natural e assim aumenta a complexidade do ecossistema.

A fauna de diferentes níveis tróficos desempenha papeis cruciais para restaurar o equilíbrio do ecossistema. Desse modo, o monitoramento da fauna é fundamental para verificar o restabelecimento das relações fauna-flora em projetos de restauração. Nessa perspectiva, as armadilhas fotográficas forneceram uma abordagem inovadora no contexto da restauração ecológica, que permitiu avaliar aspectos da ecologia comportamental das espécies, sem o viés do pesquisador, de forma econômica e minimamente invasiva. Assim sendo, a presença da fauna de diferentes classes, hábitos alimentares, sociabilidade e padrão de atividade neste estudo indica que à medida que o processo sucessional avance espera-se que aumente a complexidade das interações ecológicas intraespecíficas e interespecíficas.

As técnicas de restauração ecológica, as ações de preparo e conservação de solo e a preservação de fragmentos florestais realizadas pela Companhia Brasileira de Alumínio (CBA) foram eficientes e estão colaborando para o aumento da cobertura florestal na área do presente estudo. Além disso, a utilização de técnicas alternativas de restauração e o monitoramento da fauna por meio de armadilhas fotográficas demonstram o comprometimento da parceria entre o Laboratório de Restauração Florestal (LARF / UFV) e a CBA, em prol de uma mineração de bauxita sustentável, com foco em recuperação da biodiversidade.

Como áreas mineradas na Zona da Mata mineira vem sendo há mais de uma década restauradas pela empresa, e outras inúmeras áreas não mineradas, como pastagens e áreas 
como a deste estudo, vem passando por restauração florestal compensatória, a atividade de mineração de bauxita tem contribuído para um ganho ambiental na região, com o aumento da cobertura vegetal e o retorno da biodiversidade.

Em suma, este estudo demonstra que quando as técnicas de restauração são bem conduzidas e em conformidade com as legislações ambientais estaduais e federais vigentes, é possível que sejam gerados bons resultados, em aspectos ambientais, ecológicos e também no âmbito social e econômico, para toda a sociedade. Portanto, este é mais um estudo da Parceria LARF/UFV e CBA que comprova a viabilidade e a sustentabilidade da mineração de bauxita na Zona da Mata Mineira. 